BIJDRAGEN TOT DE KENNIS DER FAUNA VAN CURAÇAO.

Resultaten eener reis van Dr. C. J. VAN DER HORST in 1920.

\title{
WESTINDISCHE OPISTHOBRANCHIATE MOLLUSKEN
}

\author{
VON \\ H. E N GE L. \\ (Mit 15 Figuren im Text).
}

I. AEOLidiadAe.

Das Material dieser Untersuchung lieferten die 1920 von Dr. C. J. van DER HoRst auf Curaçao gesammelten Opisthobranchiaten. Hier wird nur die einzige vom ihm gefundene Aeolidiade: Phidiana brevicauda nov. spec. besprochen.

Dr. Th. MORTENSEN stellte mir eine Sammlung Opisthobranchien aus dem zoologischen Museum in Kopenhagen zur Verfügung, welche auch dem westindischen Meere entstammten. Darunter befand sich auch nur eine Aeolidiade: Berghia coerulescens Laur.

Ausserdem bekam ich von Dr. F. HaAs noch einige westindischen Opisthobranchien aus dem Senckenbergischen Museum in Frankfurt a. M. zur Untersuchung, wobei sich eine neue Aeolidiade, Caloria occidentalis, befand.

Die Nudibranchiensystematik ist durch die Untersuchungen von BERGH, TRINCHESE, VAYSSIĖRE und ElIOT gar nicht-vernachlässigt zu nennen. Doch liegen aber nur wenige kritische Zusammenstellungen der bisherigen Befunde vor. Ich habe darum das zur Bestimmung der genannten drei Tiere unumgängliche Literaturstudium benutzt um ausser den Beschreibungen der untersuchten Tiere eine solche Übersicht der. Geschlechter Berghia (sowie der nahe verwandten Aeolidiella und Spurilla), Phidiana und Caloria zu geben, wobei ich die Synonyme zusammenfügte und versuchte deutliche Diagnosen, sowie Bestimmungstabellen für die Arten zusammenzustellen.

Herzlich möchte ich hier Dr. van DER HORST, Dr. MORTENSEN und Dr. HAAs danken für das mir zur Verfügung gestellte wertvolle Material.

\section{AEOLIDIELLA, SPURILLA und BERGHIA.}

ALDER und HaNCock stellen in ihrer Monographie (Part VII, 1855) im Synopsis S. 48 die Eolis glauca und Eolis alderi der Eolis papillosa gegenüber, weil bei ersteren die Schneide der Zahnplatten einen Doppelbogen bildet, bei letzterer nur einen einfachen.

Dieser Unterschied wurde von BERGH im Jahre 1867 ('68) benutzt (S. 99 Fussnote) zur Aufstellung des Geschlechts Aeolidiella, Aeolidia gegenüber.

Schon 1864 ('68) (S. 205) hatte BERGH aus dem Geschlecht Aeolidia die Spurillen abgeschieden, weil sie perfoliierte Rhinophorien haben. Er bemerkt in der Diagnose noch nichts über die Zahnplatten. Erst 1871 (S. 1283) sagt er, dass die Spurillen sich in der doppelbogigen Gestalt derselben den Aeolidiellen näherten. Sie unterscheiden sich aber in den Rhinophorien die bei Aeolidiella nicht perfoliiert sind.

Im Jahre 1881 (S. 151) endlich hat auch TRINCHESE noch ein mit doppelbogigen Zahnplatten versehenes Geschlecht aufgestellt, das er Berghia nannte, und das sich von den beiden genannten 
Geschlechtern unterscheidet durch den Besitz perfoliierter Rhinophorien, die an der Hinterseite mit kleinen Tuberkeln besetzt sind. (Rinoforî, ellitici perfoliati moriformi). Leider geben uns noch TRINCHESE (1878), noch BERGH (1882) Abbildungen dieses merkwürdigen Unterscheidungsmerkmals. Wie es scheint, hat Costa (1867) eine gegeben, (wozu BERGH bemerkt, dass die Verhältnisse übertrieben dargestellt worden sind); CostA's Arbeit aber war mir nicht zugänglich. Die erste deutliche Abbildung gibt TRINCHESE (1882). Er meldet, dass die Rhinophorien hinten Tuberkeln tragen und vorn besetzt sind mit schrägen konischen Bändern.

VAYSSIÈRE gibt, als er 1888 (S. 116) einige Bemerkungen macht über eine neue Berghia, die er leider nicht anatomisch untersuchen konnte, eine Abbildung des ganzen Tieres und bildet dann auch die merkwürdig gerunzelten Rhinophorien ab. Die Schilderung derselben überlassen wir am besten VAYSSIẺRE, wenn er sagt: „Les thinophores ou tentacules dorsaux offraient une multitude de nodosités très accentuées, excepté sur une partie de leur face antérieure qui formait une large bande longitudinale complètement lisse."

Er hebt also die Perfoliierung gar nicht hervor. Mit diesen Angaben und mit Hilfe der Bemerkung BERGH's: „wenn sie kontrahiert sind sehen diese Organe maulbeerförmig aus”, ist es möglich sich einigermassen vorzustellen, wie dieselben aussehen, wenn man sie im konservierten Zustande vor Augen hat.

Ich lenke die Aufmerksamkeit besonders auf diese Tatsachen, weil sich bei der Untersuchung des mir vorliegenden, zu dieser Gruppe gehörigen, Tieres folgende Schwierigkeit ergab: nachdem ich mit grosser Mühe bestimmt hatte, dass bei diesem Exemplare die zusammengezogenen Rhinophorien (Fig. 1), obgleich sie vorne regelmässige Falten zeigten, doch wahrscheinlich nicht perfoliiert waren,

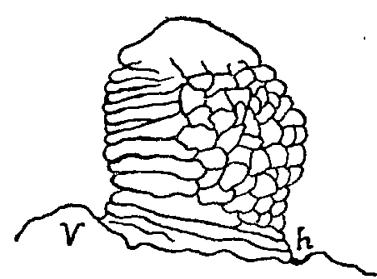

Fig. 1. Berghia coerulescens Laur. Rhinophor.

Vergr. $25 \times, \mathrm{v}=$ Vorder seite, $\mathrm{h}=$ Hinterseite. weil sie an ihrer Hinterseite ein unregelmässiges Durcheinander von Fältchen zeigten, versuchte ich mit Hilfe der von BERGH in seinem System (1892) gegebenen Diagnosen zu bestimmen zu welcher Gattung das Tier gehöre. Die Untersuchung der Zähne hatte mir schon gezeigt, dass es entweder eine Aeolidiella oder eine Spurilla oder eine Berghia war. Dass hier eine Berghia vorliegen könnte, schien mir ganz ausgeschlossen, sagt doch BERGH als er die Rhinophorien derselben beschreibt in seinem System: „Rhinophoria perfoliata moriformia” und in seiner ausführlichen Behandlung des Geschlechts (1882), wohin er in seinem System verweist: „Rhinophorien mit gegen 20 schrägen Blättern der Keule welche am Rande rundzackig waren, und die Zacken ein wenig, aber unter der Loupe wenig auffallend verdickt."

Unschlüssig, $a b$ ich das Tier zur einen oder zur anderen Gattung stellen sollte, machte ich, um dadurch eine Übersicht der anderen systematisch wichtigen Merkmale zu gewinnen, eine Zusammenstellung aller bisher bekannten Aeolidiellen, Spurillen und Berghien, wobei ich aus der vorliegenden Literatur für jede Art eine Diagnose aufstellte, die nur die zur Unterscheidung benutzbaren Merkmale enthielt. (Das Resultat dieser Zusammenstellung folgt weiter unten). So kamen mir auch die schon oben zitierten Abhandlungen von TRINCHESE und VAYSSIĖRE in die Hände. Diese änderten meine Vorstellung über die Rhinophorien der Berghia und lehrten mich, wie dieselben gar nicht deutlich perfoliiert auszusehen brauchten und da verstand ich auch BERGH besser, als er sagte, dass sie eine unregelmässig zusammengezogene moriforme Gestalt hätten. So wurde es mir deutlich, dass ich eine Berghia untersuchte. Die regelmässigen Fältchen der Vorderseite (s. Fig. 1) sind wahrscheinlich der Zusammenziehung zu verdanken und stellen die von VAYSSIĖRE genannte „bande complètement lisse” vor, sowie TRINCHESE'S schmale konische Bänder.

Die ausführliche Beschreibung des untersuchten Exemplars folgt weiter unten, nachdem ich hier zuerst das Resultat meiner Zusammenfassung der Aeolidiellen, Spurillen und Berghien gegeben habe.

Bei dieser Zusammenfassung stellte es sich heraus, dass zur Artunterscheidung fast nur die äusseren Merkmale wichtig sind. Die schönen ausführlichen Untersuchungen BERGH's haben uns dautlich gezeigt, dass wir zur Unterscheidung der Arten keines der anatomischen Merkmale benutzen können, ausser der Gestalt der Basalfläche der Zahnplatten.

Es ist nämlich eine interessante Tatsache, dass zwar bei allen diesen Gattungen die Zähne einen doppelbogigen Schneiderand aufweisen, welcher den kürzeren mittleren Dentikeln zu verdanken 
ist, dass aber bei einigen Arten dies noch verstärkt wird dadurch, dass die Basalfläche in der Mitte eingeschnitten und schmal ist und seitwärts flügelartig sich verbreitert. Bei den anderen Arten ist dieselbe überall gleich breit. Ob dieser Unterschied in der Gestalt der Basalfläche konstant ist, ist noch nicht mit Gewissheit den vorliegenden Untersuchungen zu entnehmen, es ist aber sehr wahrscheinlich und ich habe dieses Merkmal denn auch in die Diagnosen aufgenommen. Es sei hier darauf hingewiesen, dass oben die Breite der Basalfläche gemeint ist gemessen etwa in der Richtung der Längsachse der ganzen Radula (in der Fig. 2 die Richtung a-b). Man nennt dies auch öfters Höhe, aber auch dies könnte Verwirrung stiften. Wichtig ist nur, dass man weiss, was ich hier damit meine.

Eine Frage ist weiter, ob diese drei Gattungen nicht vereint werden könnten in eine, die dann wie Elrot (1910) vorschlägt Aeolidiella heissen könnte. Seine Bemerkungen lauten: Auf Seite 16: „Again, Aeolidiella, Spurilla and Berghia differ only in the surface of the rhinophores. These organs show a complete series of gradations from a smooth to a perfoliate or tuberculate surface, and there is no point in the series which can be fixed as a generic division, for the rhinophores of Aeolidiella are not

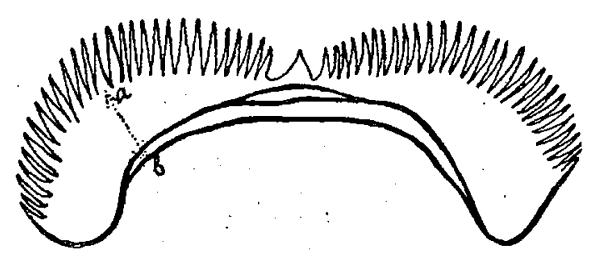

Fig. 2. Berghia coerulescens Laur. Zahnplatte. always smooth (as the definition of the genus implies) but in some species exhibit furrows or rudimentary perfoliations. All three genera should therefore be included in the earliest, viz. Aeolidiella." Und auf Seite 174: "Spurilla Bergh, which differs from Aeolidiella only in having the rhinophores perfoliate, and Berghia Trinchese in which they are perfoliate and also bear small knobs should probably be regarded as sub-genera of Aeolidiella. In Aeolidiella the rhinophores are a little wrinkled, and it does not seem as if the greater development of these wrinkles should constitute a generic difference".

Dass die Aeolidiella eher beschrieben wurde als die anderen ist nicht richtig, denn den Namen Aeolidiella hat BERGH erst 1867 ('68) benutzt, Spurilla aber schon 1864 (aufgenommen im Band für 1868, die Arbeit aber trägt das Jahr 1864). Auch 1913 sagt Elıot wieder: „Aeolidiella and Spurilla two genera which is my opinion should be united."

Bei meiner Vergleichung der Arten kam ich zur Überzeugung, dass in den Spurillen und Berghien wirklich andere Formen vorliegen als in den Aeolidiellen, obschon die Unterschiede nicht sehr gross sind. Zur Vermeidung allerhand nomenklatorischer Schwierigkeiten schlage ich darum vor, die Frage der Berechtigung der Aufrechterhaltung verschiedener Genera bei so geringen Differenzen unbeachtet zu lassen und diese drei Gattungen als zwar sehr nahe verwandte aber doch verschiedene $z u$ betrachten. Der Vorschlag Trinchese's (1882) die Aeolidien, Aeolidiellen und Berghien in einer Familie Ctenodontae zu vereinen, ist in der späteren Literatur nicht mehr beachtet.

Schliesslich möchte ich hier noch eine Bemerkung einschalten über die Beschreibung der Anordnung der Papillen auf dem Rücken der Aeolidien im allgemeinen besonders mit Rücksicht auf der Terminologie.

Die Papillen können angeordnet sein:

a. in Querreihen, welche wenn sie schräg stehen auch Schrägreihen genannt werden. Dieselben können auf Kissen oder Leisten gestellt sein oder nicht. Sie bestehen im einfachsten Falle aus einer einzigen Reihe Papillen. Es kommt aber sehr oft zur Bildung sogenannter Doppelreihen, worin die Papillen meistens abwechseln, und öfters unvollständig doppelt sind. Wenn die Querreihen auf Kissen gestellt sind, stehen solche Doppelreihen (die also als eine Querreihe gerechnet werden) auf einem Kissen.

$b$. Die Querreihen können vereint sein zu Gruppen, die die Papillen, unregelmässig durcheinander gestellt oder in deutlichen Querreihen, tragen können. Jede Gruppe kann auf einem Kissen stehen oder jede Querreihe kann auf einem eigenen Kissen eingepflanzt sein (die Kissen dann nahe aneinander gerückt und durch einen deutlichen Zwischenraum getrennt von den Kissen der anderen Gruppen) oder es können die Kissen ganz fehlen.

c. Weiter ist es noch möglich, dass die Querreihen (einzelne oder doppelte) paarweise an der Rückenseite verbunden sind $\mathrm{zu}$ hufeisenförmigen Figuren (meistens auch auf hufeisenförmige Kissen gestellt). Diese aus zwei Querreihen gebildeten Bogen soll man also nicht verwirren mit den Doppelreihen. Die Schenkel eines Bogens stellen je eine Querreihe vor, welche selber wieder eine Einzelreihe oder eine Doppelreihe sein kann. 


\section{AEOLIDIELLA Bergh. \\ Aeolidiella glauca Alder and Hancock.}

$$
\begin{array}{cl}
\text { Aeolidiella } & \text { glauca (A. \& H.). } \\
& \text { angulata (A. \& H.). } \\
& \text { nov. sp.? Heincke. } \\
& \text { alderi (Cocks). } \\
& \text { soemmeringii Bgh. } \\
& \text { sanguinea (Norman). }
\end{array}
$$

Eolis inornata A. \& H.

Diese 1845 p. 314 von ALDER und $\mathrm{HANCOCK}_{\mathrm{A}}$ als Eolis glauca begründete und in ihrer Monographie (Part IV, Fam. 3, Plate 11, 1848 und Part VIl, 1855, Plate 7 Supplementary, Fig. 5, Synopsis p. 48, Appendix p. VII) näher geschilderte Art wird 1867-'68 (Seite 99, Fussnote) von BERGH bei der Aufstellung der Gattung Aeolidiella zu derselben gestellt.

Als FISHER (1875) die Nudibranchien der französischen Küste behandelt, nennt er auch (S. 210): Eolis glauca von Brest, bassin d'Arcachon und Roscoff. TRINCHESE behandelt 1882 die Art ausführlich (Er meint die Ae. Alderi Cocks sei eine Varietät der Ae. glauca).

BERGH hat 1885 die Art beschrieben und daneben eine Varietät mediterranea aus der Adria.

VAYSSIERE (1888) bespricht die Art auch in seiner ausführlichen Arbeit über die Nudibranchien des "Golfe de Marseille" und nennt als Synonyme: Eolis angulata A. et H. 1855 und Eolis Alderi Cocks (d'après A. et H.) 1855. Auch 1901 nennt dieser Verfasser die Art in seiner Liste der französischen Opisthobranchien.

Garstang meldet (1890 S. 433) ein Exemplar von Plymouth. Auch Hecht (1895) nennt natürlich die Art (S. 549). Eliot (1906, p. 357) hat eine Eolis angulata (Alder and Hancock, Monograph, Part II, 1845, Fam. 3, Plate 23) untersucht, von Prof. Herdman bestimmt. Das Tier stimmte ganz mit den Abbildungen ALDER und HANCOCK's überein. Als er es dann weiter studierte, wurde es deutlich, dass auch hier eine Aeolidiella glauca vorlag.

ELIOT meint dann, dass Eolis angulata „merely a broad and immature specimen of Aeolidiella glauca" sei, eine Tatsache die er in seiner späteren Arbeit (1910) wieder bezweifelt.

Besonders die Synonymie wird 1906 von CuÉnot besprochen. Er führt die Eolis Alderi und angulata, sowie die Aeolidiella Soemmeringii der Art zu. Auch Eolidina paradoxum Quatref. und Eolis pallidula Lafont. rechnet er zur Ae. glauca. Obgleich auch FISCHER 1867 meint die Eolid. paradoxa (Quatrefages, A. DE, Mémoire sur l'Eolidine paradoxale S. 274 in: Ann. des sc. nat., sér. 2, Tome XIX Zoologie, Paris 1843) sei mit der Eolis angulata synonym, glaube ich, dass die sehr schöne und ausführliche Beschreibung von QUATREFAGES doch nicht genügende für uns wichtige Merkmale meldet, um mit Sicherheit bestimmen zu können, welche Art er untersucht hat. Die grossen glandulae salivales weisen zwar auf Aeolidiella, es bleibt aber eine grosse Beschwerde, dass er meldet: die Genitalöffnung liege vor den Rhinophorien und der Anus in der Mitte des Rückens, er habe gar keine Schundkopfbewaffnung gesehen. Man kann vermuten, dass hier Beobachtungsfehler vorliegen, Sicherheit besteht aber keineswegs. Ich lasse die Art darum weiter unbeachtet. Die Eolis pallidula (Lafont, A. Note pour servir à la faune de la Gironde, Actes Soc. Linn. de Bordeaux XXVIII, 3e sér. VIII, 1871, S. 267) ist eine Art, die zwar in einigen Merkmalen mit Ae. glauca übereinstimmt, aber zu unvollständig beschrieben worden ist, um mit Sicherheit als Synonyme aufgenommen zu werden.

Von Nils ODhner wird die Ae. glauca im Jahre 1907 auch genannt, als vorkommend in den Sammlungen des schwedischen Staatsmuseums, mit den Angaben (S. 78) : „Habitat: Gullmarn, Bohuslän, 1 sp. (L. 11 m.m.). General Distribution: Denmark Limfjorden (Collin 1884), British Coasts (Jeffreys 1869), France (Vayssière 1901), Portugal (Nobre 1905), Mediterranean and Adriatic (Carus 1889)."

Die hier genannten Arbeiten von COLLIN und NOBRE waren mir nicht zugänglich.

In seinem schönen Supplement zu ALDER und HaNcock's Monographie, behandelt Eliot (1910, S. 131-132) unter mehreren wieder die Aeolidiella angulata (A. et H.) die er jetzt als ? = Ae. glauca, var. kennzeichnet, denn Mr. C. W. WALTON hat ihm eine Beschreibung einer von ihm untersuchte 
Art geschickt, die anders ist als die Ae. glauca. Eliot meint aber: „I am inclined to agree with CuÉNoT (Faune d'Arcachon, Eolidiens, p. 3 (d. h. S. 97)) that all the so-called European species glauca, alderi, angulata, soemmeringii are really varieties of one, which ought to bear the first of the above names." Auf S. 174 seiner Synopsis am Ende desselben Werkes nennt ElioT: Ae. glauca, alderi, angulata und sanguinea und sagt dazu: „One may doubt if these species are really distinct from one another, or from Ae. Soemmeringi found in the Mediterranean." Auch VAYSSIĖRE (1919) macht einige Bemerkungen über diese Art.

Eine ausführliche Beschreibung endlich dieser Art finden wir bei PAUL LøYNING (1922 S. 74). Obgleich er die Bemerkungen ELIOT's vermeldet spricht er selber kein Urteil aus.

Wie wir weiter unten sehen werden, sind keine genügende Gründe vorhanden, die oben genannten Arten noch als selbständige zu betrachten und darum behandle ich sie hier zugleich mit der Ae. glauca. Diese zweifelhafte Arten sind: Ae. nov. sp.? Heincke, Ae. Alderi (Cocks), Ae. soemmeringii Bergh, Ae. sanguinea Norman, und Ae. angulata A. et $\mathrm{H}$. Die Literatur der Ae. angulata habe ich schon erwähnt, folge jetzt die der anderen Arten:

Aeolidiella nov. sp.? Heincke. Von HeINCKE wird 1897 eine nov. sp.? beschrieben dieser Gattung (S. 247). Er gibt der Art keinen Namen, sie ist wahrscheinlich der Ae. inornata sehr nahe verwandt. Eliot (1910) bemerkt, während er auf S. 132 die Ae. angulata bespricht: „But pending the examination of further specimens $A$ e. angulata merits provisionally separate recognition. It is probably the species from Heligoland described by HeINCKE as Ae. nov. sp.?"

Aeolidiella alderi (Cocks) wurde (nach ALDER and HANcock's Monographie Part VI, 1854, Fam. 3, Plate 10) von Cocks beschrieben im mir nicht zugänglichen Naturalist, V, 2, p. 1, pl. 1, fig. 1.

ALDER and HANCOCK melden sie auch in Part VII, 1855, p. 48 ihrer Monographie. Als Bergh 1867-'68 (S. 99 Fussnote) die Gattung Aeolidiella begründete wurde auch diese Art von ihm zu diesem Genus gestellt. Jeffreys (1869) (S. 38) bezieht sich für seine Eolis Alderi auf ALDER und Hancock. FISHER (1872) meldet S. 17 Eolis Alderi von Saint-Malo und bemerkt: „Cette espèce n'a aucun rapport avec l'Eolis Alderiana Deshayes (FrÉDol, Monde de la Mer, pl. 11, fig. 7) qui est synonyme de l'E. conspersa Fisher." [Diese E. conspersa ist eine von FISHER (Journ. de Conch. 17 p. 7) aus dem Bassin d'Arcachon sehr dürftig beschriebene Art, die wie CuÈNOT (1906) nachwies eine Spurilla neapolitana ist]. Die Ae. Alderiana Deshayes wird aber von TRINChESE (1878) zur Spurilla neapolitana geführt. Dies scheint, wenn man die Abbildung FRÉDOL's (= MOQUIN TANDON) betrachtet, richtig zu sein.

Die Ae. alderiana wird in BERGH's spätern Listen $(1874,1882,1888,1890,1892,1904)$ auch stets genannt, sei es auch mit der Andeutung, dass sie niemals näher untersucht worden sei. VAYSSIẺRE (1888) stellt sie als Synonyme zur Aeolidiella glauca, so auch CuÉnot (1906). Nur Garstang gibt 1890 einige nähere Mitteilungen über die Art.

Aeolidiella soemmeringii Bergh wurde als Eolidia Soemmeringii 1828 von LEUCKART aufgestellt. BERGH gibt 1864 ('68) eine ausführliche Beschreibung der Art und bemerkt, dass sie zur Gruppe der Aeolidien gehöre, die versehen seien mit aus zwei Bogen zusammengestellten Zahnplatten. Im Jahre 1867 ('68) stellt BERGH sie natürlich zu seiner neuen Gattung Aeolidiella (S. 99 Fussnote).

Eine ausführliche Beschreibung gibt er wieder 1882, hat aber zugleich eine nomenklatorische Schwierigkeit entdeckt, die von ihm 1864 beschriebenen Tiere waren von Eschricht fälschlich bestimmt als Ae. soemmeringii. Die von BERGH beschriebenen Tiere sollten also einen neuen Namen erhalten, wenn nicht die Ae. soemmeringii Leuckart von ihm, zwar zweifelnd, zur Amphorina coerulea Montagu (1804) gestellt wäre. (Sieh BERGH 1882, S. 8 und S. 57). Um keine unnötigen Verwirrungen zu schaffen scheint es mir am besten den von BERGH eingeschlagenen Weg zu verfolgen und die von ihm beschriebenen Tiere Ae. soemmeringii Bergh zu nennen. Der Typus dieser Art ist also das 1864 von BERGH benutzte Tier aus dem Giessener Museum, das 1827 von Eschricht in der Nähe von Cette gefunden wurde. CUÉNOT (1906) stellte die Art zur Ae. glauca.

Aeolidiella sanguinea Norman. Eine der Aeolidiella glauca verwandte Art wird 1877 von NormaN beschrieben. Er nennt sie E. sanguinea, gibt aber keine Angaben über die Zähne.

BERgh stellt die Art 1882 zur Gattung Aeolidiella ohne nähere Angabe, ebenso 1888 (Malakol. Unters. S. 781). An letzterer Stelle aber hat er die Ae. alderi und diese Art nicht spatiieren lassen, 
um anzugeben, dass er sie niemals näher untersuchte. In allen weiteren von BERGH gegebenen Listen. erscheint sie dann (1890, 1892, 1904), aber immer ohne nähere Angaben.

Eliot (1910) fragt, ob dies nicht eine Ae. glauca sei.

Die Diagnosen, die ich mit Hilfe der von den genannten Autoren gemachten Angaben zusammenstellte sowie die daraus gezogenen Folgerungen sind folgende:

Fangen wir an mit der Aeolidiella glauca, so wie sie von ALDER und HANCOcK 1845 begründet und in ihrer Monographie (Part IV, Fam. 3, Plate 11 und Part VII, Synopsis p. 48, Plate 47 Supplementary Fig. 5, und Appendix p. VII) näher beschrieben wurde: Körper: etwas niedergedrückt; am Ende in eine feine Spitze ausgezogen; Länge $1 \frac{3}{4}$ inch. Papillen: konisch; „vermicular”; in 14 Reihen gestellt; welche die Rückenmitte bis zur Hälfte des Rückens nackt lassen; Vorderreihen in Gruppen von 2-3 Reihen; Papillen auf Leisten gestellt, welche je eine einzelne oder doppelte Reihe von $\mathrm{Pa}$ pillen tragen. Tentakel: glatt, mit stumpfer Spitze. Rhinophorien: weit von einander entfernt. Fuss: Vordereçen des Fusses ein wenig vorragend; hinten zugespitzt. Farbe: Steinrot, intensiver zum Kopfe hin; Papillen blaugrün („glaucous”) oder olivgrün mit braunen und weissen Fleckchen, öfters mit rotem Anfluch nahe der Spitze; Tentakel rot mit weisslicher Spitze; Rhinophorien weiss mit rotem Anfluch, fein dunkelrot getüpfelt. Fuss durchsichtig hell („pellucid”).

Die 1882 von TRINCHESE gegebene Schilderung stimmt ganz gut mit dieser Diagnose überein, nur meldet er, dass die Farbe mehr gelblich sei und gibt uns im allgemeinen ein Bild der Farbenverhältnisse, das zwar keine Unterscheidung mit der oben gegebenen Art nötig macht, aber doch in sehr vielen Einzelheiten abweicht, sodass unsere Auffassung der Variationsbreite der Farben dieser Art erheblich erweitert wird.

Die zwei 1885 von BERGH als Ae. glauca beschriebenen Individuen gehören ganz gewiss zu dieser Art, denn sie stimmen in Einzelheiten mit der Beschreibung von ALDER und HaNCock überein. Die var. mediterranea Bergh, stimmt nach ihm ganz gut mit den typischen Representanten überein, was Form- und Farbenverhältnisse angeht, nur ist die Farbe der Rhinophorien und der Papillenspitzen etwas abweichend und die vordersten Papillenreihen sind weisslich (wie bei der Ae. alderi) und dies variiert nach TRINCHESE (1882) mit den "periodi della digestioni” und ist also unwichtig.

Die Diagnose dieser Varietät mediterranea Bergh lautet: Körper: Verhältnis der Breite zur Länge in $\mathrm{mm} \frac{3.5}{18}=\frac{1}{5}$. Papillen: in $11-13-15$ Reihen (mehr oder weniger doppelt). Farbe: die zwei ersten Papillenreihen weisslich, der dunkelgraue Leberstamm nur im unteren Drittel oder in der unteren Hälfte der Papillen durchschimmernd. Die Papillen sonst wegen der durchschimmernden Leberstämme meistens grünlich dunkelgrau; das äusserste Drittel oder Viertel ockerroth; Rhinophorien am Grunde rötlich, sonst weisslich mit rötlicher Spitze, aussen am Grunde ein weisslicher Fleck und in demselben das abstechende schwarze Auge.

Das 1885 von BERGH als Varietät hervorgehobene Tier, besitzt die folgenden Eigentümlichkeiten: Rhinophorien: untere Hälfte rot, dann weiss, Spitze rot. Papillen graulich (Farbe der Leberlappen!), an der Spitze schimmert der weisse Nesselsack durch.

VAYSSIERE (1888) hat sehr viele Exemplare untersucht und wir können von ihm wahrscheinlich viel über die Variationsbreite vernehmen. Eine Beschwerde scheint es aber zu sein, dass er auch die Ae. angulata und die Ae. alderi zu dieser Art stellt als Synonyme. Seine Diagnose könnte dann eine Zusammenstellung der Diagnosen der drei Arten sein und es wäre eine petitio principii dieselbe zu benützen um die Berechtigung der Aufrechterhaltung der genannten Arten zu prüfen. Dies aber scheint mir nicht der Fall zu sein, vergleicht man nämlich seine Beschreibung und seine Diagnose so zeigt sich, dass letztere nur auf erstere begründet ist, dass er sogar die Diagnose von BERGH oder ALDER und HANCOcK für Ae. glauca nicht hineingezogen hat. Ihm hat eine grosse Individuenzahl einer einzigen Art zur Verfügung gestanden. Er hat dieselben untersucht und eine Beschreibung und Diagnose aufgestellt und dann hat es sich gezeigt, dass die Art wahrscheinlich die Ae. glauca war. Vergleicht man nämlich seine Diagnose mit der von ALDER und HANCOCK gegebenen, so meint man hier eine neue Art vorzuhaben. Zieht man dann aber die von BERGH beschriebenen Varietäten heran, so bilden diese 
das Verbindungsglied zwischen beiden Beschreibungen, wodurch aber auch ihre Anerkennung als selbständige Varietäten beendet ist.

Man könnte noch zweifelnd die von VAYSSIÈre beschriebenen Tiere als Varietät der Ae. glauca betrachten, eine Varietät die sich dann vornehmlich durch die geringe Zahl der Papillenreihen und die bleiche Körperfarbe unterscheiden würde. Dies zu entscheiden soll aber spätern zu diesem Zweck angestellten Untersuchungen überlassen werden. Jetzt folgen wir besser VAYSsiÈRE und führen seine Tiere der Ae. glauca zu.

Nur möchte ich, bevor ich seine Diagnose gebe und dann eine erweiterte Diagnose der Ae. glauca, hier noch hinweisen auf VAYSSIĖRE's Bemerkung (1917), er habe ein Individuum gefunden bei dem der mittlere kurze dreieckige Dentikel fehle. Betrachten wir seine Figur, so sehen wir, dass hier, wie auch VAYSSIĖRE meint, eine Eigentümlichkeit, aber kein wichtiger Unterschied vorliegt.

Die Diagnose für die 1888 von VAYSsIĖRE geschilderten Tiere lautet: Körp er niedergedrückt, sehr breit, Länge bis $24 \mathrm{~mm}$. Papillen in 8-10 Querreihen (je 6-9 Papillen tragend). Rhin ophorien zylindrisch; konisch, mit einer Spiralfurche versehen (so dass sie „torses” bilden). Fuss breiter als der Körper, mit zurückgebogenen verlängerten Vorderecken. Farbe durchsichtig, mit kleinen weissen oder blaugelben Pünktchen versehen. Die Mundtentakel und Rhinophorien von hell-rotoranger Farbe. Bei den erwachsenen Individuen sind die Papillen orange gefärbt, aber weniger hell als die Tentakel. Die Tiere sind im allgemeinen weniger hell gefärbt als die von ALDER und HANCOck beschriebenen.

Nachdem wir also diese Tiere auch zur Ae. glauca gestellt haben und die von BERGH beschriebenen Varietäten nicht mehr als solche betrachten, sondern auch der Art selber einverleiben, bekommen wir die hier gegebene erweiterte Diagnose: Körper: breit und niedrig. Das Verhältnis der Breite zur Länge beträgt $\frac{1}{2.5}$ bis $\frac{1}{5.5}$ (nämlich in $\mathrm{mm} \frac{3.5}{18}, \frac{9}{45}, \frac{5}{28}, \frac{1.25}{5 \frac{5}{6}}, \frac{12}{48}$, während es von einem Tiere bekannt ist, dass dieses Verhältnis beim lebenden Tier $\frac{10}{25}$, beim selben in Alkohol $\frac{5}{12}$ war). Das Verhältnis der Höhe zur Länge war $\frac{1}{5}-\frac{1}{9}$ (nämlich in $\mathrm{mm} \frac{2.75}{12}, \frac{5}{45}$ ). Nur BERGH gibt uns Angaben über die Stelle der Körperöffnungen. Die Analpapille am hinteren Rande des unteren Endes der fünften (sechsten?) Papillenleiste. Die Genitalpapille etwa unter der dritten bis vierten Papillenleiste. Wahrscheinlich schwanken diese Stellen zwischen bestimmten Grenzen. Papillen: konisch; schlank, zahlreich; auf Querreihen, die die Rückenmitte nackt lassen; Anzahl der Reihen 8- 17. Dass die Zahl dieser Querreihen nicht bloss abhängig ist von der Grösse des Tieres kann man folgender Tabelle entnehmen:

\begin{tabular}{lll|l|l|l|l|c} 
Länge des Tieres & $:$ & $45 \mathrm{~mm}$. & $12 \mathrm{~mm}$. & $18 \mathrm{~mm}$. & bis $50 \mathrm{~mm}$. & $48 \mathrm{~mm}$. & bis $24 \mathrm{~mm}$. \\
Anzahl der Reihen & $:$ & $14 \ldots$ & $16-17$ & $13-15$ & $12-15$ & 12 & $8-10$
\end{tabular}

Die Reihen stehen vorn und hinten meistens dichter aneinander gerückt. Sie sind auf erhabenen Leisten gestellt, die eine einzelne oder meistens nach aussen doppelte Reihe von Papillen tragen, sodass die Papillen nach dem Fuśse hin dichter gedrängt erscheinen. F us s sehr breit, die Vorderseite abgerundet und in spitze Ecken ausgezogen. Hinten scheint der Fuss sich plötzlich zu verschmälern zum kurzen Schwanz. Tentakel und Rhinophorien fast gleich lang, beide glatt, die Rhinophorien bisweilen ein wenig runzelig, oder eine wenig tiefe spiralförmige Furche aufweisend. Farbe: wechselt zwischen durchsichtig bleichgelb, gelbgrün und rotgelb, welches am tiefsten am Kopfe erscheint. Das ganze Tier besäht mit vielen dunkelweissen oder rötlichen Pünktchen. Die Tentakel und Rhinophorien sind meistens orangerot gefärbt, nur kann dies an der Spitze oder am Grunde oder in der Mitte mit dem Weiss der Fleckchen abwechseln. Die Papillen mit grau oder bläulich oder grünlich durchschimmerndem Lebersack, öfters mit rotem Anflug nahe der Spitze, teilweise besäht mit weissen Fleckchen. Die beiden ersten Reihen der Rückenpapillen können weisslich erscheinen. Fuss weisslich oder gelblich. Radula mit Zähnen, welche die für Aeolidiella typische Gestalt zeigen: in der Mitte sehr schmal, mit einem einzigen breiten kurzen dreieckigen Dentikel; der bisweilen aber fehit; die Basalfläche auch in der Mitte schmal, seitwärts aber flügelartig verbreitert, mit stark gebogenem Oberrande, worauf die Dentikel eingepflanzt sind. Die letzteren sind seitwärts länger als in der Mitte. 
Die anderen von den verschiedenen Autoren gemachten Angaben scheinen gar keine spezifischen Merkmale zu liefern, auch die immer sorgfältig abgebildeten Mandibel nicht. (Man vergleiche die verschiedenen Abbildungen in der Literatur).

Da wir jetzt so weit gekommen sind, dass wir uns eine Vorstellung der Variationsbreite dieser Art machen können, ist es möglich die zweifelhaften Arten darauf zu untersuchen, ob sie wirkliche Arten vorstellen, oder nur Varietäten (vielleicht sogar gar keine Varietäten) dieser Art.

Nachdem TRINCHESE (1882) schon bemerkt hatte Ae. glauca und Ae. Alderi seien Varietäten einer Art, war VAYSSIĖRE der erste Verfasser, der die Ae. angulata und die Ae. alderi als Synonyme zur Ae. glauca stellte. Er bemerkt: „Les figures des dents des E. glauca et Alderi donneés par ALDER et HaNCOCK dans leur ouvrage sur les Nudibranches des côtes anglaises, sont identiques entre elles et l'E. Alderi établi par Cocks fait double emploi, aussi l'avons-nous 'mis en synonymie."

Betrachtet man (wenn wir unsere Vergleichung mit Ae. angulata anfangen) die Figuren von ALDER und HANCOCK, so fällt es einem sofort auf wie sehr die Gestalt dieses Tieres der des von VAYSSIĖRE abgebildeten Tieres gleich sieht. Das Verhältnis der Breite zur Länge ist $\frac{2.5}{8.5}=\frac{1}{3.5}$ und fällt also zwischen die für Ae. glauca oben angegebenen Grenzen, ebenso wie das Verhältnis der Höhe zur Länge welches hier $\frac{1.2}{8.5}=\frac{1}{7}$ beträgt.

Auch in der weiteren Beschreibung von ALDER und HANCOcK dieser Art findet sich nichts, das auch nicht für Ae. glauca gilt und es scheint mir denn auch richtig die Tiere dieser ursprünglichen Beschreibung zur Ae. glauca zu stellen, wie auch CuÉNot (1906) es macht. Nach ihm ist die Ae. angulata eine sehr junge Ae. glauca. Eine gesonderte Betrachtung verdienen die Ausführungen von Eliot. Die von ihm 1906 erwähnte Form besass, während des Lebens, nach Professor Herdman, der das Tier fand: „the external characters of Eolis angulata. The preserved specimens also seemed to have these characters as far as could be recognized, except that the cerata were more numerous." Er selbst schlägt denn auch vor das Tier zur Ae. glauca zu stellen, denn er meint dass Eolis angulata „merely a broad and immature specimen of Aeolidiella glauca" sei. Im Jahre 1910 aber nennt derselbe Autor ein von Mr. C. W. WATson geschencktes Exemplar dieser Art, das ganz stimmte mit dem in der Monographie geschilderten oben genannten Tiere. Das Verhältnis der Länge zur Breite beträgt $\frac{7}{16}=$ etwa ${ }_{2 \frac{1}{3}}^{1}$, das ist also breiter als die uns bekannten Exemplare, die bis $\frac{1}{2.5}$ gehen. Eliot bemerkt: "the opinion of ALDER und HaNCOCK, now supported by Mr. WALton, that the two species are distinct cannot be neglected. The animal described by Mr. WALTON is clearly an Aeolidiella, and it differs from Ae.lla glauca (1) in colour; (2) in the broad foot with projecting angles; (3) in the cerata, which do not show the same curious vermicular shape and movements; (4) in the shape of the teeth, in which the central cusp is flanked by two denticles pointing outwards. I confess that I am not convinced that these characters are really of specific value for specimens of Aeolidiella apparently referable to the same species show great variation both in external characters and in the denticulation of the teeth." Demgegenüber können wir bemerken: $1^{0}$. wie wir gesehen haben variiert die Art erheblich was Farbe anbelangt; die Ae. angulata besitzt keine Farbe die nicht in den oben geschilderten Ramen passt; $2^{n}$. auch bei Ae. glauca ist der Fuss breit. VAYssiÈRE hebt dies für die von ihm untersuchten Tiere besonders hervor und vergleicht man seine Abbildungen mit denen ALDER und HANCOCK's so sieht man darin keinen Unterschied. Vielleicht lag hier eines der äusseren Exemplare einer Variationṡeihe vor. (Mr. WALTON hatte nur ein Tier!); $3^{\circ}$. dass die Tatsache, dass die Papillen nicht die eigentümlichen "vermicular shape and movements" zeigen (die das eine Exemplar ALDER und HANCOCK's von Ae. glauca aufwies) kein wichtiges Merkmal liefert, wie schon von VAYSSIĖRE und BERGH und neuerdings noch von LøYNING hervorgehoben worden ist; $4^{\circ}$. Wir kennen nur wenige radulae, aber aus den uns bekannten können wir leicht folgern, dass der Mittelzahn öfters beim selben Tier keine oder mehrere Dentikelchen trägt. (Vergleiche zum Beispiel BerGH 1874, Taf. VIII, Fig. 15, $16 ; 1885$, Taf. V, Fig. 13; 1888, Taf. XVI, Fig. 18).

Man sieht, dass keines der vier von ElioT zweifelnd angegebenen Unterscheidungsmerkmale unserer jetzigen Kenntnis gegenüber standhalten kann und ich schlage darum vor auch diese Art unserer Ae. glauca unterzuordnen. 
Die folgende fragliche Art ist die Heinckesche, der er selber nicht den Mut hatte einen Namen zu geben. Er bemerkt: „Die Platten der vorliegenden Art gleichen am meisten denen von glauca, unterscheiden sich aber doch hinreichend davon, um vermuten zu lassen, dass es sich um eine besondere Art handelt, ganz abgesehen davon, dass die ganze äussere Körperform wesentlich von derjenigen von glauca abweicht. Dagegen zeigt die letztere und auch die Färbung ziemliche Ähnlichkeit mit denen der Eolis angulata von ALDER und HANCOCK, die von ihnen Taf. 23 abgebildet und beschrieben wird. Im Appendix p. IX $\mathrm{N}^{0} .25$ beschreiben dieselben Autoren eine der Eolis angulata sehr ähnliche Nacktschnecke als Eolis inornata. Von beiden ist die radula nicht untersucht worden. Möglicherweise handelt es sich bei der Helgoländer Form um eine dieser beiden Arten." Wir können dazu bemerken: $1^{\circ}$. Eolis inornata wurde von ALDER und HaNCock beschrieben in Ann. Mag. Nat. Hist. XVI (1845) p. 315 und wieder in der Monographie Part VII, Appendix p. IX: „The species is founded on a single specimen", "which unfortunately was not preserved". Liest man die Beschreibung, so macht keines der genannten Merkmale eine Unterscheidung mit Ae. glauca nötig. Es ist deutlich, dass hier eine junge bleiche Ae. glauca vorlag. Später wurde sie nicht mehr in der Literatur genannt. (Die Spurilla inornata scheint eine andere Form zu sein). Die Ähnlichkeit des Heinckeschen Tieres mit dieser Art deutet also auf Ae. glauca. Zugleich haben wir hier wieder eine Art, Ae. inornata, die synonym ist mit Ae. glauca. $2^{0}$. Die Körperform ist nach HeIncke auch der der Ae. angulata gleich. Seine Abbildung, zeigt das Verhältnis Breite zur Länge $=\frac{1}{5}$, also noch innerhalb der Grenzen von Ae. glauca bleibend. Auffallend ist der lange Schwanz, den aber nur drei der vier Tiere besassen. Das vierte Tier hatte einen kurzen Schwanz, und dieser scheint die eigentümliche zugespitzte Form besessen. zu haben, die Ae. glauca auch zeigt. Höchstens also können wir die drei Exemplare als var. longicauda unterscheiden, nötig aber scheint mir dies durchaus nicht. $3^{0}$. Die abgebildeten Zahnplatten sind denjenigen der Ae. glauca ganz gleich. Ich kann wenigstens keinen Unterschied finden. Ich schlage darum vor auch die von HeINCKe beschriebene nov. sp.? der Ae. glauca einzureihen.

Unsere nächste Untersuchung gilt jetzt Al. alderi, schon von VAyssière zu Ae. glauca gestellt. Als Alder und HANCOCK 1854 (1852) diese Art beschreiben, welche von ihrem Freunde W. P. Cocks aufgestellt wurde (Naturalist V, 2) sagen sie neben anderem: „It comes very near to our E. glauca, but Mr. Cocks who has had the opportunity of studying both species in a living state, considers it quite distinct: The white ruff, formed by the first two rows of papillae, he assures us, is a permanent and good character in this species, besides that it is never more than half the size of $E$. glauca in the adult state and the colour is also different. Unlike $E$. glauca this is a very active and restless creature, erecting its branchiae and showing much irritability when disturbed."

Die weissen („opaque white”) ersten Papillenreihen kommen, wie wir oben gesehen haben, auch bei Ae. glauca var. mediterranea vor. Auch BERGH hat da aber gemeint, dass man ein solches Merkmal nicht benutzen dürfe zur Aufstellung einer neuen Art. Der Grössen-Unterschied ist unwichtig. Die Tiere sind, der Beschreibung nach, ein wenig bleich, zeigen aber hier und da noch eine "pale orange” Farbe. Die weissen Pünktchen werden auch hier gemeldet. Ob auch die „irritability” genügt zur Aufstellung einer neuen Art? Vorläufig jedenfalls nicht.

GARSTANG ist der erste, der diese Art wieder erwähnt, er gibt als Ursache der weissen ersten Tentakelreihen an: "It appears to be caused by the cerata of the first two rows, having each a very short hepatic diverticulum, instead of one reaching to the tip of the cerata." Auch dies aber kann uns nicht veranlassen hier eine neue Art zu unterscheiden. CuÉNot (1906) meint: „la collerette caractéristique formée de chaque côté de la tête par les papilles antérieures, plus petites et moins colorées que les suivantes, n'apparaît pas encore chez les individus jeunes et n'est peut-être plus très évidente chez les individus de grande taille"; Ae. angulata sei die jüngere, Ae. alderi die mittlere und $A e$. glauca die erwachsene Form. Diese Hypothese wird gestützt durch die Angaben über die Grösse der Tiere. Der Autor weist auch noch darauf hin, dass die Abbildungen von Ae. glauca öfters deutlich die Spuren des „Halsbandes” zeigen. Die Zähne stimmen ganz mit denen von Ae. glauca überein. Auch diese Art kann also der Kritik keinen Stand halten.

Eine weitere Art, die wir zu untersuchen haben ist Aeolidiella soemmeringii Bgh. (non Leuckart). Die Leuckartsche Art ist, wie BERGH 1882 bemerkt, Amphorina coerulea Montagu. BerGH beschreibt sie 1864 ('68) und 1882, während er ohne nähere Beschreibung 1885 noch Abbildungen gibt. Am Ende 
seiner Beschreibung von Ae. glauca var. mediterranea (1885) sagt er aber: „Es ist kaum über allen Zweifel gehoben, dass diese Art von der (viel grösseren) Ae.olidiella Soemmeringii spezifisch verschieden sei, oder also, dass die letztere sowie die Ae. glauca nur Varietäten einer und derselben Art darstellen." Auch ich kann mich bei sorgfältiger Vergleichung der Abbildungen der Überzeugung nicht entziehen, dass auch hier Ae. glauca vorliege. Das Verhältnis der Breite zur Länge ist $\frac{5 \mathrm{~mm}}{20 \mathrm{~mm}}=\frac{1}{4}$ und fällt also zwischen die gestellten Grenzen für Ae. glauca. Das Verhältnis der Höhe zur Länge ist $\frac{4.3}{n}= \pm \frac{1}{5}$ und liegt also gerade an der Grenze, die wir für Ae. glauca gefunden haben. Auch die Schilderung der Papillenverteilung, wie BERGH sie 1882 gibt, ist nicht von der von Ae. glauca verschieden. Die anatomischen Merkmale liefern auch keine Unterscheidungsmerkmale und ich folge darum CUÉNOT und stelle auch diese Art zu Ae. glauca.

Zuletzt gehört meiner Meinung nach auch Eolis sanguinea Norman zu dieser Art. Der Autor sagt: „Our new form comes nearest to E. glauca from which it differs in its more attenuated form, in its more numerous transverse rows of branchiae and more numerous branchiae in those rows, in its more brilliant body-colour and its branchiae being blood-red instead of "sage-green" ". Betrachten wir diese Merkmale, so ist dazu zu bemerken: $1^{0}$. Norman gibt uns keine Masse und wir sind also nicht im Stande $z u$ vergleichen. Ich weiss nicht ob er das Verhältnis $\frac{1}{5}$ schon „narrow” nennen würde. $2^{\circ}$. Achtzehn Papillenreihen ist in der Tat eine grosse Anzahl. BERGH gibt höchstens 17 Reihen an. Sie kommen einander jedoch sehr nahe. $3^{\circ}$. Die Farbe der Papillen wechselt mit deren Inhalt. Übrigens scheint mir die blutrote Farbe von der roten Farbe der Ae. glauca nicht wesentlich verschieden. Wir sehen also, dass auch diese Art mit der Ae. glauca identisch ist, niemand wird sie je doch wegen der obengenannten Merkmale als eine selbständige Art betrachten wollen, vielleicht wird sie später wegen der grossen Papillenzahl und der blutroten Farbe noch als var. sanguinea unterschieden werden. ELIOT (1910) hatte recht als er sagte: „I am inclined to agree with CuÉNOT that all the so-called European spejies: glauca, alderi, angulata and Soemmeringii are all varieties of one".

Eine Liste der Synonyme der Aeolidiella glauca lautet:

Eolis glauca Alder et Hancock 1845, 1848-1855, Jeffreys 1869, Fisher 1875.

Aeolidiella glauca (A. et H.), Bergh 1867, 1885 etc., Trinchese 1882, Collin 1884, Vayssière 1888, 1901, 1917, Carus 1889, Garstang 1890, Nobre 1905, Cuénot 1906, Nils Odhner 1907, Eliot 1910, Løyning 1922.

Eolis angulata, A. et H. 1845 ('46).

Eolis (Aeolidiella) angulata A. et H., Eliot 1906.

Aeolidiella angulata (A. et $\mathrm{H}$.), Eliot 1910.

Eolis inornata A. et H. 1845 und 1855.

Aeolidiella nov. sp.? Heincke 1897.

Eolis Alderi Cocks \pm 1852 .

Aeolidiella Alderi (Cocks), Garstang 1890.

Aeolidia Soemmeringii Bergh 1864 (non Leuckart), 1867, 1874, 1882, 1885.

? Aeolidiella sanguinea Norman 1877, Bergh 1882, 1888, 1890, 1892, 1904.

Die Diagnose der Ae. glauca nach der Zusammenstellung mit den Synonymen lautet: Körper breit und niedrig, hinten zugespitzt, bis $50 \mathrm{~mm}$ lang $\underset{\mathrm{L}}{\mathrm{Br}}=\frac{1}{2 \frac{1}{3}}-\frac{1}{5}, \frac{\mathrm{H}}{\mathrm{L}}=\frac{1}{5}-\frac{1}{9}$. T e n takel gewöhnlich, glatt. R h in oph or i en glatt, oder mit leichter Spiralfurche versehen, oder ein wenig runzelig. Pa pill en konisch, schlank, zahlreich, in Querreihen gestellt, die die Rückenmitte nackt erscheinen lassen. Anzahl der Reihen 8-18 (vielleicht kann eine var. sanguinea mit einer grossen Zahl von Papillen unterschieden werden, und vielleicht werden später die von VAYSSIĖRE beschriebenen Tiere als var. paucipapillata den anderen gegenüber gestellt). Die Reihen stehen vorn und hinten meistens dichter an einander gerückt. Sie stehen auf erhabenen Leisten, die eine einzelne oder meistens nach aussen doppelte Reihe von Papillen tragen, sodass die Papillen nach dem Fuss hin dichter gedrängt erscheinen. Analpapille etwa am hinteren Rande des unteren Endes der 5. (6.) Leiste. Genitalpapille ungefähr unter der 3. bis 4. Leiste liegend. Die Stelle dieser Öffnungen ist noch nicht ganz sicher festgestellt. Fus s 
sehr breit, die Vorderseite abgerundet, in spitze Ecken ausgezogen. Hinten scheint der Fuss sich plötzlich zu verschmälern zum kurzen Schwanz (die Heinckesche Tierë sind vielleicht als var. longicauda zu unterscheiden). Far be wechselt zwischen durchsichtig bleichgelb oder gelbgrün und rotgelb, welches am dunkelsten am Kopfe erscheint. Das ganze Tier besäht mit vielen (dunkel-) weissen Pünktchen. Tentakel und Rhinophorien meistens orangerot gefärbt, nur kann dies an der Spitze, am Grunde oder in der Mitte mit dem Weiss der Fleckchen abwechseln. Papillen mit grau oder bläulich oder grünlich durchschimmerndem Lebersack, öfters mit rotem (orangem oder ockerrotem) Anflug nahe der Spitze (vielleicht eine var. sanguinea mit blutroten Papillen), teilweise besäht mit weissen Fleckchen. Wahrscheinlich wegen des Vorkommens eines ganz kurzen Leberstammes können die beiden ersten Papillenreihen weiss erscheinen, (var. mediterranea und var. Alderi, während aber erstere übrigens die Farbenverhältnisse der typischen Ae. glauca zeigt, ist letztere gekennzeichnet durch das Fehlen der steinroten Farbe. Ob sie aber wirklich verschieden sind?). Der Fuss weisslich oder gelblich. Rad ula mit für Aeolidiella typischen Zähnen, Basalfläche in der Mitte schmal, seitwärts stark verbreitert.

\section{Aeolidiella occidentalis Bgh.}

Als Bergh 1867 ('68) die Gattung Aeolidiella aufstellt (S. 99 Fussnote), nennt er unter anderen diese Art als nova species. Erst 1874 gibt er uns eine Beschreibung derselben nach drei Exemplaren von KREBS im Antillenmeere bei St. Thomas gefischt. MöRCH in seiner Synopsis der westindischen marinen Mollusken (1875 S. 178) erwähnt natürlich auch diese Art. Ebenso ihm folgend DALL (1885) in seiner Liste. Diese Art stellt ganz gewiss eine von den anderen verschiedene dar, welche sich unterscheidet durch den Besitz von: $1^{n}$. Zähnen, welche nicht in der Mitte schmal sind und sich dann flügelartig verbreitern, sondern überall gleich breit. Nur ist das Mitteldentikel (einzeln oder wieder gezähnelt) breiter und viel kürzer als die Seitendentikel. Man bekommt daher auch hier, wenn man den Zahn mit seinen Dentikeln als Ganzes betrachtet den sogenannten Doppelbogen des Schneiderandes, welcher diese Arten karakterisiert. Dieser ist also hier nicht der Basalplatte zu verdanken, sondern nur der verschiedenen Länge der Dentikel. $2^{\circ}$. Das Verhältnis der Breite zur Länge ist nach BERGH hier $\frac{2 \text { bis } 2.5 \mathrm{~mm}}{10 \text { bis } 12 \mathrm{~mm}}=\frac{1}{4}-\frac{1}{6}$ (während dasselbe bei Aeolidiella glauca $\frac{1}{2 \frac{1}{3}}$ bis $\frac{1}{5}$ ist; der Körper ist also hier im allgemeinen schmäler). Die Höhe beträgt $1,5-2,5 \mathrm{~mm}$ also $\frac{1}{4}-\frac{1}{8}$ der Länge (bei Ae. glauca ist es $\frac{1}{5}-\frac{1}{9}$ also fast das gleiche, allein ist Ae. occidentalis etwas weniger niedergedrückt. $3^{\prime \prime}$. Eigentümlich scheint auch die Farbe zu sein: „Die Farbe war hell graubräunlich mit eigentümlichen weissen mehr oder weniger verästelten, meistens je doch parallel laufenden, schmalen, an dem Kopfe und an dem Rücken in die Quere gehenden, an dem Halse und an den Seiten senkrecht gestellten Streifen." $4^{0}$. Der Schwanz scheint ziemlich lang zu sein, $2-3 \mathrm{~mm}$ bei einer Körperlänge von $10-22 \mathrm{~mm} .5^{\circ}$. Weiter werden noch die folgenden Angaben gemacht, die aber zur Karakterisierung der Art weniger wichtig erscheinen: Für die Rhinophorien gibt BERGH an „kürzer als die Tentakel, gestreckt kegelförmig mit dichtstehenden kreisförmigen oder schrägen Fältchen.". Dies wird der Zusammenziehung zu verdanken sein, obgleich es nicht hinzugefügt wurde, denn sonst würde BERGH seine Art nicht zu Aeolidiella gestellt haben. „Die Papillen, die fast alle abgefallen waren, waren in fast querlaufenden Reihen gestellt gewesen, die zum grossen Teile paarweise wie an niędrige Kissen zusammengerückt waren; die Anzahl der Reihen war aber bei dem Konservationszustande der Tiere unmöglich zu bestimmen.” „Die Analöffnung lag etwas mehr gegen vorne als bei den meisten echten Aeolidien."

Diese Art lässt sich mit keiner der bisher beschriebenen Aeolidiellen zusammenstellen und ist ganz gewiss eine typische deutlich unterscheidbare Form.

Aeolidiella orientalis, indica, drusilla, faustina und japonica.

Mit den orientalischen Arten sind wir nur sehr schlecht bekannt. Es liegen uns vier (eigentlich fünf) Beschreibungen von BERGH vor, nach einem oder zwei Tieren, die öfters noch dazu schlecht erhalten waren, und eine nach 5 Exemplaren von Eliot (Ae. japonica). Obgleich wir an Ae. glauca gelernt haben, wie sehr die Aeolidiellen variieren, ist es jetzt noch nicht möglich etwas zu sagen über mögliche Identität der beschriebenen Arten. Ich gebe die Diagnosen darum so wie ich sie bei BERGH und Eliot für jede Form vorfand. 
Die Literatur dieser vier Arten ist die folgende:

Im Jahre 1888 werden von BERGH publiziert das XVI. Heft der Malacologische Untersuchungen sowie der IX. Beitrag zur Kenntnis der Aeolidiaden. In beiden Schriften beschreibt er eine neue Aeolidiella aus dem Indik, in der erstgenannten Schrift Ae. indica Bgh. nach 3 Exemplaren, welche von Moebius in Grande. Baie, Mauritius gefischt wurden, in der zweiten Arbeit Ae. orientalis nach einem Exemplare von BROCK bei der Insel Noordwachter am 1. Mai 1885 gefischt. Es ist nicht leicht zu entscheiden, welche dieser beiden Arten er zuerst beschrieben hat. Der Ae. indica geht eine Liste der bekannten Arten vorab, worin Ae. orientalis nicht genannt wird, der Ae. orientalis geht eine Bemerkung vorab, worin gesagt wird, dass bis dahin nur 5 Arten bekannt seien, welche die mehrmals von BERGH genannten Ae. soemmeringii, occidentalis, glauca, alderi und sanguinea sind. Ae. indica ist hier also nicht mit hineingenommen.

Eine Wiederholung der Beschreibung in den "Beiträgen” ist die Beschreibung von Ae. indica im XVII. Heft der "Malacologische Untersuchungen”' (1890, S. 875). BERGH scheint sich später nicht mehr zu erinnern, dass er Ae. indica beschrieben hat, denn in keiner seiner späteren Listen der Arten von Aeolidiella $(1890,1892$, 1904) nennt er diese Art, niemals verweist er nach der betreffenden Arbeit. Ae. orientalis wird immer genannt.

Mit Ae. drusilla als neue Art wurden wir 1900 von BERGH bereichert, nach einem Exemplare gefischt „im French Pass an der Cookstrasse (zwischen der Nord- und Südinsel von Neuseeland, gegenüber d'Urville-Island)". Warum BERGH auch diese Art nicht nennt in seiner Liste der Aeolidiellen, die er 1904 am Anfang der Beschreibung von Ae. faustina gibt, verstehe ich nicht. In der Siboga Monographie (1905, S. 222) erwähnt er drei junge Tiere von Ae. drusilla.

Die Schauinslandsche Reise lieferte BERGH (1900) das eine Exemplar der Art, die er Aeolidiella faustina nannte. Im Jahre 1904 gibt BERGH eine Beschreibung nach zwei ihm vorliegenden Tieren, die er zweifelnd Ae. faustina nennt.

ELIOT beschrieb 1913 Ae. japonica.

Die Diagnosen dieser fünf Arten sind folgende:

Aeolidiella indica Bergh (nach 3 Tieren). Körper: Form wie bei Ae. glauca. Das Verhältnis der Breite zur Länge ist $\frac{2.6 \mathrm{~mm}}{8 \mathrm{~mm}}=\frac{1}{3}$, der Höhe zur Länge $\frac{2.2 \mathrm{~mm}}{8 \mathrm{~mm}}=\frac{1}{3.5}$. Rhinophorien und Tentakel glatt, faden- bis keulenförmig. Papillen in Reihen die in der hinteren Hälfte des Rückens von beiden Seiten her zusammenstossen. Total 18-15 Reihen in drei Gruppen (I (5-7), II (2-3), III 8). Die Genitalöffnung unterhalb der Mitte der ersten (rechten) Papillengruppe. Die Analpapille schien (?) lateral am Rücken am oberen Ende der ersten freien Papillenreihe zu liegen. $F$ us s beim lebenden Tiere „vorne abgestumpft mit kleinen dreieckigen Lappen, hinten lanzettlich." Randfurche undeutlich. $\mathrm{Schwanz}$ ganz kurz, kaum $\frac{1}{2} \mathrm{~mm}=\frac{1}{16}$ der Körperlänge. Farbe beim lebenden Tiere weissgelb und graugelb, Rhinophorien grau mit weisser Spitze, Tentakel weiss mit gelblichem Ende, die Papillen des Rückens "grau oder gelb”. Beim konservierten Tiere: Vorderrand des Kopfes und der Fussrand kalkweiss, die Aussenseite der grösseren Papillen (besunders des vorderen Teils des Körpers) mit zwei kalkweissen und mit zwei graubraunen oder noch dunkleren Längsstreifen. Radula mit Zähnen wie bei Ae. glauca.

Aeolidiella orientalis Bergh (nach 1 Tiere). Eine farbige Abbildung dieser Art findet man in Bergh Malacol. Unters. 1890. Farbe beim lebenden Tiere: „Rücken und die obere Seite des Kopfes (mit Ausnahme der Spitze) rot; am Rücken hintereinander in einer medianen Reihe mehrere längliche weisse Flecken; die Papillen rotbraun mit roter Spitze und einem weissen Ringe unterhalb der Spitze. Die Tentakel und die Rhinophorien weiss mit roter Spitze. Die Körperseiten und der Fuss scheinen weiss zu sein". Körper breit und niedrig. Das Verhältnis der Breite zur Länge $\frac{3 \mathrm{~mm}}{10 \mathrm{~mm}}= \pm \frac{1}{3}$, der Höhe zur Länge $\frac{2 \mathrm{~mm}}{10 \mathrm{~mm}}=\frac{1}{5}$. Die Länge beim lebenden Tiere $23 \mathrm{~mm}$, beim selben konserviert $10 \mathrm{~mm}$. Tentakel und Rhinophorien glatt. Papillenreihen lassen die Rückenmitte nackt (nur unten schmaler als vorn), Anzahl der Reihen 30, Analpapille zwischen den äusseren Enden der 8.-9. Papillenreihen liegend. „Genitalpapille wie gewöhnlich”. Fuss vorn gerundet (nach BERGH ein sehr wichtiges Merkmal!), mit Randfurche. Schwanz kurz. Radula mit Zähnen wie bei Ae. glauca (das Vorhandensein von kleinen Dentikeln auf der medianen Spitze ist nicht spezifisch). 
Aeolidiella drusilla Bergh (nach einem erwachsenen und drei jüngeren(?) Tieren). Farbe unbekannt. Körper breit und etwas abgeplattet; das Verhältnis der Breite zur Länge $\frac{18 \mathrm{~mm}}{28 \mathrm{~mm}}=\frac{2}{3}$ (bei den jüngeren Tieren $\frac{2.5 \mathrm{~mm}}{8 \mathrm{~mm}}= \pm \frac{1}{3}$ ), der Höhe zur Länge $\frac{7 \mathrm{~mm}}{28 \mathrm{~mm}}=\frac{1}{4}$ (bei den jüngeren Tieren $\frac{2}{8}=\frac{1}{4}$ ). Tentakel und Rhinophorien glatt. Papillen lassen nur das vordere Viertel des Körpers frei, hinten berühren die Reihen einander in der Mitte. In $25(-13)$ Reihen. Zwischen dem inneren Ende der 5. und der 6. Papillenreihe befand sich die niedrige abgestutzte Analpapille, vorn an der rechten Seite die wenig vortretende Genitalöffnung. Fuss vorn mit starker Randfurche, gebogen, mit nach hinten gebogenen Fussfühlern (bei den 3 jungen Tieren nur wenig vorspringend). Schwanz kurz. (BERGH untersuchte ein Tier mit gespaltenem Schwanze). Radula: die Zähne scheinen sich nicht stark zu verbreitern, obgleich sie nicht überall gleich ’breit sind. (Die Beschreibung der Zähne der 3 jungen Tiere ist undeutlich).

Aeolidiella faustina Bergh.

I. Nach 1 Exemplar, 1900. Farbe unbekannt. Körperform gewöhnlich. Das Verhältnis der Breite zur Länge $\frac{3.5 \mathrm{~mm}}{15 \mathrm{~mm}}=\frac{1}{4.3}$. Die Papillen lassen fast keine Partie des Rückens entblösst erscheinen; vorn bildet die Anordnung derselben zwei hufeisenförmigen Figuren, hinter diesen 4 sind noch etwa 10 etwas schräge Reihen vorhanden (total also 14). Die Analpapille scheint sich hinter dem innersten Teil der etwa 6. Reihe zu befinden. Fuss? Schwanz kurz, etwa $\frac{1.5 \mathrm{~mm}}{15 \mathrm{~m} m}=\frac{1}{10}$ der Körperlänge. Zähne wie gewöhnlich. Die Abbildung, welche BERGH gibt, zeigt einen stark gekrümmten über die ganze Breite mit sehr vielen Dentikeln versehenen Zahn.

II. Im Jahre 1904 beschreibt BERGH wieder zwei Exemplare von Aeolidiella faustina, wobei er aber bemerkt: „Durch die Form der Mandibel scheint sich diese Art von anderen Aeolidiellen zu unterscheiden, auch von der von BRock gefischten Ae. orientalis. Vielleicht ist sie mit der von mir früher beschriebenen Ae. faustina identisch, kaum mit der Ae. drusilla." Er zweifelt also. Ich möchte die Merkmale dieser beiden Tiere nicht mit denen des vorigen Exemplars vermischen und gebe sie darum hier: Farbe unbekannt. Körperform gewöhnlich. Das Verhältnis der Breite zur Länge ist dem der Höhe zur Länge gleich, nämlich $\frac{2.5 \mathrm{~mm}}{9 \mathrm{~mm}}$ bis $\frac{2.5 \mathrm{~mm}}{11 \mathrm{~mm}}$ das ist also $\frac{1}{3.6}-\frac{1}{4.4}$. Papillen in gegen 20 Reihen (in $4-5$ Gruppen). Analpapille innerhalb des Rückenrandes etwa hinter der achten Papillenreihe liegend. Fuss mit fingerförmigen Ecken. Schwanz kurz zugespitzt. Radula: Zähne im allgemeinen schmaler als bei den anderen Arten, obgleich sie deutlich eine Verschmälerung der Basalplatte zeigen. Die mittlere Spitze nicht auffallend von den anderen verschieden. Mandibel "von etwas eigenthümlicher Form"; „das gerundete Hinterende gleichsam etwas nach oben geschwungen.” Ob dies eine Monstrosität darstellt, oder ein wesentliches Merkmal ist unbekannt.

Aeolidiella japonica Eliot nach 5 Exemplaren aus den Sammlungen des "College of Science in the Imperial University of Tokyo." Körper wie bei den anderen Arten. Verhältnis der Breite zur Länge $\frac{15 \mathrm{~mm}}{50 \mathrm{~mm}}=$ etwa $\frac{1}{3}$. Rhin ophorien mit 3-4 deutlichen Ringeln, „It is hard to say whether they are natural or the result of contraction due to the preserving fluid, but since they occur in all the specimens and in the same positions perhaps they are natural." Papillen: keine Gruppen bildend; Rückenmitte nackt; bei einem Tiere, das darauf untersucht wurde, 18 Kissen jederseits, von denen die grösseren etwa 10 Papillen trugen; eine hintere Gruppe auf dem Schwanz. Fuss mit ziemlich breiten Rändern; Vorderrand verdickt und mit Randfurche versehen, mit Fussecken, welche aber nicht tentakelförmig verlängert sind. Farbe wahrscheinlich durchscheinend, weiter unbekannt. Mandibel mit glattem Kaurande. Radula: „the shape of the teeth is characteristic”; 18 Zähne von der gewöhnlichen Gestalt, "They are bilobed but the curve is unusually broad and undulating. The central cusp of each tooth is large and there are as many as 65 long and very transparent denticles on either side of it. In the smaller tooth the number of lateral denticles is somewhat less."

In der Gattung Aeolidiella bleiben also nur wenige Arten übrig. Im Atlantik finden wir: Ae, glauca Alder et Hancock; Ae. occidentalis Bergh. Im Indik und Pazifik: Ae. indica Bergh; Ae. orientalis Bergh; Ae. drusilla Bergh; Ae. faustina Bergh (I und II); Ae. japonica Eliot. 
Eine Bestimmungstabelle für diese Arten lasse ich folgen, nachdem ich auch die Spurillen und Berghien behandelt habe.

SPURILLA Bergh.

Spurilla neapolitana (d'Ch.).

Eolis neapolitana (delle Chiaje 1830).

" Alderiana Deshayes (Frédol 1865).

” conspersa P. Fischer 1869.

Spurilla sargassicola Bergh (Kr.) 1871.

” braziliana Mac Farland 1909.

Diese von Delle Chiaje als Eolis neapolitana 1830 aufgestellte Art wurde, wie uns VAyssière (1888) angibt, auch noch erwähnt von Delle Chiaje (1841) tav. 88, fig. 13 als Aeolis neapolitana und von A. Costa (1866) als Flabellina neapolitana und nach Bergh (1864) als Aeolidia neapolitana von Verany (1856). Bei seinen "Neldefiim" Untersuchungen im Jahre 1861 gibt Bergh die Art als Facelina neapolitana an. Eine ausführliche Beschreibung gab BERGH erst 1864 ('68) nach den VERANY'schen Exemplaren, als er für diese Art die neue Gattung Spurilla stiftete.

Im Jahre 1876 lieferte BERGH wieder eine Beschreibung nach einem von Prof. Costa geschenkten Exemplar. TRINCHESE behandelt die Art 1878 sehr ausführlich. Er führt die 1865 von Frédol in seinem "Monde de la mer" abgebildeten Eolis alderiana Deshayes der Spurilla neapolitana zu, worin ihm später VAYSSIĖRE und CUÉNOT nachfolgen. Diese Art wurde von FISCHER 1872 und 1874 seiner E. conspersa zugeführt; diese $E$. conspersa aber 1906 von CUÉNOT wieder als identisch mit Sp. neapolitana dieser Art untergeordnet. Diese Unterordnung ist gewiss richtig, wenn man bedenkt, was Fischer selber bemerkt: „Cette espèce appartient au groupe des Eolis punctata Alder et Hancock, et E. neapolitana Delle Chiaje mais ses papilles dorsales sont beaucoup moins nombreuses."

1882 erscheint wieder eine Beschreibung der Art von BERGH ausgeführt nach Tieren die ihm von Dr. KRUKENBERG gesandt wurden, nachdem letzterer dieselben benutzt hatte für seine: „Toxicologische Untersuchungen als experimentelle Grundlage für eine Nerven- und Muskelphysiologie der Evertebraten. Physiol. Studien an den Küsten von Adria 1879 p. 118-123."

Zugleich bespricht BERGH eine Spurilla neapolitana var., die besonders viel blässer war als die typische Form. VAYSSIẺRE (1888) bespricht natürlich auch diese Art in seiner Arbeit über die Marseiller Nudibranchien und bildet in 1901 noch eine Varietät ab auf Taf. I, Fig. 24, die er später aber als Spurilla inornata angibt. Im Jahre 1906 meldet CuÉNOT diese Art für das Bassin d'Arcachon. Er hat gefunden, dass die von P. FISCHER (1869 und 1874) und H. FISCHER (1898) beschriebene Eolis conspersa dieser Art gleich ist, und fügt mit Zustimmung von BERGH Sp. sargassicola zu den Synonymen.

Eliot (1910) endlich meldet, dass der Bau der Genitalien der von Aeolidiella papillosa gleich ist.

Zwei Spurillen, nämlich $S p$. sargassicola, sowie Sp. braziliana können meines Erachtens nicht mehr als selbständige Arten betrachtet werden. Ich behandle sie hier zugleich und lasse die Gründe der Zusammenstellung weiter unten bei den Diagnosen folgen.

Spurilla sargassicola Bergh (Kr.) wurde 1861 (S. 322) von BERGH bei seinen NesselfadenUntersuchungen als Facelina? sargassicola (Kröyer) genannt. Er hatte das Tier unter diesem Namen im Kjöbenhavner Zoologischen Museum gefunden „som KRöYER d. 23 Juni 1841 har taget i Sargassohavet." Obgleich KRÖYER diesen Namen gegeben hat, ist BERGH der eigentliche Autor, denn er hat 1871 zuerst eine Beschreibung dieser Art gegeben, die er zu seiner 1864 ('68) aufgestellten Gattung Spurilla stellt. VAYSSIĖRE nennt die Art 1901 von Arcachon (signalée par M. Fischer). (UÉNOT (1906) meldet die Synonymie mit Ae. neapolitana.

Im Jahre 1909 wurde von MAC FARLAND Spurilla braziliana beschrieben nach einem einzigen von der Branner-Agassiz Expedition in Brasilien (Riacho Doce Alagoas, July 28, 1899) gefangenen Exemplar. Nach dieser Angabe wird 1915 (S. 142) durch von IHERING verwiesen.

Die Spurilla neapolitana ist uns recht gut bekannt. Ich stelle die folgende Beschreibung zusammen aus den verschiedenen uns vorliegenden. Die zwei von BERGH beschriebenen Varietäten (1882 und 1885) habe ich auch hinzugestellt, sie sind doch nicht genügend verschieden um als Varietäten 
einen eigenen Namen zu bekommen. Körperform kräftig, langgestreckt, rund; Seiten ziemlich hoch, nach hinten allmählich abnehmend. Verhältnis der Breite zur Länge $\frac{1}{2}$ bis $\frac{1}{5}\left(\frac{4 \mathrm{~mm}}{8 \mathrm{~mm}}, \frac{1 \mathrm{~mm}}{3 \mathrm{~mm}}, \frac{1 \mathrm{~mm}}{5 \mathrm{~mm}}, \frac{8.5 \mathrm{~mm}}{36 \mathrm{~mm}}\right.$, $\left.\frac{10 \mathrm{~mm}}{40-45 \mathrm{~mm}}, \frac{10 \mathrm{~mm}}{35 \mathrm{~mm}}\right)$ und der Höhe zur Länge etwa $\frac{1}{2 \frac{2}{3}}$ bis $\frac{1}{4 \frac{1}{2}}\left(\frac{8 \mathrm{~mm}}{36 \mathrm{~mm}}, \frac{3 \mathrm{~mm}}{8 \mathrm{~mm}}, \frac{13 \mathrm{~mm}}{35 \mathrm{~mm}}\right)$. Nach CuÉNOT variiert die Länge zwischen 10 und $60 \mathrm{~mm}$. Tentakel gewöhnlich, (BERGH 1882: mit Längsfurche versehen). Rhinophorien in den oberen zwei Dritteln ihrer Länge perfoliiert. Die 20-25 Blätter beiderseits schief gestellt, von verschiedener Breite. Papillen von der gewöhnlichen Gestalt, in etwa 10 bis 22 einzelnen oder doppelten Querreihen; auf Kissen, die an der Vorderseite des Körpers paarweise vereinigt sind zu hufeisenförmigen Bogen (die Anzahl dieser Bogen variiert von 1 bis 9). Rückenmitte nackt. Analpapille im zweiten Bogen. Genitalpapille .zwiscien dem ersten und zweiten Bogen. Fuss ziemlich breit, mit abgerundeten Vorderecken oder "de petites cornes pointues, à peine saillantês". Schwanz kurz, $\frac{1}{8}$ bis $\frac{1}{16}\left(\frac{2.5 \mathrm{~mm}}{40 \mathrm{~mm}}\right)$ der Körperlänge. Farbe variiert sehr stark, durchsichtig weisslich bis hellbräunlichgelb, meistens aber „hübsch fleischfarbig, mitunter auch ziegelrot, selten grau”. Auf dem Rücken öfters, mehr oder weniger deutlich, eine longitudinale Serie von länglichen weissen Flecken. (BERGH 1882: mit zahlreichen, glänzenden, grünlichen Pünktchen besät, sowohl am Körper wie an den Papillen). CUÉNOT meldet noch: „souvent de fines arborisations pigmentaires de couleur brune se dessinent sur la couleur translucide du corps”. Die Fusssohle gelblich bis rötlich, „meistens fleischfarbig, mitunter vorne hell rosafarbig, hinten lebhaft ziegelfarbig". Die Tentakel sind unten ziegelrot, oben heller rosafarbig, oder sie sind ganz ziegelrot mit weisser Spitze, die Rhinophorien sind canariengelb oder orangengelb (giallo ranciato) oder lebhaft ziegelrot mit weisser Spitze oder braun. Die Papillen sind besonders in Farbe variabel; bald hellgrau mit kreideweisser Spitze; bald dunkel umberfarbig mit rosafarbiger Spitze; bald unten canariengelb, oben blass rosafarbig; oft tragen sie in der Nähe der Spitze einen mennigfarbigen Fleck; an der äusseren, seltener an der inneren Seite, findet sich eine Menge von weissen Punkten, besonders gegen die Spitze hin sehr zahlreich. (BerGH meldet 1882 auch grüne Fleckchen). Die Leberlappen grünlich bis bräunlich durchscheinend. Radula: die Zähne besitzen eine gebogene, überall gleich breite Basalfläche beiderseits mit 17 bis 62 fast gleich grossen Dentikeln versehen. In der Mitte findet man einen oder zwei viel kleinere Dentikel, sodass die obere Schneidefläche des ganzen Zahnes einen zweibogigen Eindruck macht. Diese Gestalt ist also nicht wie bei Aeolidiella der Basalfläche zu verdanken, sondern nur der ungleichen Länge der Dentikel. Die Mandibel wechseln erheblich in Gestalt wie man leicht VAYSSIÈRE's und TRINCHESE's Abbildungen entnimmt.

Die. von VAYSSIĖRE 1901 (Pl. I, Fig. 24) abgebildete Spurilla neapolitana var. hat er selber später (1903) als Spurilla inornata beschrieben, ich behandle'sie darum nicht hier.

Prüfen wir jetzt also die Spurilla sargassicola Bergh. Die nach 3 Tieren bekannte Art sieht im konservierten Zustande wie folgt aus: Körperform, im Ganzen etwas zusammengedrückt und schlank. Rücken gewölbt, hinten wie ein Kiel sich über dem Fuss fortsetzend; Rückenmitte nackt. Das Verhältnis der Breite zur Länge ist $\frac{3-4.5 \mathrm{~mm}}{12 \mathrm{~mm}}=\frac{1}{4}-\frac{1}{2 \frac{2}{3}}$ und der Höhe zur Länge $\frac{2.5 \mathrm{~mm}}{12 \mathrm{~mm}}=$ etwa $\frac{1}{5}$ (dieses Verhältnis ist bei $S p$. neapolitana $\frac{1}{2 \frac{2}{3}}$ bis $\frac{1}{2 \frac{1}{2}}$ ). Tentakel gewöhnlich. Rhinophorien kurz keulenförmig, etwas zusammengedrückt, sehr schlank; schön perfoliiert, mit an der Vorderfläche etwa 20 abwechselnd breiteren und schmaleren Blättern (an der vorderen Fläche waren die breiteren besonders stark, die schmaleren vollständig verbergend, an der hinteren war dieser Unterschied weniger hervortretend, hier trat aber noch eine dritte Art von Blättern auf, die noch kleiner waren und die nicht bis an die Mitte der Vorderfläche reichten, die Zahl der Blätter war somit an der Hinterfläche grösser als an der Vorderfläche). Papillen in 14 Reihen, die paarweise verbunden waren zu 7 Bogen. Rückenmitte nackt. Gestalt der. Papillen die gewöhnliche. Genitalpapille hinter dem unteren Teile des hinteren Schenkels des ersten Papillenbogens. Der Anus im zweiten Bogen. Fuss schmal, gegen hinten allmählich zugespitzt, vorn mit kurzen spitzen Ecken und starker Furche. Schwanz unbekannt. Farbe: diese war am Kopfe, an den Papillen und am Fusse bräunlich; „von derselben, aber viel helleren Farbe war auch der Rücken und die Seiten; an diesen letzteren zeigte sich eine feine weissliche Retikulierung, die aufwärts sowie an dem Rücken und im Genicke viel kräftiger wurde; die 
Papillen waren mit weisslichen Flecken bedeckt, die auch an dem hinteren Theile des Rückenkieles vorkamen." Radula: Zähne wie bei $S p$. neapolitana.

Wenn man diese Diagnose mit der von $S p$. neapolitana vergleicht, kann man sich dem Eindruck nicht entziehen, dass diese Art der $S p$. neapolitana sehr nahe verwandt ist. Sie unterscheidet sich nur durch: $1^{0}$. eine geringere Höhe im Verhältnis zur Körperlange, nämlich $\frac{1}{5}$, während es bei $S p$. neapolitana zwischen $\frac{1}{2 \frac{2}{3}}$ und $\frac{1}{4 \frac{1}{2}}$ variierte. Ein so geringer Unterschied scheint mir aber nicht wichtig. $2^{0}$. der Fuss ist hier schmal und bei $S p$. neapolitana „ziemlich breit”. Einen solchen Unterschied kann man aber kaum benutzen. $3^{\circ}$. BERGH nennt die Vorderecken des Fusses kurz und spitz und für Sp. neapolitana den Vorderrand abgerundet. Obgleich diese Angaben verschieden sind, ist hier doch wahrscheinlich kein Unterschied anwesend; kann doch die Gestalt dieser Fussecken beim selben Tier sogar erheblich wechseln. Weiter meldet CUÉNOT für Sp. neapolitana „de petites cornes pointues à peine saillantes," ich erwähnte dies aber nicht sogleich, weil ich nicht weiss, ob er in seiner Beschreibung auch die Merkmale der angeführten Synonyme verarbeitet hat. 4". Die Farbe ist hier bräunlich und zeigte "eine feine weissliche Reticulierung, die aufwärts, sowie an dem Rücken, und im Genicke viel kräftiger wurde". Die braune Farbe, wird für $S p$. neapolitana auch gemeldet, die Retikulierung von den meisten Autoren aber nicht. Wahrscheinlich ist dies aber dieselbe Zeichnung, die CuÉNOT meldet: "souvent de fines arborisations pigmentaires, de couleur brune, se dessinent sur le fond translucide du corps." Hierzu gilt nicht dieselbe Bemerkung, die ich sub $3^{0}$ machte, denn wenn CuÉNOT seine Beschreibung der Berghschen entlehnt hätte, hätte er wahrscheinlich „réticulations” statt „arborisations” gesagt. Keiner der vier hier genannten Unterschiede ist also benutzbar. Auch BERGH zweifelt an der Selbständigkeit der Sp. sargassicola, denn in der Siboga-Monographie (1905) bemerkt er, dass die Sp. neapolitana und Sp. sargassicola "vielleicht nicht einmal spezifisch verschieden sind", und an CuÉNor (1906) schreibt er: „A présent où on connaît la grande variabilité dans l'organisation de beaucoup d'espèces d'Eolidiens, et où l'apparition des Nudibranches de la Méditerranée à l'Atlantique est bien connue, il me semble vraisemblable que l'espèce de KRöYer est identique avec celle de la Mediterranée. Mais jusqu'à présent l'espèce n'a pas été retrouvée en l'Atlantique."

Ich glaube, dass wir $S p$. sargassicola zu $S p$. neapolitana stellen müssen.

Über Spurilla braziliana sagt der Autor MAC FARLAND: „After a careful comparison of its structure with that of $S p$. neapolitana and with the description of the others, I am of the opinion that it represents a distinct species, though certainty in this regard can only be secured by the study of a series of specimens". "The general differences shown by this specimen in anatomical organization especially as shown by the mandibles and radula seem sufficient to authorize its recognition as a member of a species distinct from the European ones already described." Ob diese Art aber trotz dieser von MAC FARLAND genannten Merkmale von Spurilla neapolitana verschieden sei, ist fraglich. Sie wird, wenn wir die Diagnose wie bei den vorigen Arten aufstellen, folgenderweise karakterisiert: Farbe: unbekannt. Körper: schlank, ein wenig zusammengedrückt. Das Verhältnis der Breite zur Länge ist $\frac{3.5 \mathrm{~mm}}{23 \mathrm{~mm}}=\frac{1}{6 \frac{1}{2}}$, der Höhe zur Länge $\frac{1}{5}$. Das Tier ist also breiter als Sp. neapolitana. Ob dies aber wichtig ist? Man vergleiche die Abbildungen von MAC FARLAND mit denjenigen von TRINCHESE (1878). Tentakel gewöhnlich. Rhinophorien perfoliiert, mit 8 Blättern (,which alternate on the posterior side with an equal number of lower ones, that extend forward, half way around the clavus from the posterior median line"). Fuss ziemlich schmal, vorn mit verdicktem Rande; mit Randfurche; Vorderecken kurz und zugespitzt. Schwanz sehr kurz, stumpf zugespitzt. Papillen in 8 Gruppen, die Rückenmitte nackt lassend. Die ersten 5 dieser Gruppen jederseits sịnd auf bogenförmigen Kissen gelagert (auft den Bogen in Einzel- oder Doppelreihen); Genitalpapille im ersten Bogen; Analpapille im zweiten Bogen (also ganz wie bei $S p$. neapolitana). Die Mandibel werden ausführlich von MAC FARLAND beschrieben und abgebildet als karakteristisch für diese Art. Ich glaube dieselben besitzen bei den uns hier interessierenden Arten nur einen sehr geringen, wenn nicht gar keinen systematischen Wert. Was diesen Fall besonders betrifft, wenn wir die von MAC FARLAND angegebenen Unterschiede betrachten, so zeigt sich: $1^{\circ}$. Die Gestalt der von MAC FARLAND abgebildeten Mandibel reicht durchaus nicht ab von der von VAYSSIĖRE und TRINCHESE für Sp. neapolitana abgebildeten. $2^{n}$. Bei den 
beschriebenen $S p$. neapolitana scheint der doppelte Kamm des Mandibelschlusses sich auf der linken Mandibel zu befinden, bei Sp. braziliana aber fand MAC FARLAND denselbe auf der rechten Mandibel. Als er dann aber zur Vergleichung eine $S p$. neapolitaná selber untersuchte, zeigte diese dieselben Verhältnisse wie $S p$. braziliana. Es ist deutlich, dass auch dies kein konstantes Merkmal ist. $3^{0}$. Bei $S p$. braziliana fehlen die Dentikel, leider aber zeigt auch, wie VAYssière meldet, Sp. neapolitana öfters diese Eigentümlichkeit. $4^{0}$. Die Mandibeln der Sp. braziliana sind verhältnismässig kleiner als die der Sp. neapolitana. Ob dieses Merkmal wichtig ist, wissen wir nicht, da wir die Variation dieser Grösse bei $S p$. neapolitana nicht kennen. Radula: Zähne von MAC FARLAND abgebildet. Wie bei $S p$. neapolitana. MAC FARLAND jedoch sagt: „Each plate is slightly emarginate at its summit but none so much so as to give the bilobed appearance figured by BERGH ('64, '71), TRINCHESE ('78) and VAYssière ('88, '03)'. Ist das aber richtig? Betrachten wir das hier Gesagte genau so zeigt sich: $1^{0}$. BerGH '71 bezieht sich auf $S p$. sargassicola und VAYSSIÈRE '03 auf Sp. inornata. Diese Angaben interessieren uns also hier nicht weiter. $2^{0}$. Die anderen genannten Stellen beziehen sich auf $S p$. neapolitana. Vergleicht man nun die da abgebildeten Zähne und bildet sich daraus einen Begriff der Variationsbreite und der mittleren Gestalt der Zähne dieser Art, so passt MAC FARLAND's Abbildung darin ganz gut. Was dann weiter anbelangt: $a$. die Ausbuchtung: sie wird immer nur hervorgerufen durch verschiedene Länge der Dentikel und nicht durch verschiedene Breite der Basalfläche. Die Frage ist also nur, ob bei MAC Farland die mittleren Dentikel kleiner sind als die äusseren. Dies ist in der Tat der Fall. b. die Anzahl dieser kleineren Mittelzähne. Diese ist bei MAC Farland 1 oder 2 (seine Fig. 83), bei VAYSSIÈRE 1, bei BERGH (1876) 1 und (1864) 2. Also auch hier gibt es keinen Unterschied. MAC FARLAND's Bemerkung: „In $S p$. neapolitana the 3 central denticles are very small or rudimentary while in the Brazil species the central denticle is valid and much larger", verwundert uns wenn wir die angegebenen Abbildungen von Sp. neapolitana besehen. Vielleicht war dies der Fall bei einem von MAC FARLAND untersuchten Tier der $S p$. neapolitana, dem wird aber doch durch die genannten Abbildungen widersprochen und es kann höchstens beweisen, wie variabel dieses Merkmal ist. $c$. die Totalanzahl der Dentikel. Diese variiert nach den Angaben der Autoren folgendermassen: BERGH (1864): 68-85, auf den Abbildungen ist der Zahl 38, 35, 34, 29; BERGH (1877): jederseits 30-52 (total also 60104), in der Abbildung 17; BERGH (1885) jederseits 58-90 (total also 116-180); BerGH (1882) jederseits 26-45 (total also 52-90); VAYSSIERE (1889) jederseits 30 à 40 (total also 60-80); TRINCHESE (1878) in den Abbildungen: 28-29-28-26-62 (also total 52-124); MAC FARLAND macht selber auch eine Angabe über die von ihm untersuchte Sp. neapolitana: (18-1-15), (23-1-23), (34-1-34), (32-1-35), (35-1-37), (52-1-44), (54-1-51) (total also 34-106). Vergleichen wir damit schliesslich die Angabe für Sp. braziliana: (49-1-49), (39-1-40), (57-1-53), (61-1-63), (49-1-47) (total also $80-125$ ) so treten diese Zahlen gar nicht über die oben gefundenen Grenzen hinaus. Auch die Zähne liefern also keinen typischen Unterschied. Fraglich bleibt nur der Grössenunterschied der Mandibel und, wenn man eine Sp. neapolitana var. braziliana anerkennen will, soll man sich nur auf dieses Merkmal stützen (und vielleicht noch auf das Verhältnis der Breite zur Länge des Körpers $=\frac{1}{6.5}$ ).

\section{Spurilla inornata A. Costa.}

Diese der Sp. neapolitana sehr nahe verwandte Art wurde, wie VAYSSIĖRE 1903 (S. 86) angibt, als Flabellina inornata von A. CosTA im Jahre 1866 beschrieben und von von JHERING zuerst zur Gattung Spurilla gestellt. Es ist mir aber nicht gelungen eine Arbeit von voN JHERING über diese Art in die Hände zu bekommen. Auch Vayssière gibt keine Jahreszahl an und ich vermute daher, dass für diese Angabe dieselbe Bemerkung gilt, die er auf S. 82 für Archidoris stellifera von Jhering macht: "non publié par l'auteur". Diese Art is nach VAYSSIÈRE dieselbe, die er 1901 als Spurilla neapolitana var. auf Pl. I, Fig. 24 abgebildet hat (eine von ALDER und HANCOCK 1845, p. 315 beschriebene und in der Monographie Part VIl, Appendix p. IX wieder besprochene Eolis inornata scheint eine andere Art darzustellen). Weil mir die Arbeit von A. CosTA (1866) nicht zugänglich ist, entnehme ich VAYsSIĖRE's Beschreibung folgendes: Farbe braungrün, verursacht durch eine grosse Menge Leberverzweigungen gleicher Farbe im Gewebe, welches selber aber weissgelb ist. Die Leberverzweigungen in den Papillen weisen dieselbe Farbe auf („ce réseau faisait toutefois défaut à la face intérieure du pied et 
autour de la bouche"). Körper: zart, verlängert. Das Verhältnis der Länge zur Breite $=\frac{8 \mathrm{~mm}}{60 \mathrm{~mm}}=\frac{1}{7 \frac{1}{2}}$ also schlank, hinten sich allmählich verschmälernd. Tentakel gewöhnlich. Rh in ophorien perfoliiert, mit etwa 12 Blättern. Fuss nicht breiter als der Körper, vorn zur Seite zwei scharfe Ecken bildend. Schwan $\frac{8 \mathrm{~mm}}{60 \mathrm{~mm}}=\frac{1}{7 \frac{1}{2}}$ des Körpers, also kurz. Papillen in 6 Gruppen jederseits wahrscheinlich Boggen bildend. VAYSSIĖRE sagt darüber nichts, dem Bilde aber würde man es entnehmen können. Die beiden hinteren Gruppen nur aus 1 oder 2 Papillen bestehend. Die Länge derselben bis $\frac{14 \mathrm{~mm}}{60 \mathrm{~mm}}=\frac{1}{4 \frac{1}{2}}$ der Körperlänge. Zähne der Radula wie bei Ae. glauca, das heisst also: Basalfläche in der Mitte stark verschmälert, seitwärts flügelartig verbreitert. Könnte man auch wegen der vorhergehenden Merkmale zweifeln, letzteres kennzeichnet die Art genügend als bestimmt verschieden von Sp. neapolitana.

Spurilla orientalis Bergh.

Neben der oben behandelten, auch von BERGH benannten Aeolidiella orientalis begründete derselbe Autor in der Siboga-Monographie (1905, S. 223). eine Spurilla orientalis, nach 5 Individuen gefangen auf dem Riff von Tual bei der Insel Kei, von denen er zwei näher untersuchte. Die Art sieht wie folgt aus: Farbe unbekannt. Körper gewöhnlich. Rücken etwas breiter als der Fuss, wenig gewölbt. Verhältnis der Breite zur Länge $\frac{2 \mathrm{~mm}}{10 \mathrm{~mm}}=\frac{1}{5}$. Verhältnis der Höhe zur Länge $\frac{1.5 \mathrm{~mm}}{10 \mathrm{~mm}}=\frac{1}{7}$. Tentakel lang. Rhinophorien perfoliiert. Schwanz $\frac{2 \mathrm{~mm}}{10 \mathrm{~mm}}$ also $\frac{1}{5}$ der Körperlänge. Papillen lassen die Rückenmitte nackt; in 7-8 Reihen, „die 2 vorderen Reihen convergirten nach oben in einen spitzen Winkel, dasselbe war mit der dritten und vierten der Fall”. Länge der Papillen bis $2.5 \mathrm{~mm}$ ( $\frac{1}{4}$ der Körperlänge). Anus am Rückenrande hinter der vierten Reihe. Die Genitalpapille unter dem Zwischenraume zwischen erster und zweiter Reihe. Zähne der Radula wie bei den beiden erstgenannten Spurillen, also Basalfläche über die ganze Breite des Zahns gleich breit, also ohne Verschmälerung in der Mitte. Ein oder zwei mittlere Dentikel klein.

\section{BERGHIA Trinchese.}

Im Band „Mollusques, Atlas”, der dritten Auflage des Cuvierschen „Règne Animal” wird auf Pl. 30 bis, Fig. 5, abgebildet eine Eoltdia coerulescens Lauril. Auf diese Abbildung verweist BerGH, als er die Art beschrieb. Ausserdem nennt TRINCHESE aber: Cuvier, Iconographie du règne animal, Paris, Baillière 1829-1844, Tom. III p. 19, Tom. II pl. Ix, f. 1, 1a, 1b, 2. Letzteres Werk war mir nicht zugänglich. In GRAY's Mollusca (1857, S. 224) wird die Art als Phidiana ? caerulescens angeführt und von den anderen Phidianen abgeschieden unterm Merkmal: „Foot subulate in front”.

Im Jahre 1874 gibt TRINCHESE auf S. 517 unter anderm eine Beschreibung des Nervensystems dieser Art, die er anführt als Phidiana caerulescens. Im selben Jahre erwähnt er die Art unter demselben Namen in den Rendiconti.

Im Jahre 1877 stellt TRINCHESE dann das Genus Berghia auf mit der einzigen Art: Berghia caerulescens Laurillard. Als Synonyme führt er an Flabellina verrucicornis Costa. (Annuario del museo zoolog. della R. Universita di Napoli, 1867 p. 35, Tav. II, fig. 4, 4A, 4B). Diese Schrift war mir nicht zugänglich, ich beziehe mich aber auf BERGH', wenn er sagt: „Trotz einigen Abweichungen in der Farbenzeichnung, wird das von A. CosTA beschriebene und abgebildete Thier sicherlich hierhin gehören". 1882 gibt BERGH eine ausführliche Beschreibung der Art, nach zwei Exemplaren. Im selben Jahre liefert TRINCHESE eine "Monografia del genere Berghia Trinchese”, worin er die Art ausführlich behandelt. Er meldet, dass von den von Delle Chiaje 1841 auf tav. 73 fig. 16 und 17 als Eolis peregritta Gmelin abgebildeten Tieren, das erste eine Calma Cavolinii, das zweite eine Berghia coerulescens darstellte und verweist weiter nach vol. II, pag. 16 und vol. VI, tav. 17, 18, 19 derselben Arbeit (die mir nicht zugänglich war).

Von VAYSSIĖRE (1888) wird eine nov. spec. gemeldet von der Gattung Berghia, der er aber keinen Namen gibt.

VAYSSIÈRE stellt 1901 die 1872 und 1874 von FISCHER beschriebene Eolis grossularia als Berghia grossularia zu diesem Geschlecht. 
Im Jahre 1906 erwähnt Cú́NOT diese Art auch-für das Bassin d'Arcachon. Er hat gefunden, dass die von FISCHER $(1869,1874)$ als Eolis grossularia beschriebene Form auch die $B$. coerulescens darstellt, und dass die Art von Dautzenbera und Durouchoux bei St. Malo gefunden wurde.

Über B. coerulescens meldet 1906 ELIOT: „The specimen preserved at Plymouth under this name is really a Facelina coronata, and has neither the rhinophores, nor the dentition of Berghia. Berghia should probably be removed from the list of the British fauna, as there appears to be no other record of its occurence." In ELIOT's Supplement zu ALDER und HANCock's Monographie bemerkt er noch auf S. 174: "The specimen preserved at Plymouth under this name is really a Facelina coronata, but Professor Garstang tells me, that he believes the species does occur at Plymouth. There is no reason why it should not, for it is reported to be plentiful at Arcachon and even at St. Malo. See CuÉnot (Arcachon IV, Eolidiens p. 8-9)."

Eine Karakteristik der Berghia coerulescens Laur, zusammengestellt nach TRINCHESE, BERGH und CuÉNOT sowie nach der Abbildung CUVIER's, lautet: Farbe: Oberseite des Körpers, mitsamt den Papillen von durchsichtig-weisslicher Farbe, welche zum Roten oder zum Gelben hinneigt; Oberseite des Kopfes von derselben Farbe, bisweilen aber mit bläulichem Schimmer, bisweilen mit einem grossen glänzend-opakweissen Flecken. Der Fuss ist reinweiss bis gelblich, öfters durchscheinend mit vielen dunkelweissen Pünktchen, an dem Vorderrande ein schmales dunkelweisses Band, das sich bis in die Fussecken '(Fusstentakel) ausbreitet. Tentakel im untern Drittel durchsichtig gelblich, in den oberen zwei Dritteln glänzend opakweiss, bisweilen mit roter Spitze. Rhinophorien mit weisser bis orangeroter Grundfarbe, die Tuberkeln weisslich bis karmin- oder mennigrot oder braun, Spitze immer glänzend weiss. Papillen von der Körperfarbe, die Leberlappen grünlich bis bräunlich durchschimmernd. Unterhalb der weissen durchscheinenden Spitze findet sich ein rotes bis gelbes Band oder Ring, welcher öfters mit einem chromgelben Flecken versehen ist. Zwischen der Basis der Tentakel und der Rhinophorien findet sich öfters eine rote gegen vorne offene hufeisenförmige Figur oder zwei mit den Schenkeln des Hufeisens homologe Flecken; durch Falten in der Haut, können dieselben gestreift erscheinen. Auf dem Rücken findet man meistens einen länglichen rotgefärbten Flecken, welcher verschiedene Einschnürungen zeigt. Körperform: schlank, etwas niedergedrückt. Verhältnis der Breite zur Länge, beim lebenden Tiere $\frac{5 \mathrm{~mm}}{30 \mathrm{~mm}}=\frac{1}{6}, \frac{3 \mathrm{~mm}}{18 \mathrm{~mm}}=\frac{1}{6}$ und $\frac{7 \mathrm{~mm}}{20 \mathrm{~mm}}=\frac{1}{3}$, beim konservierten Tiere: $\frac{2.4 \mathrm{~mm}}{9,5 \mathrm{~mm}}=$ etwa $\frac{1}{4}$. Die Abbildung CuvieR's zeigt das Verhältnis $\frac{1}{5}$. Verhältnis der Höhe zur Länge $\frac{2.5 \mathrm{~mm}}{9.5 \mathrm{~mm}}=$ etwa $\frac{1}{4}$. Tentakel gewöhnlich. Rhin ophorien: Hinten besetzt mit runden Tüberkeln in schrägen Reihen stehend. Vorn mit schmalen konischen Bändern besetzt (muniti di sottili cordoni conici), welche in zwei Reihen von unten und aussen, nach oben und innen verlaufen. Die Spitze des Rhinophors ist eine runde Anschwellung. (BERGH beschreibt die Organe sehr undeutlich: mit gegen 20 schrägen Blättern der Keule, welche am Rande rundzackig waren und die Zacken ein wenig, aber unter der Loupe wenig auffallend verdickt, wenn sie kontrahiert sind sehen diese Organe maulbeerförmig aus). Fus s kräftig, mit starker Randfurche und tentakelförmigen Ecken. Schwanz nicht lang, beim lebenden Tiere $\frac{1}{3}$ oder $\frac{1}{4}$ oder $\frac{2.5 \mathrm{~mm}}{18 \mathrm{~mm}}=\frac{1}{7}$ der Körperlänge, beim konservierten Tiere $\frac{1.8 \mathrm{~mm}}{9.5 \mathrm{~mm}}=\frac{1}{5}$ derselben, in der Abbildung CuvieR's $\frac{1}{7}$. Papillen bis $2.5 \mathrm{~mm}$ lang; sie lassen die Rückenmitte nackt; auf Kissen gelagert; die Angaben über die Verteilung derselben sind nicht bei allen Autoren dieselben. Im allgemeinen kann man sagen, dass sie auf Querreihen stehen die öfters Bogen bilden. Nach BERGH ist bei den von ihm untersuchten Tieren die Anordnung: auf dem ersten Kissen, in etwa 11-12 Schrägreihen mit je 3-6 Papillen im Ganzen etwa 40-50 Papillen, dann folgen zwei Reihen, die an der rechten Seite hufeisenförmig verbunden sind und den Anus umschliessen, dann wieder 2 Reihen und abermals 2 und schliesslich 10-18 Reihen dicht aneinander. TRINCHESE (1876-'77) gibt an: erste Gruppe 2 Reihen, dann 5 Gruppen je aus 2 Reihen gebildet; schliesslich 5 einfache Reihen; Genitalöffnung unter der ersten Gruppe. Anus zwischen den beiden Reihen der zweiten Gruppe. TRINCHESE (1882) fand, als er eine grosse Anzahl von Tieren untersuchte, bei einem grossen Tiere 5 hufeisenförmige Bogen und 5 einfache Querreihen, von denen die hintere nur eine Papille trug; Genitalöffnung rechts zwischen den Schenkeln des ersten Bogens, Anus zwischen denen des zweiten. Mandibel nicht genügend von denen der verwandten Gattungen verschieden. $Z$ ähne der Radula mit einer in der Mitte etwas verschmälerten 
Basalfläche, mit einem oder zwei kleineren dreieckigen Mitteldentikeln und zu jeder Seite etwa 45-60 Dentikel. Nervensystem war nicht zur Unterscheidung zu benutzen.

Über Berghia $s p$. Vayssière wissen wir nur wenig. VAYSSIÈre sagt: „Nous n'en avons rencontré qu'une seule fois un individu, nous paraissant appartenir à ce genre.” „Un accident ne nous ayant pas permis d'étudier aucun des caractères internes nous ne pouvons donner ici que quelques renseignements sur sa forme générale et sur sa coloration, renseignements trop incomplets pour pouvoir établir ses caractères spécifiques."

Interessant ist was er über die eigentümlichen Rhinophorien sagt: „Les rhinophores ou tentacules dorsaux offraient une multitude de nodosités très accentuées, excepté sur une partie de leur face antérieure qui formait une large bande longitudinale complètement lisse."

Seine Abbildung zeigt das Tier von der gewöhnlichen Form. Das Verhältnis der Breite zur Länge $\frac{2 \mathrm{~mm}}{12.5 \mathrm{~mm}}=$ etwa $\frac{1}{6}$. Die Fussecken sehr lang. Schwanz etwa $2 \mathrm{~mm}=\frac{1}{6}$ der Körperlänge. Über die Anordnung der Papillen lässt sich nichts sagen. Die Rhinophorien bildet er sehr deutlich ab. Obgleich ihnen also die Perfoliierung (TRINCHESE's konische Bänder) zu fehlen scheint, meine ich doch, dass dies eine $B$. coerulescens war.

Die B. grossularia Fischer stellt (wenn hier eine Berghia vorliegt, eine Tatsache, die sehr wahrscheinlich ist, man lese FISchER's Beschreibung (1874) der Rhinophorien) unzweifelbar B. coerulescens vor. Ich weise nur auf die roten Flecken im Halse, sowie auf den roten Ring um den Papillen. FISCHER sagt, dass bei senien Tieren die Fusstentakel fehlen.

Mir lag eine Form vor, die ganz mit der Berghia coerulescens übereinstimmt und sich nur in dem weniger Niedergedrücktsein des Körpers, sowie in der Länge des Schwanzes, der hier sogar ganz fehlt, unterscheidet (die Länge desselben scheint aber bei der typischen Form auch erheblich zu wechseln). Ich stelle sie darum, obgleich sie von der amerikanischen Seite der Atlantik stammt, zu der typischen Art.

Das Tier wird folgenderweise karakterisiert: Farbe unbekannt. Körper nicht breit und niedrig. Verhältnis der Breite zur Länge sowie der Höhe zur Länge $=\frac{1}{3.5}$. Tentakel glatt. Rhinophorien wie bei der typischen Art (vgl. weiter unten die genauere Beschreibung derselben). Papillen lassen die breite nackte Rückenmitte frei; auf hufeisenförmigen Leisten; im Ganzen sind 6 solcher Leisten vorhanden sowie eine hintere Gruppe von Papillen, in welcher die Bogenform nicht mehr deutlich war; Genitalpapille im ersten Bogen, Analpapille in dem zweiten. Fuss mit Randfurche, Ecken tentakelförmig. Schwanz fehlt. Zähne wie bei Aeolidiella glauca, also mit einer Basalfläche, die in der Mitte deutlich verschmälert und seitwärts flügelartig verbreitert ist. Unterschiede von den typischen Tieren: das Fehlen des Schwanzes, sowie die runde Körperform.

Ich gebe schliesslich hier noch die ausführliche Beschreibung des mir vorliegenden Tieres. Das Tier war konserviert in Formalin, wurde später aber in Alkohol gebracht. Es wurde ge-

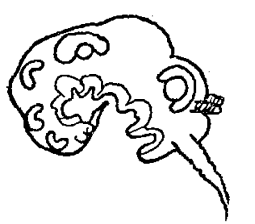

Fig. 3. Berghia coerulescens Laur. Das Tier ohne Papillen; man sieht die hufeisenför migen Papillenkissen im ersten Bogen befin det sich die Genital papille, im zweiten die Analpapille. sammelt von Dr. TH. MoRTEnsen in Tobago, Brit. W. Ind., auf einem Koralriff im April 1916 und wird aufbewahrt im Zoologischen Museum in Kopenhagen. Durch das Konservieren war der ganze Körper gekrümmt, sodass. Vorder- und Hinterseite einander berührten (Fig. 3) und man die Messungen nur schwer ausführen konnte. Die Körperlänge war $7 \mathrm{~mm}$, die Breite $2 \mathrm{~mm}$, die Höhe $2 \mathrm{~mm}$; der Körper ist also rund und nicht breit und niedrig. Das Verhältnis der Breite zur Länge sowie der Höhe zur Länge war also $\frac{1}{3.5}$. Der runde Kopf trug den Mund vorn unter der Anheftungsstelle der Tentakel.

Die ein wenig runzelig-zusammengezogenen Tentakel waren mehr als $2 \mathrm{~mm}$ lang, ihre Breite, die am Grunde etwa $\frac{1}{2} \mathrm{~mm}$ war, nahm nach oben nur wenig $a b$, und erst im distalen Drittel wàren sie konisch zugespitzt. Die Tentakel standen etwa $1 \mathrm{~mm}$ auseinander. Etwa $1 \frac{1}{2} \mathrm{~mm}$ hinter denselben befanden sich die Rhinophorien (Fig. 1), kurz beieinander, etwa $1 \mathrm{~mm}$ lang, und fast gleich breit. Sie zeigten an ihrer ganzen Vorderseite eine regelmässige Querfaltung in solcher Weise, dass man die Art wegen des Besitzes perfoliierter Rhinophorien zur Gattung Spurilla stellen möchte. Besieht man aber die Rückenseite derselben, so sieht man, 
dass hier die Folien ganz und gar fehlen, oder doch wenigstens von, einer unregelmässigen Zusammenziehung der Haut ganz verhüllt sind. Man fragt sich sogleich, ob nicht auch die vorderen Falten der Zusammenziehung zu verdanken seien und ob hier nicht eine Aeolidiella vorliege. In dem Falle aber wäre die Zusammenziehung nicht so ungleich gewesen. Betrachtet man die Art aber als eine Berghia, so ist diese Gestalt leicht als die von TRINCHESE und von VAYSSIĖRE (sieh, oben) geschilderte, hier aber im zusammengezogenen Zustande erscheinend, zu verstehen. Beide Rhinophorien waren einander gleich. Ich habe das Rhinophor der rechten Seite abgebildet (Fig. 1) von der Seite gesehen. Deutlich sieht man vorn die regelmässige und hinten die unregelmâssige Faltung. Der Fuss war vorn mit einem Rande umsäumt, der, etwas weisser als der im Alkohol gelb gefärbte Kopf, sich scharf weiss abhob vom durchsichtigen dunkelweissen Fuss. Die Vorderseite des Fusses war in deutliche Tentakel ausgezogen, welche $4 \mathrm{~mm}$. lang und $2 \mathrm{~mm}$ breit waren, stark zusammengezogen mit vielen Falten.

Der Saum des Körpers war stark gefaltet (s. Fig. 3), der Körper war erst im hinteren Fünftel zugespitzt, ohne Schwanz, bis zur Spitze mit Papillen besetzt. Der gewölbte Rücken war zur Seite besetzt mit Papillen; die papillentragenden Teile viel schmaler als der nackte Mittenteil. Die Pericardialgegend trat als eine ovale etwa $2 \frac{1}{4} \mathrm{~mm}$ lange Erhabenheit hervor und teilte die Papillen deutlich in zwei Gruppen. Die nackte Rückenmitte verschmälerte sich nach hinten, war aber auch an der hintersten Körperspitze noch zu sehen.

Zur rechten Seite befand sich zuerst eine aus $13+8$ (oder 9) Papillen bestehende Gruppe, welche wie es sich nach Entfernung der Papillen zeigte, auf einem hufeisenförmigen Kissen standen, um die Genitalpapille herum. Letztere war eine grosse halbmondförmige Papille von einem Hautwulst umgeben. Hinter dieser ersten Gruppe folgte eine nackte Stelle zur Seite der Pericardialgegend. Dann folgten, auch in halbmondförmigen Bogen stehend, die weiteren Papillen. Im ersten (also dem zweiten der ganzen Reihe) dieser Bogen fand ich die Analpapille. Die Papillen standen in den Bogen in einzelnen oder doppelten Reihen. Sie waren am grössten an der Innenseite, nahmen nach aussen allmählich an Grösse $a b$, und wurden an dem Hinterteil des Körpers plötzlich viel kleiner. Einer der grösseren war etwa $2 \mathrm{~mm}$ lang. Im ganzen zählte ich zur rechten Seite sechs Bogen und eine hintere Gruppe, die man keinen Bogen mehr nennen konnte, zur linken Seite ganz die gleiche Gruppierung, natürlich ohne Genital- und Analpapille. Die Gestalt der Papillen war zylindrisch, oben zugespitzt, gelblich, nach oben durchsichtig. Der Nesselsack in der Spitze schimmerte bei allen deutlich weiss durch.

Der Schlundkopf wurde herausgeschnitten. Er zeigte an seinem Umkreis hier und da eine weinrote Farbe, welche durch rote Pigmentkörner im Gewebe verursacht wurde. Der Schlundkopf war rund etwa $1 \mathrm{~mm}$ im Durchmesser. Die gelben Kiefer hatten die gewöhnliche Gestalt. Durch einen Unfall gingen sie während der Präparation verloren, bevor ich untersuchen konnte, ob hier Dentikulierungen vorhanden waren. Sicher ist nur, dass bei 50 -facher Vergrösserung unterm Binokular-Mikroskop noch gar keine Dentikulierung sichtbar war. Ich meine behaupten zu können, dass der Kaurand glatt war.

Die Radula besass eine Reihe Zähne von der gewöhnlichen Form (Figur 2). Die Basalplatte war in der Mitte stark verschmälert, seitwarts aber flügelartig verbreitert. In der Mitte ein kurzes breites. Dentikel. Die übrigen Dentikel nach aussen zuerst in Grösse zunehmend, dann wieder abnehmend. Weitere anatomische Untersuchungen nahm ich nicht vor, erstens weil es nicht nötig war zur systematischen Karakterisierung der Art, zweitens zur Erhaltung der äusseren Körpergestalt des einzigen Exemplars, welches sich im Zoologischen Museum zu Kopenhagen befindet.

\section{TAXONOMIE.}

Die Geschlechter Aeolidiella, Spurilla und Berghia sind karakterisiert durch eine Serie kammförmiger Zähne in der Radula, die einen zweibogigen Schneiderand zeigen. Diese Gestait wird hervorgerufen durch die kleineren mittleren Dentikel und kann noch verstärkt werden dadurch, dass die Basalfläche in der Mitte verschmälert ist.

Bis jetzt sind die folgenden Arten dieser drei Gattungen bekannt: 1 Aeolidiella glauca (Alder und Hancock) (mit var. sanguinea), Atlantischer Ozean und Mittelmeer; 2 Ae. occidentalis Bergh, Atlantischer Ozean; 3 Ae. indica Bergh, Indischer Ozean; 4 Ae. orientalis Bergh, Indischer Ozean; 5 Ae. drusilla Bergh, Indischer Ozean; 6 Ae. faustina Bergh, Indischer Ozean; 7 Ae. japonica Eliot, Pazifischer Ozean; 8 Spurilla neapolitana (d'Ch.) (mit var. braziliana), Atlantischer Ozean und Mittel- 
meer; 9 Sp. inornata (A. Costa), Atlantischer Ozean; 10 Sp. orientalis Bergh, Indischer Ozean; 11 Berghia coerulescens (Laurillard), Atlantischer Ozean und Mittelmeer.

\section{Bestimmungsschlüssel.}

1. a. Rhinophorien glatt, oder nur wenig gerunzelt oder mit sehr oberflächlicher Spiralfurche versehen . . . . . . . . . . Aeolidiella.

b. Rhinophorien deutlich perfoliiert. . . . . . . . . . . . 2

2. $a$. Rhinophorien einfach perfoliiert ............. Spurilla.

$b$. Rhinophorien vorn mit schrägen Blättern oder Bändern, oder an der Vorderseite eine breite glatte longitudinale Strecke frei lassend; hinten mit Tuberkeln besetzt. (Im zusammengezogenen Zustande sehen diese Organe maulbeerförmig aus) . . . . . . . . . . . Berghia.

AEOLIDIELLA Bergh.

1. a. Atlantisch-mediterrane Arten ... . . . . . . . . . . . . . . . 2

b. Pazifisch-indische Arten . . . . . . . . . . . . . . . . . . . . . 3

2. a. Zähne mit einer Basalfläche, die in der Mitte stark verschmälert (eingeschnitten) ist. Verhältnis der Körperbreite zur Körperlänge $\frac{1}{2 \frac{1}{3}}$ bis $\frac{1}{5}$. Farbe wechselt zwischen durchsichtig bleichgelb oder gelbgrün und rotgelb, welches am dunkelsten am Kopf erscheint; das ganze Tier besäht mit vielen opakweisen Pünktchen; Tentakel und Rhinophorien meistens orangerot gefärbt, nur kann dies an der Spitze, am Grunde oder in der Mitte mit dem Weiss der Fleckchen abwechseln. Papillen auch öfters mit rotem Anflug. . . . . . . . . . . . . . . . Ae. glauca (A. \& H.). Mit blutroten Papillen. . . . . . . . . . . . . . . . . var. sanguinea.

b. Zähne mit etwa überall gleich breiter Basalfläche. Das Verhältnis der Körperbreite zur Körperlänge $\frac{1}{4}-\frac{1}{6}$. „Farbe hell graubräunlich mit eigentümlichen weissen mehr oder wenig verästelten, meistens jedoch parallel laufenden, schmalen an dem Kopfe und an dem Rücken in die Quere gehenden, an dem Halse und an den Seiten senkrecht gestellten Streifen." Ae. occidentalis Bgh.

3. a. Auf dem Rücken eine mediane Reihe weisser Flecken. Fuss vorn gerundet, ohne Ecken. . . . . . . . . . . . . . . Ae. orientalis Bgh.

b. Fuss mit Ecken, mehr oder wenig deutlich . . . . . . . . . . . 4

4. a. Papillen einander in der Rückenmitte berührend. . . . . . . . . . 5

b. Rückenmitte nackt . . . . . . . . . . . . . . . . . . . . 6

5. a. Papillenreihen lassen nur das vordere Viertel des Rückens frei, hinten berühren sie einander in der Mitte, Basalfläche der Zähne der Radula in der Mitte nicht so tief ausgeschnitten, wie bei den anderen Arten. Ae. drusilla Bgh.

$b$. Papillenreihen berühren einander in der hinteren Hälfte des Rückens. Zähne wie bei Ae. glauca. . . . . . . . . . . . . . . . . . Ae. indica Bgh.

6. a. Papillenreihen vorn auf hufeisenförmigen Leisten gestellt. Basalfläche der Zähne schmaler als bei den anderen Arten . . . . . . . . . Ae. faustina Bgh.

$b$. Einfache Papillenreihen. Zähne mit zwei Bogen, welche ungewöhnlich breit und wellig sind. Mitteldentikel gross, jederseits etwa 65 Seitendentikel. . . . . . . . . . . . . . . . Ae. japonica Eliot.

SPURILLA Bergh.

1. a. Zähne der Radula mit in der Mitte verschmälerter, seitwärts verbreiterter Basalfläche. Eine grosse Menge Leberverzweigungen im Gewebe des ganzen Körpers geben dem Tiere seine Farbe. Verhältnis der Breite zur Länge etwa $\frac{1}{7 \frac{1}{2}}$, der Körper also schlank. . . . . . . . . . . Sp. inornata (A. Costa). 
b. Zähne der Radula mit überall gleich breiter Basalfläche (die zweiflüglige Gestalt entsteht durch die kurzen mittleren Dentikel). Hier nicht die oben genannten Leberverzweigungen. Verhältnis der Breite zur Länge $\frac{1}{2}$ bis $\frac{1}{5}$. 2 .

2. $a$. Indische Art. Die Papillenreihen sind zwar an ihrer Oberseite vereint, bilden aber einen spitzen Winkel. Anus am Rückenrande hinter der vierten Papille. Farbe? Das Verhältnis der Breite zur Länge $\frac{1}{5}$, der Höhe zur Länge $\frac{1}{7}$. . . . . . . . . . . . . . . . . . . . Sp. orientalis Bergh.

b. Atlantische Art. Die vorderen Papillenreihen bilden paarweise hufeisenförmige Bogen. Anus zwischen der dritten und vierten Reihe (also im zweiten Bogen). Das Verhältnis der Breite zur Länge $\frac{1}{2}-\frac{1}{5}$, der Höhe zur Länge $\frac{1}{2 \frac{2}{3}}-\frac{1}{5}$. Der Schwanz kurz. Farbe durchsichtig weisslich bis hellbräunlichgelb, meistens aber hübsch fleischfarbig; Tentakel rötlich; Rhinophorien gelblich; öfters besät mit weissen oder grünen Pünktchen und Fleckchen. Papillen öfters mit rotem Anfluch. . . . . . . . . . Sp. neapolitana (d'Ch.). Verhältnis der Breite zur Länge $\frac{1}{6.5}$. Manıdibel verhältnismässig kleiner als bei der typischen Form . . . . . . . . . . . . . . var.? braziliana.

BERGHIA Trinchese.

Papillenanordnung in Querreihen, die an der Vorderseite des Körpers hufeisenförmige Bogen bilden können; schliesslich folgen immer mehrere Einzelreihen. Farbe milchweiss mit bläulichem Schimmer, hier und da mit rotem oder gelbem Anflug. Vor den Rhinophorien an der Stirne kann eine rötliche, gegen vorne offene, hufeisenförmige Figur vorkommen, die meistens aus zwei Flecken, die nicht verbunden sind, besteht. Die Papillen mit rotem Ringe unter der Spitze. Verhältnis der Breite zur Länge $\frac{1}{3}$ bis $\frac{1}{6}$ $\left(\frac{1}{3.5}\right)$, der Höhe zur Länge $\frac{1}{4}\left(\frac{1}{3.5}\right)$; Schwanz $\frac{1}{3}-\frac{1}{7}$ der Körperlänge oder fehlend . . . . . . . . . . . . . . . . . . . B. coerulescens (Laur.).

PHIDIANA (Gray) Bergh.

Schon im Jahre 1850 wurde dieses Genus von Gray aufgestellt zur Aufnahme der Aeolidien mit keulenförmigen, perfoliierten Rhinophorien, sehr langgestreckten Tentakeln und in dichtstehenden Querreihen gestellten Papillen. Es wurden von ihm in dasselbe fünf Formen vereinigt, nämlich: $P h$. patagonica (d'Orb.), Ph. inca (d'Orb.), Ph. northumbrica (Ala. et Hanc.), Ph. caerulescens (Laurillard) und Ph. longicauda (Quoy et Gaim.). Als Gattungsmerkmale gab er (1850 und 1857) „Body stout. Dorsal tentacles clavate, perfoliate. Labial feelers very large, subulate. Gill in close cross rows. Sides of the foot rounded. Lingual membrane - ? Foot in front rounded or subulate." Diese Diagnose wurde auch von ALDER und HANCOCK in ihrer Monographie übernommen (1855).

Als BERGH anfing die Nudibranchiaten-Systematik in neue Bahnen zu führen, gehörte die Gattung der Phidianer somit zu den ersten, die er einer scharfen Revision unterwarf. Nachdem er in 1864 ('68) schon eine Bemerkung über Phidiana gemacht hatte, konnte er auf Grund seiner eigenen zoologischsystematischen Untersuchung eines Exemplars der Art Phidiana inca und dreier Exemplare einer neuen Art, die er Phidiana lynceus nannte, im Jahre 1867-'68 eine ausführliche Beschreibung der Gattung geben. Mit einiger Sicherkeit zu bestimmen, ob die von den älteren Autoren beschriebenen Arten seiner neuen Diagnose unterzuordnen seien oder nicht, war wegen der nur die äusserlichen Merkmale in Betracht ziehenden Methode, die man bisher befolgt hatte, eine sehr schwierige, wenn nicht unmögliche Aufgabe. Es war denn auch immer BERGH's Bestreben, die Original-Exemplare zur Untersuchung in die Hände zu bekommen. Meistens stellte sich heraus, dass sie anderen Gattungen zugehörten, öfters 
auch waren die Typen entweder verloren gegangen oder befanden sie sich, wenn aufbewahrt, in einem jämmerlichen, zusammengeschrumpften Zustande. Trotz aller dieser Schwierigkeiten blieben doch noch vier Arten übrig, die zur Gattung gerechnet werden konnten. Die neue Diagnose lautete: Corpus gracilius, elongatum. Rhinophoria perfoliata, tentacula elongata. Papillae dorsales in series obliquas confertas dispositae. Podarium antice rotundatum vel subtruncatum. Margo masticatorius mandibulae singula serie denticulorum praeditus. Radula paucidentata, dentibus uniseriatis.

Diesem scharf umgrenzten Genus Phidiana wurden dann folgende Arten zugeordnet: $P h$. inca (d'Orb.), Ph. patagonica (d'Orb.), Ph. unilineata (Ald. et Hanc.) und Ph. lynceus Bgh.

Wenden wir uns, ehe wir die Geschichte der Gattung weiter besprechen, zuerst der Herkunft dieser Arten zu, so zeigt sich: Phidiana inca (d'Orb.) wurde von D'OrBignY in vielen Exemplaren gesammelt an der Küste von Chili und Peru, von Valparaiso $\left(34^{\circ} \mathrm{S}\right.$.) bis Lima $\left(12^{\circ} \mathrm{S}\right.$.) und beschrieben als Cavolina inca, abgebildet aber unter dem Namen Eolidia inca.

Es gelang BERGH eine Phidiane zur Untersuchung $z u$ bekommen, die von Prof. KRöYER 1841 bei Callao gefischt wurde, von ungefähr demselben Orte, wo auch die d'Orbigny'schen Exemplare herstammten. Diese wurde von Bergh (1867-'68) als Phidiana inca beschrieben, weil er auf Grund der äusseren Gestalt und des übereinstimmenden Fundorts vermutete, dass ihm dieselbe Art vorliege. Seine neue, auch die anatomischen Merkmale in Betracht ziehende Diagnose der Gattung gründete er denn auch, ausser auf die zugleich beschriebene $P h$. lynceus, auf den Befund bei diesem Exemplare. Das BERGH darin recht hatte, erwies sich später, als PLATE, in derselben Gegend sammelnd, die lebenden Tiere mit dem Bilde D'ORBIGNY's vergleichen und die conservierten BERGH zur Untersuchung geben konnte.

Phidiana patagonica (d'Orb.). Von dieser Art wurden zwei Exemplare von D'Orbigny gesammelt und beschrieben (1. c. p. 192: Cavolina patagonica und pl. XIV f. 4-7. Eolidia patagonica) von der Küste von Südpatagonien, zwischen Rio Negro und Bahia de San Blas, bei Punta de Piedras (BERGH sagt in seiner Angabe: „Mare pacif. or., dies soll also sein: Mare atlant. occ.).

Die Tiere sind äusserlich dem $P h$. inca so ähnlich, dass sie sehr wahrscheinlich der Gattung Phidiana zugehören. Eine nähere Untersuchung hat niemals stattgefunden. Sie unterscheiden sich nicht nur durch die Farbe, sondern auch durch den langen, etwa $\frac{1}{3}$ der ganzen Körperlänge einnehmenden Schwanz.

Phidiana unilineata (Alder et Hancock), Diese Art war im Jahre 1866 als Eolis unilineata von ALDER und HANCOCK unvollständig beschrieben nach sechs Exemplaren gesammelt in Waltair, in the presidency of Madras. Wegen der äusseren Form und der Angabe, dass die Zunge nur eine Reihe Zähne trug, wurde diese Form von BERGH zur Phidiana-Gattung gestellt. Wie ElIOT 1906 nachweisen konnte, mit Recht.

Phidiana lynceus Bgh. Drei Exemplare von St. Thomas (Antillen) standen BERGH zur Verfügung bei der Beschreibung dieser nova species (1867-'68), die mit dem Exemplar von Ph. inca, die Angaben für die neue Gattungsdiagnose lieferten.

Bis so weit was die von BERGH 1867-'68 genannten Arten anbelangt. Die weitere Entwickelung der Phidianen-Literatur ist dann die folgende: Im Jahre 1873 beschreibt BERGH ein Exemplar, gesammelt bei. Guadeloupe, das er bezeichnet als Phidiana lynceus Bgh. var. (Ausser den schon genannten Arten, nennt BERGH noch eine Phidiana jodinea Cooper. Eine spätere Untersuchung wies jedoch nach, dass diese eine Flabellina war). Obgleich mit der Bezeichnung "var.” angedeutet wurde, dass hier ein Exemplar vorlag, das von den zur Beschreibung der Art benutzten Individuen verschieden war, hat BERGH doch glücklicherweise keine neue Art geschaffen für dieses einzelne Tier. (MöRCH (1875) verweist nach diesen vier Exemplaren auf S. 178 und nennt BEaU als Sammler für Guadeloupe; BERGH aber nennt Schramm. Dall (1885) verweist wieder nach dieser Mörchschen Angabe). Leider schaffte BERGH wohl eine neue Art für ein anderes einzelnes Exemplar aus der Umgebung der Prayagrande, Rio Janeiro gegenüber, das er 1879 als nova species unter dem Namen Ph. selencae einführte. Es unterscheidet sich von $P h$. lynceus, wie BERGH noch besonders hervorhebt, hauptsächlich durch die eigentümliche Pigmentierung des Neurilems der cerebro-visceralen Ganglien, welche hier fehlt, und die Form des Penishakens, „welche hier eine ganz andere ist." Worin aber diese ganz andere Form sich von der von Ph. lynceus unterscheidet ist weder aus dem Text, noch aus dem Bilde ersichtlich, wie 
wir auch später noch zu besprechen haben. Auch die Pigmentierung des Neurilems scheint mir kein taugliches Merkmal zur Artunterscheidung zu sein. Und wäre es auch möglich dann doch andere, vielleicht tauglichere Merkmale zu finden (z. B. verschiedene Anzahl der Papillenreihen, keine Beiaugen vorhanden u. s. w.), so bekommt man doch den Gesamteindruck, dass auch dieses Exemplar besser als $P h$. lynceus, sei es denn mit der Hinzufügung „var.", wäre beschrieben worden. Weil das Übel nun einmal geschehen ist, wollen wir vorläufig $P h$. lynceus und $P h$. selencae als verschiedene Arten nennen bis mehr Tiere aufgefunden worden und eine Enfscheidung, ob hier zwei Arten oder nur eine vorliegen, wird statt finden können.

Als Neuerwerb wird dann in derselben Schrift noch dem conspectus specierum, die Phidiana attenuata Couth. zugefügt, eine Form, welche von Gould, nach dem Manuscripte des Sammlers Couthouy beschrieben wurde als Eolis attenuatus. Wie Ph. patagonica wurde auch diese Art niemals näher untersucht und ihre Unterordnung geschah bloss auf Grund äusserlicher Merkmale. Sie wurde gesammelt "on a fragment of Megacystus off the Coast of Chili, lat. $36^{\circ} 5^{\prime}$, long. $74^{\circ}$ W." Obgleich eine Angabe der Exemplareanzahl fehlt, ist doch aus der Beschreibung deutlich, dass nur eines vorlag. Die 1874 (Mem. dell' accad. Bologna Ser. III T. V, p. 517) von TRINchese als Phidiana coerulescens beschriebene Art wurde später Berghia coerulescens genannt (TRINCHESE 1877) und interessiert uns also hier nicht. VON JHERING nennt in seiner Arbeit „Zur Kenntnis der Nudibranchien der brasilianischen Küste" (1886) unter mehreren die Phidiana selencae Bgh. mit Literatur- und Fundortsangabe.

Im "System der Nudibranchiaten Gasteropoden" (1892) die Zusammenstellung aller bis dahin bekannten Nudibranchien gebend, sagt BERGH unter Phidiana: „Rhinophoria perfoliata; podarium antice rotundatum vel subtruncatum. Margo masticatorius singula serie denticulorum. Penis hamo armatus" und nennt dann die sechs uns bekannten Arten mit ihren Fundorten. (N. B. Auch hier soll also bei $P h$. patagonica M. pac. or. in M. atl. occ. verändert werden).

Nachdem Plate (1894) einige sehr interessante und ausführliche Mitteilungen über den Bau der Ph. inca geliefert hat, erschien 1898 BERGH's "Die Opisthobranchien der Sammlung Plate”, worin er wieder eine ausführliche Beschreibung der $P h$. inca gibt, nach den vielen von PLATE bei Coquimbo, Tumbes und Calbuco gesammelten Exemplaren. Auch befand sich in dieser Sammlung ein Exemplar aus Coquimbo, das von $P h$. inca äusserlich sehr abwich und, weil es auch wahrscheinlich nicht zur Phidiana patagonica gehörte, als neue Art, Phidiana exigua Bgh., beschrieben wurde.

Weiter wird hier noch unter den bekannten aber nicht von BERGH geprüften Arten $u$. a. genannt Phidiana longicauda Hutton, und in einer Fussnote wird Bezug genommen auf: HutTon, Contrib. to the New-Zeal. Malacol. in: Trans. Proc. New-Zeal. Instit. V, 13, 1881, p. 203. Wahrscheinlich war diese Arbeit BERGH nicht zugänglich, denn, wenn man genannte Transactions auf Seite 203 aufschlägt, findet man nur folgende kurze Notiz: „Phidiana longicauda. Although Quoy describes the tentacles as clavate, he figures them as tapering. The generic position therefore of the animal must remain uncertain until it is re-discovered." Es ist sehr deutlich, dass Hutton, als er dies schrieb, selbst keine Exemplare der genannten Art zur Verfügung hatte, er hat hier nur die von QuoY und GaImard (Voyage de l'Astrolabe, Zoologie II, 1832, p. 288) beschriebene Eolidia longicauda wieder genannt und diese zur Gattung Phidiana gestellt und hat wahrscheinlich nicht gewusst, dass BERGH selber nachgewiesen hat, dass diese Form eine Fiona war (Naturh. Foren. vidsk. Meddel. for 1857, 1858, p. 336; R. BERGH, Contrib. to a monogr. of the Gen. Fiona Hanc. 1859, p. 16). Diese Phidiana longicauda muss also gestrichen werden aus der Reihe der Phidiana-Arten.

Im Jahre 1904, beschieb C. ElIOT eine neue Phidiana-Art, nämlich Ph. tenuis nach zwei Exemplaren gesammelt bei Wasin-Insel, Britisch Ostafrika. Eigentümlich sind bei dieser Art die grosse Zahl der Denticulierungen an den Zähnen und die Leberverzweigungen, die hier deutlich kurze Äste tragen, während sie bei anderen Arten „knotig” sind.

Im Jahre 1906 (a) hatte C. Eliot das Glück unter andern die sechs Original-Exemplare der Phidiana unilineata Ald. et Hanc. untersuchen zu können, welche im Hancock-Museum in Newcastleon-Tyne aufbewahrt werden. Leider waren die Tiere hart und trocken und es gelang nur die Mundteile eines einzigen Exemplares zu untersuchen. Aber dies genügte doch um festzusetzen, dass auch diese Art eine Phidiana war.

Endlich beschrieb Eliot 1906 (b) eine neue Art, Phidiana longicirra, nach einem einzigen Exemplar. 
Mr. Crossland, von dem das Tier gesammelt wurde, gibt ausser einer ausführlichen Beschreibung des lebenden Tieres, welche später wird besprochen werden, folgende Fundortsangabe: „Crawled out of stones dredged in shallow water off the north shore, Porte Grande". Die Zuweisung der Art zum Genus Phidiana motiviert Eliot folgenderweise: "This animal does not seem referable to any described species of Aeolid, and the long annulated cerata form a remarkable character which will probably render its recognition easy. I refer it somewhat doubtfully to Phidiana, though it does not seem to possess the armature on the male genitalia which BERGH considers characteristic of the genus."

Verfassen wir ein Verzeichnis der bis jetzt bekannten Phidiana-Arten geordnet nach ihrem Fundorte, so bekommen wir (die Angabe der Abbildung bezieht sich auf die des lebenden Tieres):

1. Ph. inca (d'Orb.), Pazifischer Ozean (Peru, Chili), gut bekannt nach vielen Exemplaren, äusserlich sowie anatomisch, Abbildung bei D'Orbigny; 2. Ph. attenuata (Couth.), Pazifischer Ozean (Chili), nur äusserlich bekannt nach einem Exemplare, Zuweisung zur Gattung mit Vorbehalt, Abbildung bei Gould; 3. Ph. exigua Bgh., Pazifischer Ozean (Chili), nur anatomisch bekannt nach einem schlecht conservierten Exemplare; 4. Ph. patagonica (d'Orb.), Atlantischer Ozean (Patagonien), Zuweisung zur Gattung bloss auf Grund einer äusseren Beschreibung nach zwei Exemplaren, Abbildung bei D'ORBIGNY; 5. Ph. selencae Bgh., Atlantischer Ozean (Brasilien), Farbenangabe des lebenden Tieres und anatomische Beschreibung, nur ein Exemplar bekannt; 6. Ph. lynceus Bgh., Antillenmeer, nur anatomisch beschrieben nach vier Exemplaren; 7. Ph. longicirra Eliot, Atlantischer Ozean (Kap Verd. Ins.), mit Vorbehalt dem Genus zugeordnet, bekannt aus Beschreibung des lebenden Tieres und der anatomischen Untersuchung, ein Exemplar; 8. Ph. unilineata Ald. et Hanc., Indischer Ozean (Vorderindien), äusserlich und anatomisch unvollständig beschrieben nach sechs Exemplaren, Abbildung bei ALDER und HANCOCK; 9. Ph. tenuis Eliot, Indischer Ozean (Br. Ostafr.), bekannt nach zwei anatomisch untersuchten Exemplaren.

Zur tropisch atlantischen Fauna, welche in unserer Untersuchung besonders in Betracht kommt, gehören, wie auch schon Eliot (1910) hervorhebt, also 3 Phidianen: selencae, lynceus und longicirra. Vom Südatlantik kennen wir $P h$. patagonica, während von der pazifischen Küste Südamerikas $P h$. inca, $P h$. attenuata und $P h$. exigua bekannt sind. Nur zwei Arten wurden aus dem Indischen Meere beschrieben, $P h$. unilineata und $P h$. tenuis.

Wenn wir dann auf die Suche nach sicheren Unterscheidungsmerkmalen zur Vergleichung der genannten Phidiana-Arten vorschreiten, stossen wir immer wieder auf die Schwierigkeit, dass die Beschreibungen von den verschiedenen Autoren auf so ungleiche Weise gegeben worden sind. Während nämlich die älteren nur auf die Kenntnis des lebenden Tieres Wert legten und sich abmühten womöglich eine Abbildung und Beschreibung desselben für jede gesammelte Art zu geben, haben sich die neueren Untersucher nur den Merkmalen des konservierten Tieres zugewendet, teils auf Grund der praktischen Erwägung, dass die letzteren auch eine Bestimmung des Museummaterials ermöglichen, teils weil ihnen Angaben nach dem Leben fehlten.

Obgleich letztere Methode natürlich den Vorzug verdient, bedauert man doch öfters, dass keine Abbildung oder Beschreibung der Farben- und Formverhältnisse beim lebenden Tiere vorliegen. Spätere Sammler werden denn auch die Untersuchung sehr erleichtern, wenn sie dieselben jeder, ihrer Ansicht nach selbständigen, Art beifügen.

Bekannt ist uns über die Farbe der lebenden und konservierten Tiere folgendes:

Für Phidiana inca besitzen wir eine Angabe D'OrBigny's und eine Bemerkung Plate's hierzu. BERGH meldet uns, wie sich dieselbe bei den in Chromsäure und Alkohol gut konservierten Tieren erhalten hat.

Allgemeine Farbe: durchsichtig weiss, mit rötlicher Überzug nach D’ORBIGNY, nach PLATE jedoch niemals rötlich, sondern immer grauweiss (die konservierten Exemplare zeigten Kopf, Rhinophorien und Tentakel gelblich und den Rücken hell gräulich oder gräulichweiss. Das 1867 von BERGH untersuchte Individuum aber war hellbräunlich). Zeichnung: Ein weisser Fleck zwischen oder vor den Rhinophorien, nach hinten sich verschmälernd, nach vorne sich verbreiternd, sich teilend und als eine feine Linie sich fortsetzend auf den Tentakeln. Über dem. Herzen ein zweiter weisser Fleck, welcher dem Plate'schen Exemplar zu fehlen scheint, bei diesem setzte sich der interrhinophoriale Fleck als eine feine Linie über dem Rücken fort. (Die konservierten Exemplare hatten zwischen den Rhinophorien 
eine weisse Linie erhalten, welche sich vorn gabelte und noch bis an den Grund der Tentakel zu verfolgen war. Die Fortsetzung nach hinten war auch noch anwesend. „Längs der Gegend des Pericardiums verlief eine weisse mediane Linie. Der Rücken des Schwanzes zeigte einen medianen, weissen oder mitunter silberweissen Streifen, der sich bei mehreren Individuen am Grunde des Schwanzes teilte und als ein ziemlich (bis $0.6 \mathrm{~mm}$ ) breiter Streifen längs der Mitte der Körperseiten bis oberhalb der Genitalpapille verlief"). Obgleich also die Zeichnung in der Hauptsache übereinstimmt, kann sie in Einzelheiten doch erheblich verschieden sein. Papillen: Mit violett bis violett-schwarzem Inhalt. Die Spitze reinweiss, vom untern durchsichtigen Teil abgegrenzt durch einen hellroten schmalen Ring. (Im konservierten Zustande war die Spitze gelblich-weiss oder weisslich, der Ring undeutlich und blaugrau, der Inhalt schwach violettgrau oder grau. Sie zeigten sich in einer grossen Länge mitunter gleichsam versilbert). Phidiana attenuata ist bekannt aus der Handschrift des Sammlers CouTHouY, welcher sagt, Körper farblos, nur auf dem Rücken einen leichten rötlichen Anstrich. Papillen gelblich mit braunem Inhalt. Phidiana exigua kennen wir nur in konserviertem Zustande (BERGH). („Die Farbe des Körpers war weisslich, die Rückenpapillen schwach gelblich mit meistens langer weisser Spitze und gräulich durchschimmerndem Leberlappen"). Beim lebenden Tiere werden wahrscheinlich auch die Spitzen der Papillen weiss gewesen sein.

Phidiana patagonica ist wieder besser bekannt weil sie wie $P$ h. inca von D'ORBIGNY beschrieben wurde. Der Körper ist hell-rötlich, die Unterseite des Fusses mit violettem Anstrich in der Mitte. Die Tentakel sind weiss. Zeichnung: ein dreieckiger hellroter Flecken vor den Rhinophorien, mit der Spitze nach hinten sich fortsetzend zwischen den Rhinophorien und sich dann wieder erweiternd zu einem gleichförmigen Flecken hinter den Rhinophorien. Über dem Herzen einen ovalen, hinten zugespitzten, ebenfalls hellroten Fleck. Papillen: proximal violett, distal allmählich ins hellrote übergehend.

Eine Schilderung der Phidiana selencae verdanken wir Selenka (bei Bergh): „Auf der Unterseite weiss, am Rücken hell fuchsbraun, mit intensiv braunen Papillen." (Im Alcohol, meldet uns BerGH, war sie am Körper weisslich, während die Papillen die Leberlappen grau durchschimmernd zeigten).

Phidiana lynceus ist uns nur im conservierten Zustande bekannt. BERGH schreibt: „Die Farbe des Tieres war gelblich weiss die Papillen meistens wegen der durchschimmernden Leberlappen graufarbig mit weisslicher. Spitze” und „Die Farbe war weisslich gelb, nur die Papillen grauschwarz mit einer ziemlich langen weissen Spitze. Diese schwarze Farbe war an der Aussenseite der Papillen dunkler als an der Innenseite und erstreckte sich da auch weiter nach oben, wodurch die weisse Spitze gewöhnlich schief aussah." Auch hier wird beim lebenden Tiere die Spitze der Papillen weiss gewesen sein.

Phidiana longicirra ist nach der Angabe CROssland's (aus Eliot) am Körper durchsichtig weiss, mit einigen Anhäufungen weisser Flecken. Rhinophorien von braungelber Farbe. Während die Leberverzweigungen anfänglich farblos sind, bekommen sie in den Papillen, sich allmählich verjüngend, eine dunklere (braune) Farbe, bis sie am Ende einen schwarzen Faden im Inneren derselben bilden. Die medianen Papillen leicht geringelt. Sie haben eine ansehnliche Masse gelbe Pigmentes in der Haut sowie in den Leberverzweigungen. Auch einige weisse Flecken.

Bei Phidiana unilineata geben ALDER und HANCOCK an: Körper hellgelb (buff-coloured). Rhino. phorien fleischfarbig mit sechs Ringen, Tentakel unten fleischfarbig mit gelblichweisser Spitze. Zeich nung: eine scharlachrote Linie, in der Mitte des Kopfes anfangend, läuft bis zum Anfang der Papillen nur wenig unterbrochen zwischen den Rhinophorien. Papillen von purpurbrauner Farbe.

Phidiana tenuis kennen wir nach zwei von Elıo beschriebenen Exemplaren. Körper fleischfarbig. Fuss weiss. Tentakel und Rhinophorien weiss, die letzteren leicht geringelt in ihrem distalen Ende, welches undurchsichtig ist. Das proximale Ende durchsichtig. Papillen ganz zinnoberrot (vermillion), bei einem Exemplar nach dem Fang allmählich über violett-blau ihre Farbe verlierend, bis sie farblos mit einem blauen Hauch waren. Die roten Leberverzweigungen füllen die Papillen fast nicht an.

Wir können also sagen, dass die Farben, obschon erheblich variierend bei einer Art, ja sogar beim selben Individuum, einen Halt bei der Artunterscheidung gewähren. Besonders wenn man die von den durchschimmernden Leberverzweigungen hervorgerufenen Farben der Papillen ausser Betracht lässt, kann man eine allgemeine, artspezifische, zwischen weiten Grenzen schwankende Färbung und Zeichnung angeben. 
Deutlich ist eine Tendenz bei fast allen Arten zur Bildung weisser Papillenspitzen. Wenn eine Zeichnung vorhanden ist, besteht diese aus medianen und symmetrischen Flecken und Linien auf dem Rücken, besonders auf dessen Vorderteil.

In einigen Fällen bleibt auch beim konservierten Tier noch einen schwachen Abglanz dieser Verhältnisse behalten, die meisten aber werden gelb mit dunkler durchschimmernden Leberverzweigungen.

Berücksichtigen wir sodann Form und Grösse des lebenden sowie des konservierten Tieres so zeigt sich:

Phidiana inca, bekannt als lebendes Tier aus der Beschreibung D'ORBIGNY's, als konserviertes aus denen BERGH's und PLATE's, besitzt einen langgestreckten kräftigen Körper, in der Länge variierend zwischen 15 und $90 \mathrm{~mm}$, in der Breite zwischen 5 und $15 \mathrm{~mm}$ und in der Höhe zwischen 4 und mehr als $13 \mathrm{~mm}$. Drückt man das Verhältnis der Länge und der Breite in Zahlen aus, so findet man beim lebenden Tier $\frac{1}{6}-\frac{1}{5}$, beim konservierten $\frac{1}{4}-\frac{1}{3}$. Der schlanke Kopf, der.im zusammengezogenen Zustande kurz und breit erscheinen kann, trägt die in Länge erheblich variierenden Tentakel $\left(\frac{1}{6}, \frac{1}{3}, \frac{1}{4}\right.$ der Körperlänge). Die keulenförmigen, in Alkohol stark zusammengezogenen Rhinophorien sind besetzt mit 15 bis 25 oft unvollständigen und dann alternierenden Blättern. Der gewölbte Rücken geht allmählich in den Kopf über und trägt beiderseits die in schrägen Querreihen gestellten Papillen; der nackte Teil des Rückens, der zwischen den papillentragenden Teilen liegt, ist ganz eben und breiter als letztere. (Beim konservierten Tier tritt die Pericardialgegend etwas vor). Die Seiten des Körpers ziemlich hoch. Der Fuss ist vorn abgerundet und mit einer tiefen Randfurche versehen; die Breite nimmt nach hinten nur langsam ab. Der Schwanz (gemessen von der hintersten Papillenreihe bis zur Körperspitze) ist kurz (lebend $\frac{x}{12}-\frac{1}{9}$, in Alcohol $\frac{1}{10.5}$ der Körperlänge). Die runden, konischen, mit stumpfer Spitze versehenen Papillen sind in nach hinten und aussen verlaufende Reihen gestellt. Die Totalanzahl dieser Reihen ist 20 bis 26 , jede 1 bis 20 Papillen tragend. Die Länge der einzelnen Papillen nimmt wie gewöhnlich von vorn (das heisst von der 3. oder 4. Reihe an) nach hinten und von innen nach aussen $a b$. Man kann bei dieser Art gewöhnlich an jeder Seite zwei durch die Reihen gebildete und von einer papillenlosen Lücke getrennte Gruppen unterscheiden, eine vor und eine hinter dem Herzen. Die Genitalpapille befindet sich rechts unter der Mitte der vordern Gruppe von Papillenteihen nach dem Fusse zu oder ein wenig mehr nach hinten. Die feine Nierenöffnung im Zwischenraum zwischen vorderer und hinterer Papillengruppe der rechten Seite, hart am Rückenrande, mehr der vordern Gruppe zu. Die Analpapille mehr oder weniger vortretend, meistens in der Mitte zwischen der 7. und 8. Reihe der hintern Gruppe. Wichtig für die Abgrenzung gegen andere Arten scheinen nur zu sein: der kurze Schwanz (wie auch BERGH in seiner lateinischen Diagnose hervorhebt), die Breite der nackten Rückenmitte, sowie die Verteilung der Papillen (relative Anzahl, und Breite der Reihen, wie auch ob sie gedrängt stehen oder nicht.)

Betrachten wir Phidiana attenitata, wie sie von Couthouy beschrieben und abgebildet wurde, so fällt sofort auf, dass sie leicht von den anderen Arten zu unterscheiden sein wird, wenn sie sich überhaupt als zur Gattung gehörig erweisen sollte. Ihre Merkmale sind: Körper sehr langgestreckt, schmal, hinten sehr lang zugespitzt. Die Abbildung zeigt eine Länge von $52 \mathrm{~mm}$, bei einer Breite von $6 \mathrm{~mm}$ und einer Höhe von $5 \mathrm{~mm}$. (Verhältnis $\mathrm{Br}: \mathrm{L}=\frac{1}{9}$ ). Der Schwanz nimmt $\frac{1}{2}$ der Körperlänge ein im Bild, im Text jedoch sagt Couthouy der papillentragende Teil nehme $\frac{2}{3}$ der Körperlänge ein, für den Schwanz bleibt also noch etwa $\frac{1}{3}$ übrig. Tentakel und Rhinophorien sehr dünn und schlank, erstere $\frac{1}{7}$ der Körperlänge messend. Kopf abgerundet. Ebenso die Vorderseite des Fusses. Die kurzen Papillen zeigt die Abbildung in etwa 20 Reihen, in der gewöhnlichen Weise auf den Rücken gelagert. Geschlechtsöffnung etwa $6 \mathrm{~mm}$ vom Vorderende; Anus $12 \mathrm{~mm}$ dahinter, beide unter den Papillenreihen. Der nackte Mittenteil des Rückens breit. Wichtig ist der lange Schwanz. Der feine zarte Bau wird die Bestimmung sehr erleichtern.

Phidiana exigua zeigt im einzigen bekannten konservierten Individuum eine Länge von $14 \mathrm{~mm}$, während Breite und Höhe respektive 4 und $3.5 \mathrm{~mm}$ betragen. Länge und Breite verhalten sich also wie $\frac{1}{3.5}$, etwa das gleiche Verhältnis, das wir auch bei $P h$. inca vorfanden. Tentakel $3 \mathrm{~mm}$ lang $\left(=\frac{1}{4.7}\right.$ der Körperlänge). Der Schwanz ist länger als bei inca, jedoch viel kürzer als bei attenuata, nämlich $3 \mathrm{~mm}= \pm \frac{1}{5}$ der Körperlänge. Der Fuss ist vorn gerundet. Die Mitte des Rückens nackt und breiter 
als die papillentragenden Teile. Die Papillen liefern, wie BERGH uns meldet, ein spezifisches Merkmal, weil sie „in dicht gedrängten nicht deutlich unterschiedenen Querreihen gestellt” sind, und "die Anzahl der Papillen in den Reihen nicht sehr gering” ist. „Die schlaffen Papillen langgestreckt meistens ziemlich dünn, fast cylindrisch ziemlich leicht abfallend". Die Analpapille liegt nach innen zwischen zwei Papillenreihen ein wenig hinter dem Pericardium. Die Genitalöffnung liegt nicht so weit nach vorn wie gewöhnlich. Der kurze Schwanz, sowie die Beschaffenheit des Papillenbesatzes scheinen die Kennzeichen dieser Art zu sein.

Von Phidiana patagonica kennen wir das Tier aus der Beschreibung und den Abbildungen D'ORBIGNY's, welche uns lehren, dass der $40 \mathrm{~mm}$ lange Körper sehr langgestreckt ist. Entnehmen wir dem Bilde das Verhältnis Breite zur Länge, so finden wir $\frac{1}{8}$. Die Breite wäre also etwa $5 \mathrm{~mm}$. In gleicher Weise die Höhe des Körpers berechnend ergiebt sich $\pm 3.5 \mathrm{~mm}$. Im Gegensatz zur Phidiana inca ist der Schwanz hier auffallend lang $\frac{1}{3}$ der ganzen Körperlänge. Der kleine Kopf trägt die $\frac{1}{4}$ der Körperlänge messenden Tentakel, eine beträchtliche Länge, welche aber, wenn wir das Tier auch im konservierten Zustande kennten, wahrscheinlich weniger merkwürdig erscheinen würde. Der Fuss endet vorn in zwei ganz kurzen abgerundeten Verbreiterungen. Die zylindrischen, abgerundeten Papillen stehen in 18 schrägen Querreihen und lassen einen breiten nackten Teil in der Rückenmitte frei. Die Genitalpapille auf $\frac{1}{4}$ der Körperlänge, rechts ein wenig unter den Papillen. Anus rechts ein wenig hinter dem Herzen. Eigentümlich ist nur der Schwanz, sonst sieht diese Art der Ph. inca auffallend gleich.

Kommen wir dann zur Phidiana selencae, so zeigt sich, dass das einzige bekannte konservierte Exemplar (BERGH) die gewöhnliche Körperform hat, d. h. die Länge ist $22 \mathrm{~mm}$, die Breite $4 \mathrm{~mm}$, die Höhe $6 \mathrm{~mm}$. Das Verhältnis Breite zur Länge ist also $\frac{1}{5.5}$. Der Schwanz nimmt $\frac{1}{4.5}$ des Körpers ein. Auf dem ziemlich kleinen Kopf ragen die starken Tentakel ( $5 \mathrm{~mm}$ lang, d. h. $\frac{1}{4.5}$ der Körperlänge) hornartig empor. Die Zahl der Blätter an den $2.5 \mathrm{~mm}$ langen Rhinophorien ist mindestens 25. Der nackte Teil des Rückens schmal, kaum breiter als die mit Papillen besetzten Teile. Die Seiten des Körpers hoch. Der Fuss mit gerundetem Vorderrande. Die langgestreckt-konischen Papillen sind 4.5-6 mm lang, stehen in sehr schrägen Querreihen, welche Gruppen bilden. Im Ganzen etwa 32 Reihen. Die Genitalpapille unterhalb des Anfangs des letzten Viertels der ersten Papillengruppe, welche hier aus 6 Reihen besteht. Die feine Nierenpore an dem oberen Teil der Seite und etwa in der Mitte der Körperlange. Die Analpapille im Rückenrande etwạ $3.5 \mathrm{~mm}$ vom Hinterende des Rückens. Als spezifische Merkmale erscheinen der schmale Mittenteil des Rückens und die grosse Anzahl der Papillenreihen, während die Länge des Schwanzes der von $P h$. exigua nahe kommt.

Phidiana lynceus kennen wir nach den auf vier konservierte Exemplare begründeten Beschreibungen von BerGH. Die Länge des langgestreckten aber kräftigen Tieres ist 11.5-13 mm, die Breite $3-4 \mathrm{~mm}$ und die Höhe $3-3.5 \mathrm{~mm}$. Das Verhältnis der Breite zur Länge beträgt also $\frac{1}{3}$ bis $\frac{1}{4}$. Der Schwanz nimmt bei allen Exemplaren eine Länge von $3 \mathrm{~mm}$ ein, das ist $\frac{1}{4}$ bis $\frac{1}{5}$ der Körperlänge. Der ziemlich kleine Kopf trägt die sehr langgestreckten Tentakel, welche $\frac{1}{4}-\frac{1}{3}$ der Körperlänge messen (man sieht wie sehr die Länge verschieden sein kann, je nachdem die Tentakel mehr oder weniger zusammengezogen sind bei der Konservierung). Die keulenförmigen Rhinophorien, mit einem Stiel versehen, tragen 12 bis 20 Blätter. Der nackte Rückenteil ist hier wieder breiter als die mit Papillen besetzten Teile. Die Körperseiten sind hoch. Der Fuss vorn vẹrbreitert und abgerundet, nach hinten verschmälert. Er ist nur in seinem schmalen Mittelteil an den Körper angeheftet, die Seiten treten stark hervor. Die Papillenreihen sehr schräg gestellt, Gruppen bildend, im Ganzen 12 bis 20 Reihen zählend, welche 3.5-4.5 mm lange Papillen tragen, die konisch und langgestreckt sind. Die Genitalöffnung näher dem Fuss als dem Rücken unter oder hart hinter der Mitte der ersten Papillengruppe, welche sechs Reihen zählt. Spuren einer Nierenöffnung soll BERGH unter der Mitte der 8. Reihe gesehen haben. Der Analtubus, etwa $2.7 \mathrm{~mm}$ vom Hinterende des Rückens. Für diese Art charakteristisch scheint der mit einer runden Verbreiterung versehene Fuss. Der Schwanz nimmt eine Länge des Körpers ein, welche der von selencae und exigua gleich kommt.

Phidiana longicirra kennen wir nach Mr. Crossland's Beschreibung des lebenden und Eliot's Beschreibung des konservirten Tieres. Der Körper ist schlank, $9 \mathrm{~mm}$ lang, $3 \mathrm{~mm}$ breit $(\mathrm{L}: \mathrm{Br}=3: 1)$, zusammengedrückt. Beim lebenden Tiere sind die Vorderecken des Fusses ausgebreitet, im konser- 
vierten Zustande sind diese jedoch verschwunden und die Vorderseite ist dann abgerundet. Die Tentakel sowie die perfoliierten Rhinophorien sehr lang. Ein Schwanz fehlt. Der Rücken in der Mitte nackt, Papillen in schrägen Reihen, welche zwei deutlich geschiedene Gruppen bilden. Die langen (bis $6 \mathrm{~mm}$ ), dünnen, sich verjüngenden Papillen geringelt. Dies scheint, wie ELIOT betont, spezifisch für diese Art zu sein. Wir können hinzufügen: Rücken nackt und Schwanz fehlt.

Phidiana unilineata ist das zuerst von ALDER und HANCOCK und später von ElIOT untersuchte Tier. Nur ALDER und HANCOCK geben uns in Beschreibung und Abbildung Auskunft über Form und Gestalt. Der Körper schlank, 12-13 mm lang. Die Tentakel lang, sich verjüngend. Die Rhinophorien von mittelmässiger Länge, mit 6 Blättern. Papillen kurz und kräftig in fünf bis sechs undeutlichen Gruppen. Der Fuss ist schmal, vorn gerundet ohne Ecken. Dem Bild entnehme ich folgende Verhältnisse: $\mathrm{Br}: \mathrm{L}=\frac{1}{6}$, Tentakel etwa $\frac{1}{4}$ der Körperlänge. Die Papillen in 14 Reihen, welche fast keinen Teil des Rückens frei lassen. Schwanz kurz, $\frac{1}{6}$ der Körperlänge. Ich möchte hervorheben: die geringe Zahl der Papillen, das Fehlen eines nackten Rückenmittelfeldes und der $\frac{1}{6}$ der Körperlänge messende Schwanz.

Phidiana tenuis, von Elrot beschrieben nach zwei ihm vorliegenden Exemplaren, wobei ihm "notes on the living animal" zur Dienste standen, sieht wie folgt aus: etwa $9 \mathrm{~mm}$ lang, $2 \mathrm{~mm}$ breit, also $\mathrm{Br}: \mathrm{L}=\frac{1}{4.5}$. Es wird in den genannten "notes" gesagt: "Tail long, but bearing cerata to the tip." Weil wir bisher immer nur den Teil des Körpers Schwanz genannt haben, welcher nicht mit Papillen besetzt ist, bedeutet dies also für uns: kein Schwanz vorhanden. Während der Fuss hinten sehr schmal ist, ist er vorn zu einer halbkreisförmigen Scheibe verbreitert, welche an ihrer Vorderseite mit einer Grube versehen ist. Die Tentakel beim einen Exemplar lang und auswärts gerichtet, beim zweiten Exemplar ebenso lang wie die Rhinophorien. Die Rhinophorien distal leicht geringelt, mit 15 Blättern, proximal glatt. Papillen lang, zylindrisch, fast alle abgefallen. Ihre Stellung war daher nicht mehr ganz deutlich. Die Reihen bildeten mehrere Gruppen. Eigentümlich ist nur: das Fehlen des Schwanzes, und die Scheibe am Vorderende des Fusses.

Fassen wir die Resultate dieser Vergleichung der Form- und Grössenverhältnisse der Phidianen zusammen so zeigt sich, dass viele Teile des Körpers, die man beim ersten Anblick für wichtig zur Artbestimmung halten würde und auch öfters gehalten hat, erheblichen Schwankungen in Grösse und Gestalt unterworfen sind, dass dasselbe Organ beim selben Individuum sich lang und schlank oder kurz und dick zeigen, sich um vielfaches verlängern oder verkürzen, ja eine ganz andere Gestalt annehmen kann u.s. w.. Hierzu gehören wohl zuerst die Tentakel, die zum Beispiel beim Ph. inca, von welcher Art wir die meisten Exemplare kennen und am besten Auskunft erhalten haben über die Variation, von einer "erheblichen Länge bis "ganz kurz," von $\frac{1}{3}$ der Körperlänge bis weniger als $\frac{1}{6}$ derselben variieren kann. Die Papillen können je nach dem Konservierungszustande des Individuums konisch, rund und gefüllt oder erschlafft und unregelmässig zusammengezogen, schräg zugespitzt, löffelförmig oder säbelförmig, sogar blattförmig erscheinen. Auch die Gestalt des Vorderrandes des Fusses, die abgerundet oder in Ecken ausgezogen sein kann, hat man bei den meisten Arten sorgfältig beschrieben. Wie jedoch aus dem Beispiel von $P h$. longicirra hervorgeht, kann sich dieselbe beim conservieren gänzlich ändern. Hier war ja vom Sammler angegeben: „Foot with expanded angles in front," während ELIOT beim selben aber conservierten Exemplar fand: "The anterior end of the foot is rounded,... and the angles are not visible." Der Kopf kann beim selben Tier kurz und breit oder schmal und lang erscheinen.

Die Stellung der Genital-, Nieren- und Geschlechtsöffnung liefert uns auch keinen Anhalt, liegt doch bei $P h$. lynceus der Analtubus bei einem $12 \mathrm{~mm}$ langen Exemplar $2 \mathrm{~mm}$ vom Hinterende, bei einem $15 \mathrm{~mm}$ langen $7 \mathrm{~mm}$.

Obgleich man also sehr vorsichtig sein soll beim Benutzen solcher Merkmale zur Artunterscheidung, gibt es doch auch Körperteile, die des Zusammenziehens der Muskeln und des Schrumpfens während der Konservierung ungeachtet uns einen Halt beim Bestimmen zu gewähren scheinen. $\mathrm{Zu}$ diesen dürfte man meines Erachtens rechnen: 1. Das Vorkommen einer halbkreisförmigen Scheibe an dem Vorderteil des Fusses, welche breiter ist als der dahinter folgende Teil, wie sie zum Beispiel $P h$. lynceus und $P h$. tenuis uns zeigen. 2. Die Länge des Schwanzes (wobei unter Schwanz zu ver- 
stehen ist die Körperstrecke hinter der letzten Papillenreihe. 3. Die allgemeine Beschaffenheit der Papillenbesatzung d. h. die Breite des nackten Mittelfeldes, die Höhe der Seiten (worüber leider nur wenige Angaben vorliegen), die Breite der Papillenreihen und ihre relative Häufigkeit, also ihr wohl oder nicht Gedrängtsein und die Zahl der Papillen in einer Reihe. Die Verteilung der Reihen in Gruppen mit deutlichen $Z$ wischenräumen scheint bei einigen Arten konstant zu sein, unterliegt bei anderen jedoch erheblichen Schwankungen, sodass ich es nicht wage auch diese zu den Merkmalen zu rechnen, auf die wir unsere Diagnosen bauen könnten. Ausserdem sind doch, wie BERGH sagt, „die Verhältnisse ja bei allen Aeolidiaden durch Ausfallen von Papillen, unregelmässige Regeneration und durch Verschiebungen durch unregelmässige Contraction des Körpers oft auch durch einzelne in den Intervallen enstandenen Papillen ziemlich unklar.” 4. Auch scheint mir die allgemeine Körpergestalt, also das Verhältnis der Länge und der Breite, ziemlich konstant zu sein. Wäre dieses Verhältnis bei den Arten nur mehr verschieden!

Diese Resultate lassen sich auch leicht verstehen, wenn man bedenkt, dass bei unseren Schnecken die Tentakel, Rhinophorien und Papillen schon beim lebenden Tiere sehr beweglich und öfters ganz einziehbar sind, ihre Grösse und Gestalt beim conservierten Tier also davon abhängig sein wird, in welchem Zustande sie fixiert wurden. Auch die Verschiedenheit in der Gestalt der Vorderseite des nach allen Richtungen beweglichen Fusses ist eben deshalb auch leicht $z$ u verstehen, ebenso die Gestalt des Kopfes. Liegt uns jedoch irgendwo am Körper eine weniger bewegliche oder sich meistens in eine bestimmte Gestalt zusammenziehende Masse vor, so wird diese uns ein spezifisches Merkmal liefern können. Dazu gehören: die Scheibe der Vorderseite des Fusses, der Schwanz und die allgemeine Körpergestalt.

Angenommen dass die allgemeine, Verteilung der Papillen auf dem Rücken, ungeachtet der oben genannten Variationen, eine konstante ist, so liefern uns also die Beschaffenheit der Papillenbesetzung sowie die Länge des Schwanzes (welche man ja vom Ende des Papillenfeldes an rechnet) noch brauchbare Unterscheidungsmerkmale. Man bedenke dazu immer, dass Ausfüllung des Körpers beim Reifen der Eier u. dgl. auch eine Änderung hervorrufen in der Breite des nackten Rückens sowie in der Höhe der Seiten und in der relativen Häufigkeit der Papillen. Das Tier macht dann aber auch immer einen aufgeblasenen Eindruck.

Eine Diagnose der äusseren Gestalt einer Phidiana soll also immer enthalten: 1. eine Schilderung der Farbenverhältnisse beim lebenden Tiere (sowie deren Erhaltung beim konservierten); 2. eine Angabe der Verhältnisse zwischen Länge, Breite und Höhe des Körpers; 3. die Länge des Schwanzes in Körperlängen angegeben; 4. die Beschaffenheit der Papillenbesetzung (wozu die Breite des nackten Rückenfeldes sowie die Höhe der Seiten).

Wenden wir uns jetzt der inneren Organisation zu und fangen dabei mit dem Nervensystem und den Sinnesorganen an, so bemerken wir, dass leider nur drei Arten daraufhin bekannt sind, nämlich $P h$. inca, $P$. selencae und $P h$. lynceus. Der Bau stimmt bei allen im allgemeinen überein: die cerebro-visceralen Ganglien sind nierenförmig und liegen einander knapp an, durch eine sehr kurze Cerebralcommissur verbunden. Die pedalen Ganglien sind am Aussenrande der cerebro-visceralen angeheftet. Sie sind oval und nur wenig kleiner als die anderen und untereinander durch eine oder mehrere längere unter dem Oesophagus hindurchgehende Commissuren verbunden. Jedes Gehirnganglion gibt vorn einen Riechnerv ab, welcher bevor er in das Rhinophor eintritt am Fusse desselben ein ganglion rhinophoriale bildet. Neben mehreren anderen Nerven geben die Gehirnganglien auch noch ein Connectivum ab nach den an der Hinterwand des Oesophagus liegenden Buccalganglien, welche wiederum auf kurzem Stiel die kleinen gastrooesophagalen Ganglien tragen. Die Verschiedenheiten zeigt uns umstehende Tabelle: 
Ph. inca.

1. Zwischen den pedalen Ganglien nur eine Commissur, welche (nach BERGH) aus drei Teilen, einem pleuro-cerebralen (nach Plate visceralen), einem pedalen und einem parapedalen besteht.

2. Von BERGH wird kein ganglion opticum gemeldet.

3. Die rhinophorialen Ganglien (Riechknoten) langgestielt.

4. Buccale und gastro-oesophagale Ganglien gleich gross.

5. Zahl und Austrittstelle der Nerven anders wie bei lynceus und selencae.

6. Kein Pigment im Neurilem.
Ph. lynceus.

1. Zwischen den pedalen Ganglien drei Commissuren. Die dritte oder sympatische nur unvollständig beobachtet. (Ich rechne die Buccalcommissur in Gegensatz zu BERGH's Angabe nicht hierzu). Gewöhnlich wird man zwei Commissuren finden ${ }^{1}$ ).

2. Die pigmentierten optischen Ganglien wurden von BERGH gefunden und als Beiaugen gedeutet.

3. Die rhinophorialen Ganglien kurzgestielt.

4. Das buccale Ganglion $8 \times$ so gross wie das gastro-oesophagale.

5. Zahl und Austrittsstelle der Nerven von inca verschieden.

6. Im Neurilem der Ganglien und der Nerve fand BERGH reichliches Pigment.
Ph. selencae.

1. Wie bei lynceus.

2. Kein ganglion opticum angegeben.

3. Über rhinophoriale Ganglien ist nichts angegeben.

4. Das buccale Ganglion $6 \times$ so gross wie das gastro-oesophagale.

5. Zahl und Austrittstelle der Nerven scheint wie bei lynceus zu sein.

6. Kein Pigment im Neurilem.

Die oben angegebenen Verschiedenheiten soll man nicht als für die Arten charakteristisch betrachten, sondern nur als die Differenzen in den Beschreibungen. Wenn BERGH das pigmentierte Neurilem als für Ph. lynceus spezifisch angibt, soll man dies nur mit Vorbehalt annehmen. Auch das Fehlen eines Teils des Systems kann andere Ursachen haben als den Artunterschied und dem beim. Herauspräparieren nicht ganz unverletzten Nervensystem zu verdanken sein. Ob weiter das Nervensystem aller vorliegenden Individuen einer Art untersucht wurde, ist sehr fraglich. Wir wissen also noch nicht genug vom Nervensystem der Phidianen im allgemeinen, noch vom Variieren desselben innerhalb der verschiedenen Arten, um mit Gewissheit sagen zu können in wie weit es zur Artunterscheidung zu benutzen sei. Wir müssen vorläufig auf die Merkmale, die uns das Nervensystem vielleicht liefern könnte, verzichten. Wenn wir dann unsere Aufmerksamkeit auf den. Darm und die dazu gehörigen Organen lenken, so finden wir bei einigen Arten eine Fülle der Tatsachen beschrieben, die leider bei allen Arten vorkommen oder bei den Individuen einer Art verschieden sind; andere Arten wieder sind uns in dieser Hinsicht nicht genügend bekannt. Der Mund scheint sich in verschiedener Weise zusammenziehen zu können, schnürlochartig oder eine Spalte bildend. Der Schlundkopf ist bei den grösseren Individuen grösser, bei den kleineren kleiner, das Verhältnis der Länge, Breite und Höhe ist bei den untersuchten Individuen nicht charakteristisch für die Arten, sondern variiert innerhalb derselben Art (ungefähr $(1.3-2): 1: 1)$. Die Raspelscheide tritt hinten etwas hervor. Im Schlundkopf findet sich ausser der Mundhöhle noch an beiden Seiten eine Nebenmundhöhle. Die gewölbten Seiten des Schlundkopfes werden durch die gelben oder gelbbraunen, bisweilen gelbgrünen, Mandibeln eingefasst. Diese besitzen eine Schlosspartie mit crista connectiva und einen mit einer einzelnen Reihe gerundeten Dentikeln versehenen Kaufortsatz. Sogar diese Hartgebilde liefern keine Unterscheidungsmerkmale, obgleich sie verschieden sind in Gestalt, leider aber meistens bei derselben Art. Vielleicht ist die Zahl der Dentikulierungen am Kaufortsatz eine konstante. Wären wir nur besser bekannt mit den Variationen

1) Man soll diese ganze Angabe sehr kritisch betrachten, stammt doch die buccale Commissur, welche BERGH als vom pedalen Ganglion abgehend abbildet, ja vom cerebralen Ganglion. Auch die viscerale Commissur wird gewöhnlich vom cerebralen Ganglion abgegeben. Ob die von BERGH als unvollständig beobachtet angegebene oder die von ihm mit Seitenzweig abgebildete Commissur als viscerale aufgefasst werden soll, scheint mir fraglich. Ebenso die pedale Herkunft der beiden. 
innerhalb der Arten. Während bei $P h$. inca $20-23$ angegeben wird, findet man bei $P h$. lynceus bald 20 , bald 14 und 15 , bei $P h$. selencae $25-30$, bei $P h$. exigua 22 . Von $P h$. attenuata, $P h$. unilineata und $P h$. longicirra wissen wir nur, dass sie eine Reihe von Dentikeln haben, deren Zahl uns aber unbekannt ist. Bei $P h$. tenuis scheinen dieselben zu fehlen. Elıot meldet: „No denticles were to be seen on the edge (of the jaws) and though it is hard to be certain of their absence in dealing with such slight and colourless material, it is to be observed that they were found without difficulty in other similar forms."

Vergleichen wir die auf der schmalen Zunge in einer Reihe gestellten Zähnen, so bekommen wir eine geringe Hoffnung hier ein brauchbares Merkmal gefundeń zu haben. Nicht die Zahl der Zahnplatten, welche z. B. bei $P h$. lynceus so sehr variiert, dass wir ohne ausführliche Untersuchungen, nichts sicheres dazu noch $z u$ deren Verteilurg sagen können (bei den darauf untersuchten Tieren stellte es sich heraus, dass die Zähne verschiedentlich. verteilt sind über den vordern und den unterm Raspeldache liegenden Teil der Zunge, wobei dem letzteren Teile etwa zwei unentwickelte Zähne zukommen), noch die Grösse der Zähnen, welche mit der Grösse des Tieres wechselt, sondern die Denticulierungen an der mittleren Hakenspitze, sowie zur Seite derselben an dem Schneiderande des Zahnes scheinen ein artspezifisches Merkmal zu liefern. Eine Bestimmungstabelle, (welche die $P h$. attenuatus und $P h$. patagonica nicht mit einschliesst, weil wir über deren Zähnen nichts wissen) welche sich auf dieses Merkmal gründet, sieht wie folgt aus:

1. a. Mit dentikulierter Hakenspitze . . . . . . . . . . . . . . . . .

Ph. lynceus oder Ph. selencae oder Ph.exigua oder Ph. brevicauda nov. sp.

b. Ohne dieselbe. . . . . . . . . . . . . . . . . . . . . 2

2. a. Mit 15-20 Dentikeln am Schneiderande. . . . . . . . . . . Ph. tenuis.

b. Weniger als 15 Dentikel. . . . . . . . . . . . . . . . . . 3

3. a. Mit 3-7, gewöhnlich 5, kräftigen, deutlichen Dentikeln. . . . . Ph. inca oder Ph. longicirra.

b. Mit 6-9 kleinere, öfters undeutlichen Dentikeln......... . Ph. unilineata.

Unsere bisherige Kenntnis der bei den einzeinen Arten vorkommenden Zustände ist folgende: Phidiana inca: die vorderen Zahnplatten trugen 3-4 (-5), die hintern 5-7 starke Dentikel an jeder Seite der gebogenen Hakenspitze (welche selber also keine feineren Denticulierungen zeigte); Phidiana attenuata wurde niemals in dieser Hinsicht untersucht; Phidiana exigua: der Schneiderand trug an jeder Seite 3-5 starke und spitze Dentikel und an der Hakenspitze waren an jeder Seite 2-3 feinere vorhanden; Phidiana patagonica ist uns in dieser Hinsicht unbekannt; Phidiana selencae: an dem Schneiderande der Vorderplatte fanden sich an jeder Seite 4 und an der hervortretenden Spitze noch 3-4 kleinere Zähnchen, an den übrigen Platten kamen an beiden Seiten des Schneiderandes 4-5 und an der Spitze 4-5 Dentikel vor; Phidiana lynceus: es fanden sich beim mit "spec" bezeichneten Exemplar (BERGH 1873) an den vordern Zahnplatten an jeder Seite (3-) 4 starke Dentikel vor und an der vorspringenden Spitze noch $4-6$ kleinere, bei den 3 anderen Exemplaren 4-5 starke Dentikel und 3-4 kleinere an der Spitze; Phidiana longicirra: „The teeth have a strong central cusp and 4-5 long distinct, clear-cut lateral denticles. The denticles do not extend up the sides of the cusp"; Phidiana unilineata: "The teeth bear from 6-9 denticles on either side, the highest of which is on the central cusp. The number of denticles often appears to be only seven when it is really more, because the additional denticles are very small”; Phidiana tenuis: „Thin pointed denticles extend almost up to the tip of the central cusp, there are as many as 20 on either side, but sometimes the number sinks to 15 . Chiefly characteristic by the large number of lateral denticulations on the teeth."

Weiter finden wir: 1. dass eine grössere oder kleinere Speicheldrüse meistens vorhanden ist, 2. dass die kürzere oder längere Speiseröhre in den ersten, eigentlichen Magen führt, welcher mit parallelen kontinuierlichen, mehrfach unterbrochenen Längsfalten versehen ist (bei $P h$. lynceus und $P h$. selencae wird ausserdem noch angegeben, dass in dessen Vorderteil an der Innenseite in Reihen gestellte Spitzen und Kegelchen vorkommen), 3. dass dieser Magen sich nach hinten fortsetzt durch zwẹi Öffnungen, von denen die eine die "Gallengänge". aufnimmt, die zweite nach dem Darm führt, welcher, auf und in der Zwitterdrüse liegend, nach dem After führt. Diese Merkmale sind aber bei allen gleich.

Die „Leber”, d. h. der ganze Komplex der „Leberverzweigungen” sowie der von diesen nach 
dem Magen führenden "Gallengänge", liefert uns vielleicht wieder etwas unserm Zweck Dienliches. Meistens sind ein rechter Vorder-, ein linker Vorder- und ein medianer Hinter-Hauptgallengang vorhanden, deren Verzweigungen distal $\mathrm{zu}$ den sogenannten Leberverzweigungen in den Papillen führen, proximal aber sich vereinen und in den Magen münden. An dieser Mündungstelle findet man ein entweder einfaches oder mehr zusammengesetztes und dann scheinbar "einen zweiten Magen" bildendes Lokulament. Vielleicht würde dieses, wenn es uns bei den verschiedenen Arten besser bekannt wäre, ein Unterscheidungsmerkmal liefern, sei es ein nicht bei allen Arten verschiedenes. Die Leberlappen in den Papillen scheinen bei einer der Arten auch einen für diese charakteristische Gestalt zu besitzen. Während sie nämlich bei den meisten $(P h$. inca, Ph. exigua, $P h$. selencae, Ph. lynceus und $P h$. longicirra) eine knotige Oberfläche zeigen und die Papillen mehr oder weniger ausfüllen, macht $P h$. tenuis eine Ausnahme und unterscheidet sich dadurch, dass die Leberlappen hier dünn sind und viele kurze mehr oder weniger horizontale Äste tragen, wie ElIOT hervorhebt. Obgleich die Angaben und Abbildungen, welche sich auf die Arten mit knotigen Verzweigungen beziehen, auch sehr verschieden sind, scheint dies doch mehr auf einer Variation innerhalb der Arten als auf Artunterschieden zu beruhen. Unbekannt sind uns die Leberverzweigungen von $P h$. attenuata und $P h$. patagonica.

An ihrem Ende sind die Leberlappen mittels eines kurzen mehr oder weniger gewundenen Röhrchens verbunden mit dem Nesselsack. Dieser mit sehr verschieden gestalteten Nesselelementen gefüllte, an der Papillenspitze durch eine feine Öffnung nach aussen mündende Sack nimmt eine verschiedene Länge der Papille ein, wie es scheint um so geringer, je länger die Papille ist. Diese individuell sehr variabele Einrichtung (die bisweilen sogar zu fehlen scheint) liefert keine unserm Zweck dienlichen Eigentümlichkeiten.

Mit dem Gefässsystem der Phidianen sind wir leider nur sehr ungenügend bekannt. Wie neuere Untersuchungen an Heliciden nachgewiesen haben, ist dieses System nicht ohne systematische Bedeutung (man vergleiche: PolINSKI, Wl. Anatomisch-systematische und zoogeographische Studien über die Heliciden Polens, in: Bulletin de l'Académie Polonaise des Sciences et des Lettres, Classe des Sciences Mathématiques et Naturelles. Série B: Sciences Naturelles 1924 p. 131). Die Untersuchung dieses Systems ist jedoch eine sehr schwierige, denn weil wegen des zarten Baues Schnittserien kein lückenloses Bild liefern und man unter der Lupe oder dem Binokular die Nerven, Nierenverzweigungen und Blutgefässen kaum zu unterscheiden vermag, sind sehr schwer auszuführenden Injektionen unumgänglich. Der allgemeine Bau scheint derart zu sein, dass die aorta anterior sich vom rückwärts liegenden, auf die gewöhnliche Weise zusammengestellten Herze nach unten biegt, unterm Magen hindurch geht und sich vorn in zwei oder mehrere Äste teilt, während die aorta posterior dem hinteren „Hauptgallengang” folgt. Weil uns nur Angaben über Ph. inca (PlATE 1894, BERGH 1898) und Ph. lynceus (BERGH 1867-'68) vorliegen, sowie eine Bemerkung (BERGH 1879), dass bei Ph. selencae das Herz wie gewöhnlich sei, scheint es mir nicht lohnend hier ausführlicher diesen Gegenstand zu besprechen. Für Einzelheiten verweise ich nach obengenannten Arbeiten.

Die mittels des pericardio-renalen Organs (Nierenherz) in das Pericard mündende Niere kennen wir nur bei Ph. inca (BERGH 1898, nach PLATE), wo sie von der Nierenöffnung nach vorne verlaufen und dann zurückbiegend zum Teil dem ersten Schenkel parallel zum pericardio-renalen Organ gehen soll. $\mathrm{Ob}$ diese Verhältnisse tatsächlich vorliegen, ist zu bezweifeln. Bei den von mir untersuchten Phidianen fand ich nämlich den, auch für andere Aeolidiaden angegebenen, grossen, flachen, sehr zarten, über den ganzen Rücken hinter dem Herzen sich erstreckenden Nierensack, der seine Verzweigungen, welche er nur seitwärts abgab, zu den Papillen sandte. Vorn zeigte er zwei hornartige Verzweigungen, welche den vorderen Körperteil versorgten. Dieser Sack mündete mittels der Nierenöffnung nach aussen und wurde durch einen Kanal mit dem pericardio-renalen Organ verbunden (vielleicht ist diese Verbindung nicht ganz ohne Bedeutung für die Systematik). Ich vermute, dass bei allen Arten diese selben Verhältnisse vorliegen und die Niere uns also auch keine Unterscheidungsmerkmale liefert.

Was sodann die Geschlechtsorgane anbelangt, der Bau derselben ist uns sehr ungenügend bekannt. Dies braucht uns nicht zu wundern, denn nur eine kombinierte Untersuchung mittels Präparation sowie mittels Schnittserien wird genügen ein etwa dem wahren Zustande entsprechendes Bild zu entwerfen. Der allgemeine (bei allen Aeolidien vorkommende) Zustand ist derart, dass es eine hintere von der aus zahlreichen Läppchen zusammengesetzten Zwitterdrüse gebildete Masse gibt, welche den 
ganzen Hinterkörper anfüllt und vom Darm gefurcht wird, und eine Vordermasse, welche folgendermassen zusammengesetzt ist: der von der Zwitterdrüse ausgehende Zwittergang bildet an der hinteren Oberseite dieser vorderen Genitalmasse eine gewundene Ampulle, welche vorn sich teilt in den Samenleiter und den Eileiter. Während ersterer an der oberen und rechten Seite der Masse sich zum Penis schlängelt, führt letzterer zu der Eiweiss-Schleim-Schalendrüse (Nidamentaldrüse) und zu der Vagina, unterwegs den Gang, der in den Windungen des Zwitterganges eingebetteten Spermatotheca aufnehmend. Die Nidamentaldrüse bildet einen verwickelten, den grössten Teil der vorderen Genitalmasse einnehmenden Komplex. Der Ausführungsgang dieser Drüse ist die Vagina.

Die Angabe Bergh's bei Ph. selencae (1879): "Die Samenblase, welche ich bei den anderen untersuchten Phidianen (inca, lynceus!) nicht gefunden hatte", scheint nicht darauf zu deuten, dass diese nur bei $P h$. selencae vorkommt, nur darauf, dass er sie nicht gefunden hat, denn in seinen späteren Untersuchungen (1898) beschreibt er sie für $P h$. inca. Unterscheidungsmerkmale könnten diese Organe uns vielleicht besorgen, dazu wäre es aber nötig sie mehr in Einzelheiten zu untersuchen, als bis jetzt geschehen ist. Der in einen Penissack zurückgezogene Penis trägt am Ende einen Haken, an dessen Spitze der Samenleiter mittels eines ovalen Lochs ausmündet. An BERGH's Angabe bei $P h$. lynceus (1873), dass die Öffnung hier hinterm Haken liege, wird wahrscheinlich eine Beschädigung Schuld sein. Dass die Form des Penishakens, welche von BERGH bei Ph. selencae als „eine ganz andere" wie bei $P h$. lynceus beschrieben und von ihm also zur Unterscheidung herangezogen wurde, wirklich ein Unterscheidungsmerkmal bildet, scheint mir zweifelhaft. Vergleicht man die Abbildungen von $P$ h. inca 1866 und $P$. inca 1898, sowie von $P$. exigua (1898), so sind diese auch nicht ganz gleich, und bringt man dann die "ganz andere" Abbildung von $P h$. selencae in dieselbe Stellung wie die der anderen Exemplare, dabei bedenkend, dass sich auch hier wahrscheinlich an der Hakenspitze ein Loch befindet, so fängt man an zu zweifeln und fragt sich, worin denn dieses ganz Andere bestehe. Vorläufig habe ich nicht den Mut die Form des Penishakens zur Systematik zu verwenden. Nur möchte ich noch die Aufmerksamkeit lenken auf ElIOT's Bemerkung für Ph. longicirra: „I refer it somewhat doubtfully to Phidiana though it does not seem to possess the armature on the male genitalia which BERGH considers characteristic of the genus." Angaben über das Vorhandensein des Hakens fehlen uns für $P h$. attenuata, $P h$. patagonica, $P h$. unilineata und $P h$. tenuis.

Eine Bestimmungstabelle der Phidiana-Arten nebst ihren kurzen Diagnosen auf Grund der obigen Vergleichung könnte jetzt folgen. Ich gebe sie jedoch am Ende meiner eigenen Untersuchung, damit ich die hier neu zu beschreibenden Art mit hineinschliessen kann.

Phidiana brevicauda nov. spec.

Obgleich ich vermute, dass spätere Untersuchungen nachweisen werden, dass meine Art dieselbe sei wie $P h$. lynceus und $P h$. selencae vielleicht auch wie die pazifische $P h$. exigua, so scheint es mir jetzt noch nicht richtig sie zusammenzufügen. Eine solche Untersuchung sollte auf mehr Material beruhen und die Lücken in den Variationsreihen ausfüllen, was ich trotz meiner sieben Exemplare nicht kann. Der Hauptunterschied mit Ph. lynceus, welchen alle sieben Exemplare zeigten ist, der Schwanz ist hier kürzer und der Bau im allgemeinen weniger schlank. Die Zähne sind länger als sie für $P h$. lynceus abgebildet wurden. Ob dies aber zur Unterscheidung dienen kann? Jedenfalls scheint mir der Unterschied zwischen $P h$. selencae, $P h$. exigua und $P h$ : lynceus nicht so gross, als zwischen $P h$. lynceus und die mir vorliegenden Exemplare und ich beschreibe sie also vorsichtshalber als neue Art mit folgender kurzer Diagnose.

Verhältnis der Länge zur Breite etwa $\frac{1}{3}$, Seiten hoch, Vorderseite des Fusses mit halbkreisförmiger Scheibe, Schwanz etwa $\frac{1}{10}$ der totalen Körperlänge, Papillen in 11-16 Reihen bei einer Körperlänge von $6.5-10 \mathrm{~mm}$, das nackte Mittelfeld des Rückens breiter als die papillentragenden Felder, Zähne der Radula mit dentikulierter Hakenspitze, Leberlappen knotig, Penis mit Haken, Farbe des lebenden Tieres unbekannt.

Es wurden von Dr. van der HoRst 7 Exemplare dieser Art gefischt bei Curaçao an folgenden Stellen.

Caracas-baai, 3 Exemplare, unter Steinen am Ufer. Eines dieser Tiere hatte Penis und Schlundkopf vorgestülpt. Diese drei Exemplare wurden anatomisch untersucht, das eine nur teilweise. 
Caracas-baai; 3 Exemplare. Diese wurden fixiert in Eisessig, zuerst auf bewahrt in Formalin, später aber in Alkohol.

Westpunt, 1 Exemplar, war in Formalin, wurde später aber in Alkohol übergebracht. Dieses Exemplar wurde auf Schnittserien untersucht.

Die ausführliche Beschreibung der neuen Art ist folgende:

Die Farbe des konservierten Tieres: die in Alkohol aufbewahrten Tiere, waren von gelbweisser Farbe, die in Formalin aufbewahrten vor dem Überführen in Alkohol grauweiss. In den Papillen schimmerten die Leberlappen dunkler hindurch. In der Spitze der Papillen zeigte sich silberglänzend der Nesselsack. Nur eines der Tiere zeigte noch ein schwarzes Pigment, welches sich am meisten konzentrierte am Fusse der Papillen, nach oben verringernd; unterm Nesselsack häufte es sich jedoch noch zu einem schwarzen Ringe an; über diesen hinaus kommt es nicht mehr vor, sodass die Spitze hell erscheint. ( $\mathrm{Ob}$ das Pigment vor dem Einbringen in Alkohol auch schwarz gewesen sei, lässt sich schwer sagen).

Die Form des Tieres (Fig. 4) war seitwärts zusammengedrückt. Das Verhältnis der Länge zur Breite etwa $\frac{1}{3}$. Die Breite war über der ganzen Länge des Tieres nahezu gleich, nahm nach hinten nur sehr wenig ab und endigte ziemlich plötzlich in den kurzen Schwanz. Hinterm Kopf befindet sich eine halsartige Verschmälerung. Die Tiere waren im Alkohol der Länge nach stark zusammengezogen, sodass sie von der Seite gesehen eine ovale Form zeigten, in der Mitte am höchsten, nach vorn in

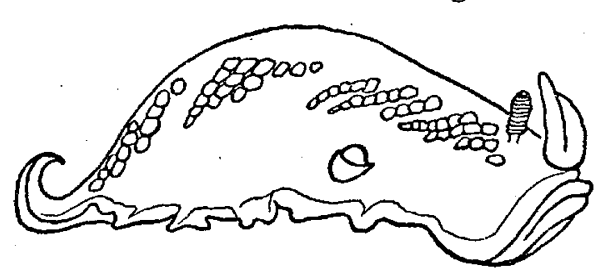

Fig. 4 Phidiana brevicauda nov. spec. Das Tier ohne Papillen. den Kopf und das aufgebogene Vorderende des Fusses endigend, nach hinten in den kurzen Schwanz zugespitzt. Je nach dem Grade der Zusammenziehung war die Höhe $\frac{1}{2}$ bis $\frac{1}{3}$ der Länge. Die Länge bei den verschiedenen Tieren war 8.5, 9, 10, 6.5, 7 und $9 \mathrm{~mm}$, die Breite respektive $3,3,3,2,2$ und $3 \mathrm{~mm}$, die Höhe $3.5,4,3,2,2$ und $3 \mathrm{~mm}$.

Bei dem am wenigsten zusammengezogenen Exemplar ging der sich nach dem Halse wieder etwas verbreiternde Kopf allmählich in die Tentakel über. Die Tentakel waren stark zusammengezogen, sodass nichts übrig geblieben war von ihrem bei den Phidianen üblichen schlanken Gestalt. Ihre Länge war 1.5, 2.5, 2, 2 und $1 \mathrm{~mm}$. Die keulenförmigen Rhinophorien trugen über der ganze Länge Blätter, deren Anzahl zwischen 15 und 20 variierte und von denen einige unvollkommen waren. Die Höhlen, worin sich die Rhinophorien zusammenziehen konnten, zeigten sich sehr schön auf Schnittserien. Eines der Tiere hatte den Schlundkopf vorgestülpt, der $2 \mathrm{~mm}$ lang und $2 \mathrm{~mm}$ breit war. Deutlich sah man auf dessen Oberfläche die braunen Kiefer hindurchschimmern; an der Vorderseite die ovale innere Mundöffnung, welche begrenzt wurde von den Kaufortsätzen der Kiefer. Die Mitte des Rückens war breit $\left(\frac{1}{5}, \frac{1}{4.5}, \frac{1}{5}\right.$ der Körperlänge). Die mit Papillen besetzten Teile viel schmaler als der nackte Mittelteil. Die Papillen in sehr schrägen Reihen auf längliche Polster gelagert. Sie setzten sich fort fast bis zum Hinterende des Tieres, sodass nur ein ganz' kleiner Schwanz übrig blieb, der nicht mehr als $\frac{1}{10}$ der Körperlänge einnahm und meistens wie ein Schweineschwanz eingerollt war. Alle Tiere zeigten zur linken sowie zur rechten Seite zwei Gruppen, welche durch die nackte Pericardialgegend geschieden wurden. Deutlich war dieses Verhältnis nur, wenn man gut zusah, denn die erste Reihe der hinteren Gruppe war eine lange (6--13 Papillen) und reichte bis zur ersten Gruppe, wodurch der Zwischenraum auch ganz von Papillen ausgefüllt erschien. Die Anzahl der Reihen in den so gebildeten vier Gruppen war respektive: rechte Vordergruppe: 8, 7, 5, 6; rechte Hintergruppe: 8, 7, 8, 5; linke Vordergruppe: 8, 7, 6, 5; linke Hintergruppe: $8,8,7,6$. Die Papillen waren von zylindrischer etwas konischer Gestalt, am Ende zugespitzt, sehr unregelmässig zusammengezogen. Öfters waren der untere Teil und die Spitze etwas aufgeblasen. Die Länge sehr variierend, bis $3 \mathrm{~mm}$. Die Pericardialgegend wie oben angegeben in der Mitte des nackten Rückenfeldes, weniger zusammengezogen als die Umgebung, und daher aufgeblasen aussehend.

Nach hinten nahm die Breite des nackten Rückenfeldes ab. Die Seiten des Körpers hoch, nackt (bis $2 \mathrm{~mm}$ ). Die Genitalöffnung befand sich auf 3 bis $4 \mathrm{~mm}$ vom Vorderende, zuweilen umgeben von einem Hautwulst. Bei einem Exemplar war der $3 \mathrm{~mm}$ lange und $1 \frac{1}{4} \mathrm{~mm}$ beite nach oben gekrümmte Penis 
vorgestreckt. Deutlich sah man mit der Lupe den Haken an der Spitze (Fig. 6). Die Nierenöffnung wurde nicht gesehen. Der Anus lag weit nach hinten, zwischen den Jetzten Papillenreihen, 2 bis $3 \mathrm{~mm}$ vom Hinterende. Der Fuss nur im schmalern Mittelteil an den Körper geheftet, die treien Seitenteile breiter, stark gefaltet. Das Vorderende desselben war nicht gefaltet sondern bildete eine halbkreisförmige, feste Scheibe, die weil sie nicht gefaltet war, breiter schien als der Rest des Fusses. Der Vorderrand war verdickt und gefurcht. Hinten war der Fuss kurz zugespitzt. Die Länge variierte zwischen 6 und $9 \mathrm{~mm}$, die Breite zwischen 1.5 und $2 \mathrm{~mm}$.

Das Zentralnervensystem wurde untersucht bei drei Exemplaren. Bei zwei derselben gelang es das ganze Gehirn herauszuheben, wenn auch mit Verlust der Rhinophorialganglien, beim dritten fand die Untersuchung mittels Schnittserien statt. Der allgemeine Bau war der gewöhnliche, über die Einzelheiten lässt sich folgendes sagen: das Ganze war in eine Bindesubstanz gehüllt, die sich auf Querschnitten als geräumige Hülle zeigte und bei den anderen Tieren, bevor weitere Untersuchung stattfinden konnte, entfernt werden musste. Es war dabei sehr schwierig nicht mit den Bindegewebsfasern auch sogleich die Nerven auszureisen. Die Rhinophorialganglien durch den kurzen starken Rhinophorialnerv an den Cerebralganglien angeheftet. Die Ganglienzellen in denselben anders als in den anderen Ganglien. Die länglich ovalen cerebro-pedalen Ganglien waren durch eine kurze Commissur verbunden. In der Mitte ihrer Aussenseite hinter dem Auge und Statocyste (Ohr) waren die ovalen pedalen Ganglien angeheftet. Diese waren nur durch eine einzige breite Commissur verbunden. Wieviele Commissuren hierin enthalten sind; war nicht deutlich zu sehen. Das Cerebralganglion gab ausser den genannten N. rhinophoriales an ihrer Vorderspitze, an ihren Seiten vor den Augen noch zwei starke Nerven ab (N. tentacularis? und N. labio-frontalis?). Dann folgten Auge und Statocyste (Ohr), weiter das Connectivum zum pedalen Ganglion, sowie ein feinerer sich mit dem Connectivum verbindender Nerv. Ein starker, fast aus dem pleuralen Teil des Ganglions stammender Nerv zog sich über das pedale Ganglion hinweg. Dahinter ging das sehr lange zarte Buccal-Connectivum ab. Der ganze Hinterteil des Ganglions gab keine Nerven ab. Aus dem pedalen Ganglion stammten nur zwei an der Aussenseite ausgehende Nerven und eine an der Innenseite ausgehende Commissur. Die Nerven ziehen zum Fuss und zu'den Genitalien, die Commissur war die unter dem Pharynx greifende pedale Commissur.

Die ovalen buccalen Ganglien liegen sogleich hinter den pedalen auf dem Pharynx. Sie sind mit den Cerebro-pleuralganglien verbunden mittels des oben genannten Connectivums und untereinander durch einen Commissur. An der Anheftungsstelle des letzteren geben sie je einen Nerv ab. Auf kurzem Stiele tragen sie die kleinen, etwa $\frac{1}{6}$ der buccalen Ganglien, messenden, gastro-oesophagalen Ganglien.

Die Augen liegen auf dem Cerebro-pleuralganglion, ihr Durchmesser beträgt etwa $0.14 \mathrm{~mm}$. Sie besitzen eine grosse gelbliche Linse, sowie einen schwarzen ebenfalls sehr grossen Pigmentbecher. Die Stato- (Oto-) cysten hinter den Augen, etwa $0.10 \mathrm{~mm}$ im Durchmesser. Sie sind gefüllt mit ovalen Statolithen (Otokonien). Zwischen Auge und Statocyste befand sich ein nicht pigmentiertes rundes Körperchen, $0.10 \mathrm{~mm}$. im Durchmesser, das ganz aussah wie die Ganglien. Auf Querschnitten zeigte es auch im Inneren dieselben Elementen wie diese: Ganglienzellen und Fasern. BERGH erwähnte solche Körperchen nur bei Ph. lynceus und nannte sie Beiaugen, weil er auch Pigment darin fand. Eine Linse oder so etwas hat er aber nie gefunden. Wahrscheinlich lagen uns sowie ihm dasselbe Organ, nämlich das Ganglion opticum, welches doch auch bei anderen Mollusken genannt wird, vor. Die Pigmentierung lässt sich leicht erklären, wenn man bedenkt, dass bei den Berghschen Exemplaren sogar das Neurilem pigmentiert war.

Alles zusammenfassend können wir sagen, dass das Gehirn dieser Art in einigen Zügen dem von $P h$. lynceus, und in anderen dem von $P h$. inca ähnlich sieht. Hier ist also: 1. nur eine Commissur zwischen den pedalen Ganglien vorhanden; 2. „Beiaugen” (ganglia optica) vorhanden; 3. Riechknoten kurz gestielt; 4. gastro-oesophagalen Ganglien " $\frac{1}{6}$ der buccalen; 5. Zahl und Austrittstelle der Nerven anders wie bei $P h$. lynceus und $P h$. inca; 6 . kein Pigment im Neurilem vorhanden.

Der Darm und die ihm zugehörigen Organe sind folgendermaassen gebaut: der Mund bildete bei drei Exemplaren eine Spalte; bei einem Exemplar war der Schlundkopf vorgestülpt, hier schimmerten die Kiefer braun hindurch, die Kaufortsätze der Kiefer umsäumten die Vorderöffnung. Der Schlundkopf war $2 \mathrm{~mm}$ lang, $\pm 1 \mathrm{~mm}$ breit und $\pm 1 \mathrm{~mm}$ hoch. Die Nebenmundhöhle verlief sich bis unter die Kiefer. 
Die Raspelscheide sich etwas hinter dem Schlundkopf fortsetzend. Die Kiefern trugen einen deutlichen Kaufortsatz, dessen Kaurand mit einer Reihe von mehr als 20 gerundeten unregelmässigen Dentikeln versehen war. Die Zunge trug eine einzelne Reihe von Zähnen, 13 bis 14 entwickelte und eine unentwickelte, die entwickelten gleich verteilt vor und unter dem Raspeldache. Die Zähne (Fig. 5) trugen eine deutliche Hakenspitze, welche mit 3 bis 4 Dentikeln versehen war. Auf dem Schneiderande der Zähne neben der Hakenspitze befanden sich 4, 5 oder 6 Dentikel, je mehr je weiter die Zähne nach hinten lagen. Eine Speicheldrüse wurde nicht gefunden. Der sehr kurze Pharynx trat sogleich in den fast über ihm liegenden Magen über. Der Magen war etwa $2 \mathrm{~mm}$ lang. Der dem Pharynx zugewendete Teil war an der Innenseite mit Falten oder langen Zotten besetzt. Im Magen mündeten in den hinteren (meistens oben liegenden) Teil die drei Hauptgallengänge (ein linker vorderer, ein rechter vorderer und ein hinterer) sowie der Darm. Dieser hintere Teil war ganz anders gebaut als der vordere zottige Teil. Er bildete nach vorn und nach der linken Seite kleine Ausstülpungen, die wie Lokulamente auf der Magenwand lagen. Sieht man dies von oben her an, so sieht es ganz aus wie BERGH es 1898 in seiner Figur 8 für Ph. inca abgebildet hat und bekommt man den Eindruck Fig. 5. Phieines "loculamentierten zweiten Magens" Das hier kein Organ für sich und auch kein diana brevi"loculamentiertes Ende des gemeinschaftlichen Gallenganges” vorlag, sondern nur der sp. Zahnplatte. hintere (obenliegende) Teil des Magens, war auf Schnittserien deutlich zu beobachten.

Der $6 \mathrm{~mm}$ lange Darm umkreiste die hintere Geschlechtsmasse und machte dabei dieselben Windungen, wie BERGH sie in der eben genannten Figur darstellt. Auch die Gallengänge sind denen dieser Abbildung gleich.

Die Leberlappen in den Papillen sind knotig und mittels eines mit einer Schlinge versehenen Kanälchens mit dem Knidosac verbunden. Die Länge der Kanälchen war in den verschiedenen Papillen sehr ungleich. Dieser letztere nahm bei den kleineren Papillen $\frac{1}{3}$, bei den grösseren $\frac{1}{6}$ der ganzen Papillenlänge ein.

Das ovale Herz lag im ovalen Pericard und zeigte in gewöhnlicher Weise die vordere und hintere Aorta sowie die Vorderkammer mit ihren in die vier Ecken mündenden Venen.

Ins Pericard mündete die längsgefaltete, gelbliche, ovale Nierenspritze, welche einen langen in die Niere mündenden Kanal absendet.

Die Niere hatte die gewöhnliche dreieckige Form und bildete, wie ich oben schon angegeben habe, einen grossen flachen sehr zarten, über den ganzen Rücken hinter dem Herzen sich erstreckenden

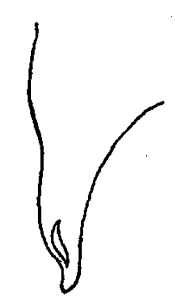

Fig. 6. Phidiana brevicauda nov. spec. Penishaken. Nierensack, der seine Verzweigungen, welche er nur seitwärts abgab, zu den Papillen sendete. Vorn zeigte er zwei hornartige Verzweigungen, welche den vorderen Körperteil versorgten. Dieser Sack mündete mittels der Nierenöffnung nach aussen und wurde durch den oben erwähnten Kanal mit dem reno-pericardialen Organ (die Nierenspritze) verbunden. Die Ausmündungsstelle dieses Kanals in die Niere lag weit nach hinten, hinter dem Pericard.

Ich finde keinen Grund hier noch die Genitalorgane, die ich auf Querschnitten und mittels Präparation untersuchen konnte, $z u$ besprechen, da sie keine von den oben geschilderten abweichenden Verhältnisse zeigen. Die Form des Penishakens (Fig. 6) war bei einem Exemplar ungefähr wie BERGH ihn für Ph. selencae (1878) abbildet, nur mit. etwas schmalerer Basis, bei einem anderen Exemplar glich er mehr der Abbildung für Ph. exigua (1898).

\section{Bestimmungsschlüssel für die Phidiana-Arten.}

(Die Merkmale der verschiedenen Arten sind bisjetzt noch unvollständig bekannt, deshalb trägt dieser Bestimmungsschlüssel nur einen provisorischen Charakter).

1. a. Schwanz lang $\frac{1}{2}-\frac{1}{3}$ der Körperlänge . . . . . . . . . . . . . 2

b. Schwanz kürzer als $\frac{1}{3}$ der Körperlänge . . . . . . . . . . . . . . 3

2. a. Bau fein und zart . . . . . . . . . . . . . . . . Ph. attenuata Couth.

Verhältnis der Länge zur Breite $\frac{1}{9}$. Seiten? Vorderseite des Fusses?

Schwanz $\frac{1}{2}-\frac{1}{3}$ der Körperlänge. Anzahl der Papillenreihen etwa 20. 
Breite des nackten Rückenfeldes? Nervensystem? Zähne? Leberlappen? Penishaken? Farbe des lebenden Tieres: farblos, nur auf dem Rücken einen leichten rötlichen Anstrich.

b. Bau kräftiger . . . . . . . . . . . . . . . . . . . . . Ph. patagonica d'Orb.

Verhältnis der Länge zur Breite $\frac{1}{8}$. Seiten? Vorderseite des Fusses? Schwanz $\frac{1}{3}$ der Körperlänge. Papillen in etwa 18 Reihen. Nacktes Rückenfeld breit. Zähne? Leberlappen? Penishaken? Farbe des lebenden Tieres: Körper hellrötlich, Tentakel weiss, Papillen hellrot bis violett. Auf dem Rücken zwei hellrote dreieckige Flecken, einer vor und einer hinter den Rhinophorien mit den Spitzen einander zugewendet.

3. a. Zähne der Radula mit dentikulierter Hakenspitze . . . . . . . . . 4

b. Zähne der Radula ohne dentikulierte Hakenspitze . . . . . . . . : 7

4. a. Schwanz $\pm \frac{1}{10}$ der Körperlänge . . . . . . . . . . . . . . Ph. brevicauda n. sp. Verhältnis der Länge zur Breite $\frac{1}{3}$. Seiten hoch. Vorderseite des Fusses mit halbkreisförmiger Scheibe, Schwanz $\frac{1}{10}$ der Körperlänge. $\mathrm{Pa}-$ pillen in 11-16 Reihen. Nacktes Rückenfeld breiter als die papillentragenden. Zähne der Radula mit dentikulierter Hakenspitze. Leberlappen knotig. Penis mit Haken. Farbe des lebenden Tieres unbekannt.

$b$. Schwanz länger als 'unter $a$. angegeben, etwa $\frac{1}{4}-\frac{1}{5}$ der Körperlänge . 5

5. a. Pazifische Art. . . . . . . . . . . . . . . Ph. exigua Bergh.

Das Verhältnis der Länge zur Breite $\frac{1}{3.5}$. Seiten? Fuss? Schwanz etwa $\frac{1}{5}$ der Körperlänge. Papillenreihen dichtgedrängt. Anzahl? Nacktes Rückenfeld breiter als die papillentragenden Felder. Zähne der Radula mit dentikulierter Hakenspitze. Leberlappen knotig. Penis mit Haken. Farbe des lebenden Tieres?

b. Atlantische Arten. . . . . . . . . . . . . . . . . . . 6

6. a. Verhältnis der Länge zur Breite $\frac{1}{3}-\frac{1}{4}$. Papillén in 12-20 Reihen. Mittelfeld des Rückens breiter als die papillentragenden Felder. (Neurilem mit Pigment). (Form des Penishakens angeblich verschieden von der von Ph. selencae) . . . . . . . . . . . . . . . . . . . . . . . Seiten hoch. Fuss an der Vorderseite mit halbkreisförmiger Scheibe. Schwanz $\frac{1}{4}-\frac{1}{5}$ der Körperlänge. Zähne mit dentikulierter Hakenspitze. Leberlappen knotig. Penis met Haken. Farbe des lebenden Tieres unbekannt.

$b$. Verhältnis der Länge zur Breite $\frac{1}{5.5}$. Papillen in 32 Reihen. Mittelfeld des Rückens kaum breiter als die papillentragenden Felder. (Kein Pigment im Neurilem). (Form des Penishakens angeblich verschieden von der von Ph. lynceus). . . . . . . . . . . . . . . . . . . . Seiten hoch. Fuss? Schwanz $\frac{1}{4.5}$ der Körperlänge. Zähne mit dentikulierter Hakenspitze. Leberlappen knotig. Penis mit Haken. Farbe des lebenden Tieres: auf der Unterseite weiss, am Rücken hell fuchsbraun, mit intensiv braunen Papillen.

7. a. Am Schneiderande der Zähne 15-20 Dentikel. . . . . . . . . . . Ph. tenuis Eliot. Verhältnis der Länge zur Breite $\frac{1}{4.5}$. Seiten? Vorderseite des Fusses mit Scheibe. Ohne Schwanz. Anzahl der Papillenreihen? Nacktes Rückenfeld? Zähne ohne dentikulierte Hakenspitze, mit 15-20 Dentikel am Schneiderande. Kaufortsatz ohne Dentikel. Leberlappen mit Ästen. Penishaken? Farbe des lebenden Tieres: Körper fleischfarbig; Fuss, Tentakel und Rhinophorien weiss, die Papillen farblos bis zinnoberrot. 
b. Am Schneiderande der Zähne weniger als 15 Dentikel. . . : . . . 8

8. a. Mit 3-7 (gewöhnlich 5) kräftigen, deutlichen Dentikeln. Schwanz kürzer als $\frac{1}{9}$ der Körperlänge. Mit nacktem Rückenfelde. . . . . . . 9

b. Mit 6-9 kleineren öfters undeutlichen Dentikeln. Schwanz etwa $\frac{1}{6}$ der Körperlänge. Kein nacktes Rückenfeld. . . . . . . . . . . . . Ph. unilineata Ald. \& Hanc. Verhältnis der Länge zur Breite $\frac{1}{6}$. Seiten? Fuss? Schwanz $\frac{1}{6}$ der Körperlänge. Anzahl der Papillenreihen gering. Kein nacktes Rückenfeld. Zähne ohne dentikulierte Hakenspitze, mit 6-9 kleineren öfters undeutlichen Dentikeln. Leberlappen? Penishaken? Farbe des lebenden Tieres: Körper „buff-coloured”; Rhinophorien und Tentakel fleischfarbig; Tentakel unten fleischfarbig mit gelblichweisser Spitze; eine scharlachrote Linie in der Mitte des Kopfes anfangend läuft bis zum Anfang der Papillen; Papillen purpurbraun.

9. a. Schwanz $\frac{1}{9}-\frac{1}{12}$ der Körperlänge. Papillen nicht geringelt. Penis mit Haken .. . . . . . . . . . . . . . . . . . . . . . . . Ph. inca d'Orb.

Verhältnis der Länge zur Breite $\frac{1}{3}-\frac{1}{6}$. Seiten hoch. Fuss gewöhnlich. Schwanz $\frac{1}{9}-\frac{1}{12}$ der Körperlänge. Papillen in 20-26 Reihen. Nacktes Rückenfeld breiter als die papillentragenden. Zähne ohne dentikulierte Hakenspitze, mit 3-7 kräftigen, deutlichen Dentikeln. Leberlappen knotig. Penis mit Haken. Farbe des lebenden Tieres: grauweiss, bisweilen rötlich; zwei weisse Flecken, einer vor und einer hinter den Rhinophorien.

b. Schwanz fehlt. Papillen geringelt. Penis ohne Haken. . . . . . . . Verhältnis der Länge zur Breite $\frac{1}{3}$. Seiten ? Fuss? Ohne Schwanz. Papillen geringelt. Rücken mit nacktem Mittelfelde. Zähne ohne dentikulierte Hakenspitze, mit 4-5 kräftigen, deutlichen Dentikeln. Leberlappen knotig. Penis ohne Haken. Farbe des lebenden Tieres: Körper durchsichtig weiss, mit einigen Sammlungen weisser Flecken; Rhinophorien braungelb; Papillen farblos; die Leberverzweigungen farblos, gelb oder braun; gelbes Pigment in der Haut.

\section{CALORIA Trinchese.}

Herr Dr. HaAs war so freundlich mir die fünf Tiere, die er im Archiv für Molluskenkunde 1920 S. 142, als Facelina bostoniensis (Couth.) erwähnt hat, aus dem Senckenberg-Museum zur Untersuchung zu senden. Es zeigte sich, dass die Tiere zwar ganz wie Facelina aussahen, dass ihnen aber die Penisbewaffnung fehlte. Das einzige in Betracht kommende Genus war das obengenannte von TRINCHESE beschriebene. Das Tier sollte denn aber auch die eigenartige Gestalt der Mandibel besitzen. Dies war wirklich der Fall.

Das Geschlecht Caloria wurde 1888 von TRINCHESE begründet. Es wurde später natürlich auch von BERGH in seine Systeme (1890 und 1892) aufgenommen. Weitere Literatur aber scheint über dasselbe nicht $\mathrm{zu}$ bestehen.

Die einzige zugehörige Art ist die von TRINCHESE an der genannten Stelle beschriebene Caloria maculata Tr. Für die Diagnose dieser Art verweise ich auf die vorzügliche Beschreibung dieses Autors.

Meine Tiere stimmen nicht ganz mit seinen Angaben. Es sind nämlich bei allen mir vorliegenden Tieren (ich habe deren fünf) die Rhinophorien perfoliiert, oder vielleicht wäre es besser zu sagen sehr ausgeprägt annuliert; die Papillen besitzen keine Drüsen zwischen den Leberlappen und Nesselsäcken 'und die Papillen sind auf eine andere Weise auf dem Rücken verteilt.

Die Rhinophorien meiner Tiere besitzen (Fig. $7 a-e$ ) deutliche dicke Blätter, die man wahrscheinlich besser Ringen nennen könnte. Ich habe eine Abbildung eines Rhinophors von jedem Tier gegeben, damit man deutlich sehen kann, dass diese Organe aus einem glatten, zusammenziehbaren und dann gefalteten (Fig. $7 a$ und $b$ ) Basalteil und einem mit 5-7 Ringen versehenen oberen Teil, 
der bei Zusammenziehung auch mehrere Falten erhalten kann, bestehen. TRINCHESE schreibt: „I rinofori... presentano delle rughe irregolari" und "Rinofori ... sparsi di lievi ripiegature ma non perfoliati." Alle die fünf von mir untersuchten Tiere zeigen, wie man leicht den Abbildungen éntnehmen kann, den gleichen Charakter und sind alle verschieden von der von TRINCHESE geschilderten Gestalt. Obgleich ich weiss, wie sehr die Rhinophorien variieren, können doch meines Erachtens diese Verschiedenheiten nicht ganz ohne Wert sein, wenn alle Tiere sie zeigen. Überdies sind diese Organe doch auch bei den anderen Aeolidien nicht ganz ohne systematischen Wert, werden sie ja bei den Spurillen und Aeolidiellen sogar zur Gattungsunterscheidung benutzt.

Von den von TRINCHESE besonders hervorgehobenen und sehr deutlich abgebildeten Drüsen, die in den Papillen zwischen dem Nesselsack und dem Leberlappen liegen, ist bei meinen Tieren keine Spur zu entdecken, obgleich ich bei allen Tieren Papillen von verschiedener Grösse und von verschiedenen Stellen stammend untersuchte (Fig. 8).

Die Papillenanordnung ist bei meinen Tieren eine andere, die Papillen sind nämlich deutlich

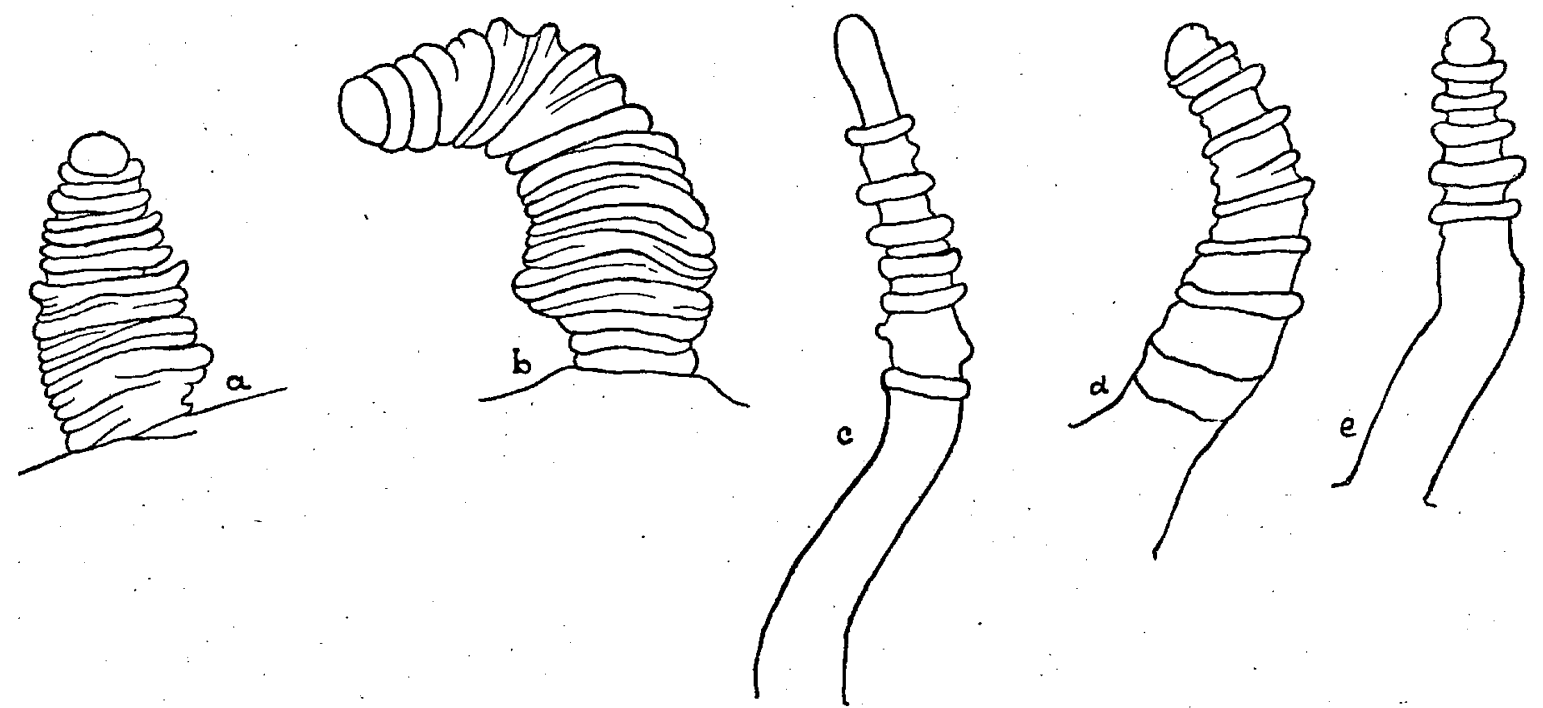

Fig. 7. Caloria occidentalis nov. spec.

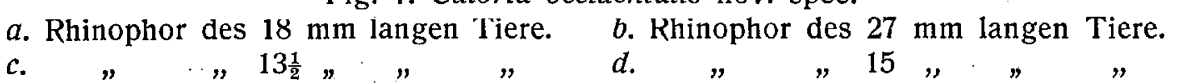

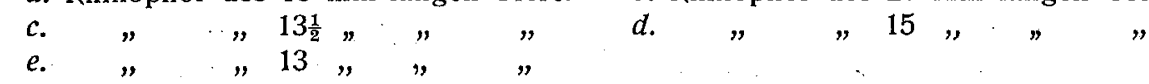

auf hufeisenförmige Bogen gestellt, während TRINCHESE meldet, dass sie bei seinen Tieren aus Querreihen bestehende Gruppen bilden. Letzteres schliesst natürlich ersteres nicht aus, hätten aber die Querreihen Bogen gebildet, so hätte TRINCHESE uns dies ganz gewiss gemeldet, um so mehr, als er sogar die Zahl der Papillen in den Querreihen angibt. Auch die Stelle der Genital- und Analöffnung ist nach ihm eine andere, als ich sie bei meinen Tieren fand. Alle fünf Tiere stimmen in diesen Merkmalen, worin sie sich von der Caloria maculata unterscheiden, untereinander ganz deutlich überein ohne eine Variation zu zeigen in der Richting der' genannten Art. Ich meine, dass hier eine neue Art vorliege, die ich Caloria occidentalis nenne.

Die Diagnose der Gattung Caloria erfährt durch diese Bereicherung eine Erweiterung und soll jetzt lauten: Körper schlank; Rhinophorien perfoliiert oder geringelt; Tentakel lang; Fuss am Vorderende mit tentakelförmigen Ecken; Radula mit einer Zähnenreihe; Schneiderand der Zähne dentikuliert, mit grossem Mitteldentikel; Mandibel ungefähr wie bei Glaucus und Facalana, mit eingebuchtetem Oberrande; Kaurand mit Dentikeln; Penis unbewaffnet.

Caloria occidentalis nov. spec.

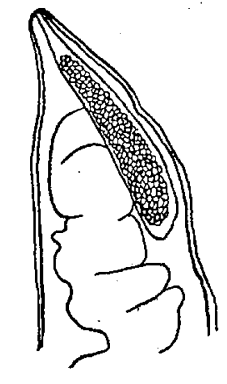

Fig. 8. Caloria occidentalis nov. spec. Spitze einer Papille des $27 \mathrm{~mm}$ langen Tieres, mit Nesselsack und Leberlappen, aber ohne Drüse.

Wie schon gesagt, standen mir fünf vorzüglich konservierte Tiere zur Verfügung, welche von A. REICHARDT für die Senckenbergische Gesellschaft 1904 auf Jamaica, Montego-Bay, gesammelt waren. 
Ich bezeichnete das $27 \mathrm{~mm}$ lange Exemplar als den Typus. Alle hatten die Farben ganz verloren und sahen sehr durchsichtig gelblich-weiss aus; überall schimmerten die inneren Organe deutlich durch. Das Verhältnis der Breite zur Länge des Körpers war $\frac{1}{4.5}$ bis $\frac{1}{6}$ (nämlich war die Breite bei den Tieren von $27,18,13,13.5$ und $15 \mathrm{~mm}$ Länge resp. 4.5, 3, 3, 2.5 und $3 \mathrm{~mm}$ ), während sich die Körperhöhe zur Körperlänge verhielt wie $\frac{1}{4}$ bis $\frac{1}{6}$ (nämlich Körperhöhe resp. 4.5, 3.5, 3, 3 und 4 mm). Der Körper ist also rundlich (Fig. 9). Der Fuss ist breit, hier und da breiter als der Körper (die grösste Breite des Fusses verhielt sich zur Körperlänge wie $\frac{1}{4}$ bis etwa $\frac{1}{5.5}$ Diese Breite des Fusses war resp. 5, 4.5, 2.5, 3 und $3 \mathrm{~mm}$ ). Der Fuss setzte sich hinten fort im Schwanz der $\frac{1}{4.5}$ bis $\frac{1}{10}$ der Körperlänge beträgt. Länge des Schwanzes resp. 4, 3,-, 3 und $1.5 \mathrm{~mm}$, der Schwanz des dritten Exemplars war abgebrochen. Der runde Kopf trug die langen schlanken Tentakel (die Länge der Tentakel war resp. 4.5-6, $4.5-5.25, \pm 4.5, \pm 4$ und $\pm 5 \mathrm{~mm}$ ) und dicht nebeneinander die Rhinophorien (Länge resp. $2.25-4$, 2, 4, 3.5 und $2.5 \mathrm{~mm}$ ). Die letzteren trugen an ihrem oberen Teil die 5-7 Ringen (Fig. $7 a-e$ ). Der Fuss mit einem breiten freien Randsaum; vorn mit verdicktem Rande, der sich in die sehr langen (resp. $2.5-3,2-2.5,1,1$ und $2 \mathrm{~mm}$ ) zurückgebogenen Fusstentakel (ausgezogene Fussecken) fortsetzte (Fig. 10). Eine tiefe deutliche Randfurche setzte sich über die ganze Länge dieser Fusstentakel fort als eine Längsfurche. Der Fuss verschmälerte sich nach hinten allmählich.

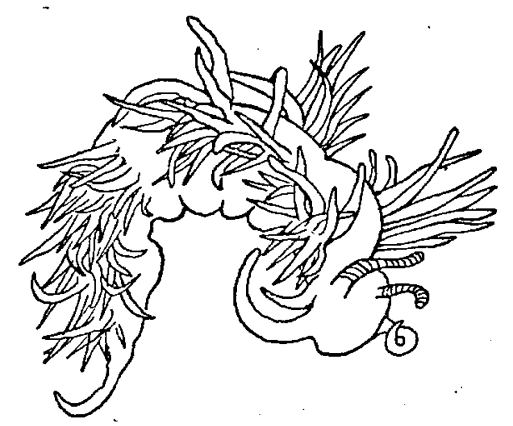

Fig. 9. Caloria occidentalis nov. spec Das $27 \mathrm{~mm}$ lange Tier (Typus). Vergr. $2 \times$.

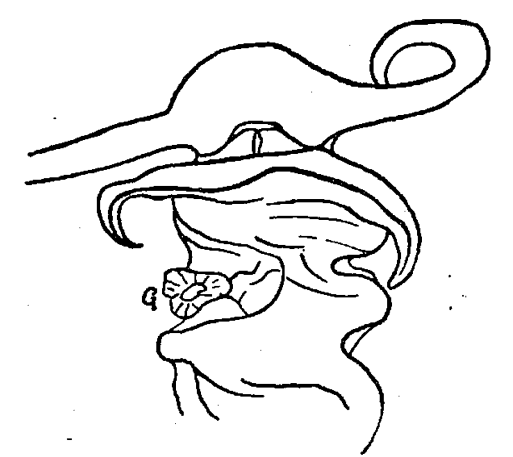

Fig. 10. Caloria occidentalis nov. spec. Vorderende des Tieres von unten gesehen; die $\mathrm{Pa}-$ pillen sind nicht angegeben; man sieht: die Tentakel, den Vorderrand des Fusses mit den Fusstentakeln wie mit der sich über letztere fortsetzenden Randfurche, und über dem Fussrande den $T$-förmigen Mund. $G=$ Genitalpapille.

Die Papillen waren keulenformig, (ihre Länge resp. bis 7, 5, 4.5, 4.5 und $3.5 \mathrm{~mm}$ ); die Leberlappen und Nesselsäcke schimmerten durch (Fig. 8); ohne Drüse; in einzelne oder doppelte Querreihen auf mehr oder wenig deutliche Kissen gelagert. Die Querreihen waren am Rücken paarweise zu Bogen vereint. Die eingeschlossenen Zwischenräume waren nicht weit und liefen oben spitz zu. Bei allen kamen sieben solcher Paare vor, die beiden hintersten aber bildeten keinen deutlichen Bogen mehr. Zwischen diesen Bogen befanden sich grössere Zwischenräume. Die Rückenmitte war nackt (Fig. 9), nur hinten standen öfters die innersten Papillen der einander gegenüberliegenden Bogen sehr nahe aneinander, niemals aber berührten sie sich.

Die Anzahl der Papillen in den Querreihen wechselte bei den verschiedenen Tieren und war auch beim selben Tiere nicht beiderseits ganz gleich. Das $18 \mathrm{~mm}$ lange Tier hatte viele in der Regeneration begriffenen Papillen, beim $15 \mathrm{~mm}$ langen waren sie fast alle abgefallen, die Anheftungsstellen waren aber noch sichtbar.

In nachfolgender Tabelle gebe ich die Zahl der Papillen in jeder Querreihe. Die beiden Schenkel eines Bogens sind durch Akkoladen verbunden, die Bogen durch römische Ziffern angedeutet. 


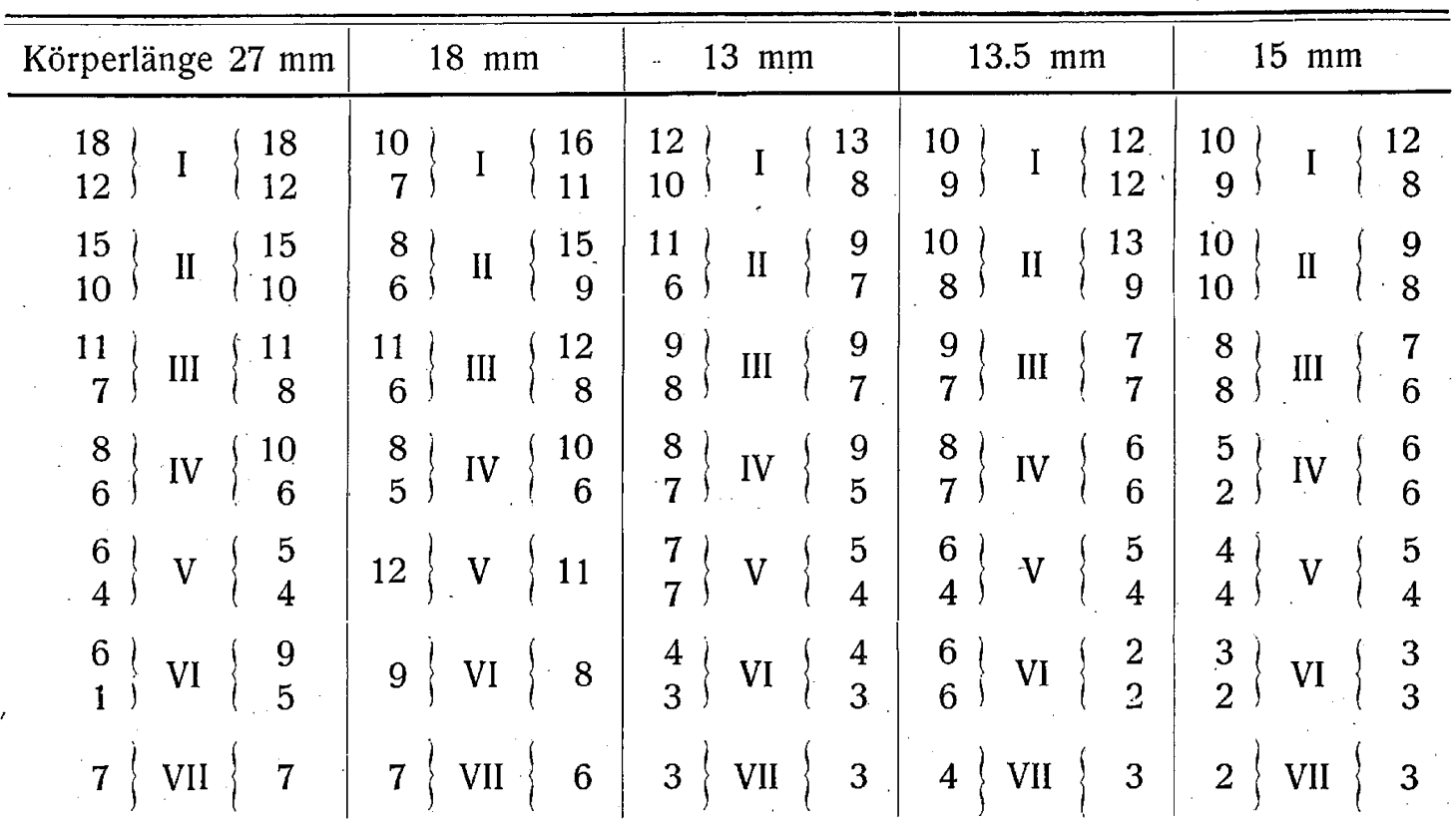

Es war sehr schwierig zu bestimmen, ob die Papillen hier auch auf Kissen standen. Wenn dieselben vorhanden sind, so sind sie sehr niedrig.

Die Analpapille befand sich bei allen Tieren an der rechten Seite in dem Zwischenraum zwischen den Schenkeln des zweiten Querreihenpaares als eine runde kegelförmige Papille.

Zwischen dem ersten und dem zweiten Querreihenpaar, an der Rückenseite des zweiten Paares angelehnt, fand sich eine flache, kissenartige Erhöhung der Körperwand mit Furchen versehen, die der Längenachse parallel gehen. Dieses Kissen zeigten auch alle Tiere; wahrscheinlich hat es mit den Geschlechtsorganen zu schaffen, denn gleich darunter, vom Kissen aber durch einen Zwischenraum geschieden, fand sich immer die Genitalpapille. Diese lag also zwischen den beiden ersten Bogen etwas hinterm Hinterschenkel des ersten dieser beiden. Eine Nierenpore habe ich nicht gesehen, es schien mir nicht wichtig genug zum Auffinden derselben die Papillen zu entfernen und mithin die Tiere zu verstümmeln.

Bei dem 27 und bei dem $18 \mathrm{~mm}$ langen Tiere wurden anatomische Untersuchungen vorgenommen. Nur die Organe wurden herausgeschnitten, die mir systematisch wichtig schienen, nämlich Mandibeln, Radula, Nervensystem und Penis.

Die Mandibeln dieser Art (Fig. 11) sind sehr zart und zerbrechlich, und es war eine sehr schwierige, wenn nicht unmögliche Sache dieselben unversehrt zu Gesicht zu bekommen. Beim $18 \mathrm{~mm}$ langen Exemplar versuchte ich in der gewöhnlichen Weise das Gewebe mit $\mathrm{Na} \mathrm{O} \mathrm{Cl} \mathrm{zu} \mathrm{destruieren.}$ Die zarten Mandibeln aber wurden schlaff und wurden beim Versuch sie zu entfernen ganz zerrissen. Bei dem $27 \mathrm{~mm}$ langen Tiere habe ich dann den Schlundkopf mit Nadeln vorsichtig auseinanderpräpariert, konnte aber auch hier die Mandibeln nicht im Ganzen zu Gesicht bekommen. Alle Stücke aber wurden gesammelt und in Glyzerin montiert (dies ist der einzige sichere Weg zum aufbewahren der Radula und Mandibeln dieser Tiere, versucht man dieselben in Fig. 11. Caloria occidentalis nov. spec Kanadabalsam zu bringen, so kann man sicher sein, dass während Die rekonstruierte rechte Mandibel des langen Weges durch die Alkohole und den Xylol Zähne verloren

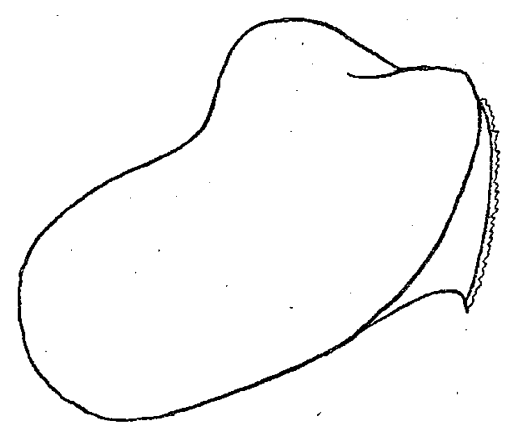
gehen, die Teile verdrehen und verschrumpfen u. s. w.). (Vgl. aber auch zum Beispiel: CLENCH W. J. Radula technique for Physa, S. 13, The Nautilus Vol. XXXVIII $n^{\circ}$. 1 July 1924). Nachdem dann die Stücke mit Hilfe des Zeichenprismas abgebildet waren, wurden die Abbildungen aus dem Papier herausgeschnitten und die Ränder der genau abgebildeten Risse aneinander gelegt. So entstand ein Model des Kiefers aus Papier und es zeigte sich dann, dass dieser wirklich die von TRINCHESE angegebene Gestallt besass, wie man meiner Fig. 11 entnehmen kann. Deutlich zeigen sie die von 
TRINCHESE erwähnte Einbuchtung. Der Kaurand (Fig. 12) trägt zur linken Seite 37, zur rechten 42 unregelmässig gestaltete Dentikel.

Die Radula beider Tiere weist Zähne auf, von derselben Gestalt wie TRINCHEsE sie für $C$. maculata abbildete. Wie man in meinen Figuren 13 und 14 sehen kann, besassen dieselben ein sehr

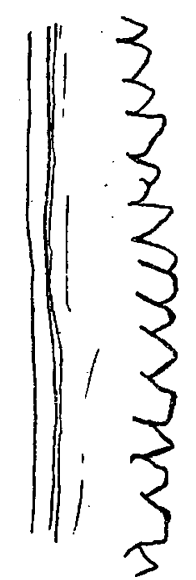

Fig. 12. Caloria occidentalis nov.

spec. Der Kaurand

eines Mandibels

des $27 \mathrm{~mm}$ lan-

gen Tieres.

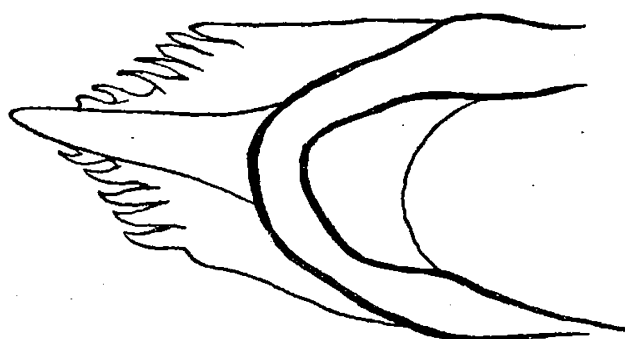

Fig. 13. Caloria occidentalis nov. spec. Flachgedrückte Zahnplatte des $27 \mathrm{~mm}$ langen Tieres.

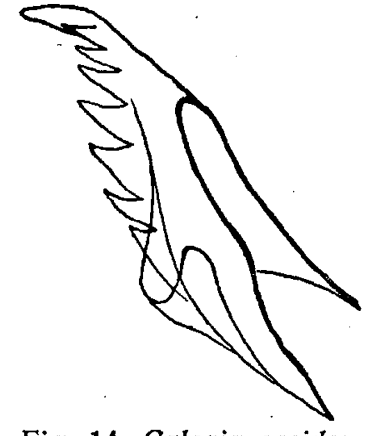

Fig. 14. Caloria occidentalis nov. spec. Zahnplatte von der Seite gesehen des $18 \mathrm{~mm}$ langen Tieres.

deutliches Mitteldentikel und jederseits 5-7 Seitendentikel. Auffallend ist der dunklere hufeisenförmige untere Rand der Basalfläche (der ganz so aussieht wie von ALDER und HANCOCK für Eolis elegans abgebildet wurde in Part VII ihrer Monographie auf Pl. 47 Supplementary Fig. 8).

Ich mache darauf aufmerksam, dass in meiner sowie in TRINCHESE's Abbildung die unteren
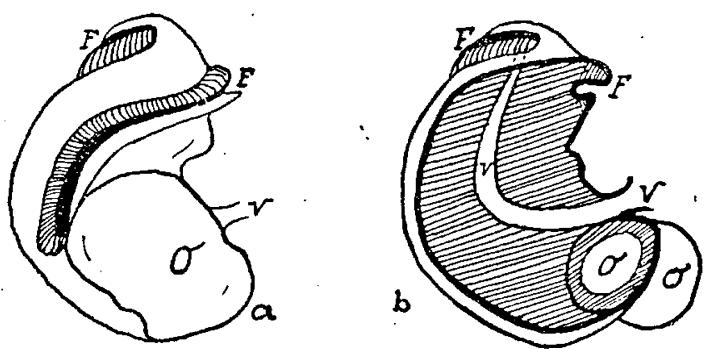

Fig. 15. Caloria occidentalis nov. spec. $a$ : der Penis. $\mathrm{F}=$ Spiralfurche, $\mathrm{V}=$ Vas deferens, $o=$ unbekanntes Organ (Drüse?); $b$ : der Penis, Längsschnitt, Die Schnittfläche schraffiert. Schenkel der Zähne divergieren. Dieses Bild entsteht, wenn man die Zähne flach drückt. Tut man das nicht, so bekommt man bei Oberansicht ein Bild, worin die Schenkel einander parallel laufen.

Das Nervensystem des $18 \mathrm{~mm}$ langen Exemplars sah ganz so aus, wie es von TRINCHESE in seiner Figur 3 angegeben wurde, nur gehören hier natürlich auch noch die Buccalganglien hinzu.

Der Penis beider Tiere war unbewaffnet und zeigte eine beim zurückgezogenen Organ spiralförmig an der Oberfläche verlaufende Furche (Fig. 15a). Am Grunde derselben mündete das vas deferens aus. (S. Fig. $15 \mathrm{~b}$, welche das Organ des $27 \mathrm{~mm}$ langen Tieres zeigt, nachdem es mittendurch geschnitten ist). Am Grunde des Penis fand sich ein hohles geschlossenes Organ (Drüse?), welches man in den Abbildungen 15a und b als ganzes, respektive halbiertes sehen kann; es zeigte gar keine Zutritts- oder Austrittsöffnung. Die Geschlechtsorgane der Nudibranchien sind zu verwickelt um ohne eingehendes Studium beurteilen zu können, was uns in diesem Organ vorliegt; ein solches Studium scheint mị aber zur Systematik nicht nötig. 


\section{LITERATURÜBERSICHT ZU DEN GATTUNGEN AEOLIDIELLA SPURILLA UND BERGHIA.}

1828. LEUCKART, F. S., breves animalium quorundam descriptio, p. 16 (nach Bergh, war mir nicht zugänglich).

1836-'46. Cuvier, G., Le Règne animal (3e Édit.). Vol.: Mollusques Atlas. Pl. 30bis, Fig. 1a.

1841. Delle Chiaje, Descrizione e notomia degli animali invertebrati della Sicilia citeriore osservati negli anni 18221830. Naples 1841.

1845. AldeR, J. and HANCócK, A., Notice of a new genus and several new species of Nudibranchiate Mollusca. Ann. and Mag. of Nat. Hist. 1st ser. Vol. XVI. S. 311.

1845. - A Monograph of the British Nudibranchiate Mollusca. Part II (Cover 1845, Title page 1846).

1848. - - - Part IV.

1854. - - - Part VI (Cover 1854, Title page 1852).

1855. - - - Part VII.

(1852?) Cocks, in: Naturalist V, 2, p. 1, pl. 1, f. 1 (mir nicht zugänglich, nach Alder und Hancock).

1856. VÉRANY, Catal. degli animal. invert. marini del Golfo di Genova e Nizza, p. 24 (nach Bergh, war mir nicht zugänglich).

? - - Descrizione di Genova e del Genovesato. Vol. I, p. 104 (nach Trinchese 1878).

1857. Gray, J. E., Guide to the Systematic Distribution of Mollusca in the British Museum, Part $I$.

1861. BERGH, R., Om Forekomsten af Neldefiim hos Mollusker. Videnskabelige Meddelelser fra den naturhistoriske Forening i Kjöbenhavn for Aaret 1860, p. 309.

1864 ('68). - - Anatomiska Bidrag til Kundskab om Aeolidierne. Diese „Bidrag” selber trägt das Jahr 1864, sie ist aber aufgenommen in: Det Kongelige Danske Videnskabernes Selskabs Skrifter, 5te Raekke, Naturvidenskabelig og Mathematisk Afdeling, 7e Bind, Kjöbenhavn, mit dem Jahre 1868. S. 139.

1865. FRÉdol, A., Le Monde de la mer. Paris, lère ed. 1865, Pl. XI, fig. 7. (2me éd. 1866, Pl. XVII, fig. 7).

1866. Costa, A.. in: Annuario del Museo zoologico de R. Univers. di Napoli: Anno III (mir nicht zugänglich, nach Vayssière 1889).

1867. Fischer, P., Catalogue des Nudibranches et Céphalopodes des côtes océaniques de la France, Journ. de Conch. Vol. XV (3e sér. VII) p. 5.

$186 \dot{7}$ ('64). Costa, A., in: Annuario del Museo Zoologico de R. Univers. di Napoli. Anno IV, p. 35. Tav. II, Fig. 4 (nach Vayssière, war mir nicht zugänglich).

1867 ('68). BERGH, R., Phidiana iynceus og Ismaila monstrosa. Videnskabelige Meddelelser fra den naturhistorike Forening i Kjöbenhavn for Aaret 1866. Andet Aarti, Kjöbenhavn 1867-'68. (Meddelt 1866!). S. 97.

1869. JeFFreys, J. G., British Conchology, Vol. V.

1869. FISHER, P., Catalogue des Nudibranches et Céphalopodes des côtes océaniques de la France, 1er suppl. (Eolis grossularia). Journ. de Conch. Vol. XVII. (3e Sér., Tome IX). S. 5.

1871. BeRGH, R., Beiträge zur Kenntnis der Mollusken des Sargassomeeres. Verhandl. d. K. K. zool. bot. Ges. in Wien, 1871, Bd. XXI, S. 1273.

1872. FISHER, P., Catalogue des Nudibranches et Céphalopodes des côtes océaniques de lă France, 2e suppl. Journ. de Conch. Vol. XX (3e Sér., Tome XII). S. 5.

1874. BERGH, R., Beiträge zur Kenntnis der Aeolidiaden II, Verhandl. d. K. K. zool. bot. Ges. in Wien, Jahrg. 1874, Bd. XXIV. S. 395.

1874. TRINCHESE, S., Nuove ricerche sull' organizzazione del cervello degli Eolididei. Mem. Acad. delle Scienze dell' Istituto di Bologna. Serie Terza, Tomo V. (Sessione 11 Febbraio 1875). S. 517. 
1874. Fischer, P., Faune conchyliologique marine du Département de la Gironde et des côtes du Sud-Ouest de la France, 2e supplément. Actes de la Société Linnéenne de Bordeaux, Tome XXIX (3me Sér. Tome IX) 1873, S. $231-232$.

1875. Fisher, P., Catalogue des Nudibranches et des Céphalopodes des côtes océaniques de la France, 3e supplément. Journ. de Conch., Vol. XXIII (3e Sér. T. XV). S. 204.

1875. MöRCH, O. A. L.,- Synopsis Molluscorum marinorum Indiarum occidentalium. Malakozool. Blätter für 1874 und 1875,22 Bd. S. 142.

1876. Bergh, R., Beiträge zur Kenntnis der Aeolidiaden IV. Verhandl. d. K. K. zool. bot. Ges. in Wien. Jahrg. 1876, XXVI Bd., Wien 1877, S. 737.

1877. Norman; A. M., On two new British Nudibranchiate Mollusca. The Ann. and Mag. Nat. Hist., 4th sér., Vol. XX, 1877. S. 517.

1877. Trinchese, S., Note zoologiche II, Descrizione del genere Berghia Trinchese. Rendic. delle Sessione dell' Acc. d. Scienze dell' Ist. di Bologna. Anno Accad. 1876-'77. Bologna 1877. S. 151

1878. - Anatomia e Fisiologia della Spurilla neapolitana. Mem. dell' Accad. delle Scienze dell' Istituto di Bologna. Ser. III, Tomo IX, Fasc. 3 (Letta nella Sessione del 21 Febbr. 1878), S. 405.

1882. - - Per la fauna marittima italiana. Aeolididae e famiglie affini. Atti della R. Accademia dei Lincei. Anno CCLXXIX, 1881-82. Serie terza. Mem. della Cl. di Sc. Fis., matem. e naturali, Vol. XI. Roma 1882, S. 3.

1882. Bergh, R., Beiträge zur Kenntnis der Aeolidiaden VII. Verhandl. d. K. K. zool. bot. Ges. in Wien. Jahrg. 1882, XXXII Bd. Wien 1883, S. 7.

1884. CoLlin, Limfjordens marina fauna, Kjöbenhavn (mir nicht zugänglich).

1885. Bergh, R., Beiträge zur Kenntnis der Aeolidiaden VIlI, Verhandl. d. K. K. zool. bot. Ges. in Wien, Jahrg. 1885, XXXV Bd. Abh. S. 1.

1885. Dall, W. H., List of Marine Mollusca, comprising the Quaternary Fossils and Recent Forms from American Localities, between Cape Hatteras and Cape Rogue including the Bermudas. Bull. of the U. S. Geological Survey $\mathrm{n}^{0} 24$, Washington 1885 . -

1888. VAYSSIĖRE, A., Recherches zoologiques et anatomiques sur les Mollusques Opisthobranches du Golfe de Marseille II. Ann. du Mus. d’Hist. Nat. de Marseille. Zoologie, 1886-1889, Tome III, Marseille 1889, Mémoire No 4, Marseille 1888.

1888. BERGH, R., Nudibranchien vom Meere der Insel „Mauritius”. Malacol. Unters. III, XVI Heft, 1e Hälfte, in: Sempers Reisen im Archipel der Philippinen II, Wiss. Res. Bd II, Wiesbaden 1888, S. 755.

1888. - - Beiträge zur Kenntnis der Aeolidiaden IX, Verhandl. d. K. K. zool. bot. Ges. in Wien, Jahrg. 1888, Bd. XXXVIII, S. 673.

1889. CARUs, J. V., Prodromus Faunae Mediterraneae, Vol. II, Pars I, Mollusca.

1890. Bergh, R., Die cladohepatischen Nudibranchien. Zool. Jahrb. (Spengel). Abth. f. Systematik etc. Bd. V. S. 1 (?) (lag mir separat vor).

1890. - - Die Nudibranchien des Sunda-Meeres. Malac. Unters. III, Heft XVII, in: Sempers Reisen im Archipel der Philippinen II, Wiss. Res. Bd. II, Wiesbaden 1890, S. 873.

1890. Garstang, W. A., A complete List of the Opisthobranchiate Mollusca found at Plymouth. Journ. of the Mar. Biol. Ass. of the Unit. Kingdom. Plymouth 1890, p. 433, 434.

1892. BERGH, R., System der Nudibranchiaten Gasteropoden. Malac. Unters III, Heft XVIII, in: Sempers Reisen im Archipel der Phil. II. Wiss. Res. Bd. II, Wiesbaden 1892, S. 1019-1020.

1895. Hechт, E., Contribution à l'Étude des Nudibranches. Mém. de la Soc. Zool. de France VIII, pour l'année 1895. S. 539.

1897. HEINCKE, FR., Nachträge zur Fisch- und Molluskenfauna Helgolands I (Nr. VII der Beiträge zur Meeresfauna von Helgoland). Wissensch. Meeresunters. (Kiel und Helgoland). Neue Folge, II Bd., Kiel und Leipzig 1897, S. 233.

1898. Fisher, H., in: Bull. Soc. Sc. d'Arcachon 1898, p. 129. (Nach Cuénot, mir nicht zugänglich).

1900. BERGH, R., Ergebnisse einer Reise nach dem Pacific (Schauinsland 1896-1897). Die Opisthobranchier. Zool. Jahrb. (Spengel) Abth. f. Syst. etc. XIII Bd., 3 Heft, 1900, Jena, S. 207.

1901. VAYSSIĖRE, A., Recherches zool. et anat. sur les Moll. Opisth. du Golfe de Marseille III. Nudibranches. Ann. du Mus. d'Hist. Nat. de Marseille. Tome VI, Section de Marseille 1901, Mém. $\mathrm{n}^{0} 1$.

1901. - - Étude comparée des Opisthobranches des côtes françaises de l'Océan atlantique et de la Manche avec ceux de nos côtes mediterranéennes. Bull. Scient. de la France et de la Belgique. Tome XXXIV (5me Sér., III) 1901, p. 281

1903. - - Rech. zool. et anat. sur les Moll. Opisth. du Golfe de Marseille. Supplément. Ann. du Mus. d'Hist. Nat. de Marseille. Tome VIII, Sect. de Zool. 1903. Mém. 3, S. 69.

1904. BERGH, R., Nudibranchiata. Malacol. Unters. in Sempers Reisen im Archipel der Philippinen II, Wiss. Res. IX Bd., 6er Theil, 1e Lief., Wiesbaden 1904.

1905. - Die Opisthobranchiata der Siboga Expedition. Siboga Expeditie, Uitkomsten L, Leiden 1905. 
1905. NoBRE, Moll. et Brachiop. du Portugal I, Porto 1905 (mir nicht zugänglich).

1906. Eliot, C., Notes on some British Nudibranchs. Journal of the Marine Biological Assoc. of the Unit. Kingdom, Plymouth, New Series, Vol. VII, No 3, issued June 1906.

1906. CuÉnOT, L., Contribution à la faune du bassin d’Arcachon, IV, Eolidiens. Travaux des Laboratoires. Stat. Biol. Arcachon IX, p. 95.

1907. ODHNER, N., Northern and Arctic Invertebrates in the Collection of the Swedish State Museum, III, Opisthobr. and Pteropoda. Kungl. Svenska Vetensk. Akad. Handl. Bd. 41, No 4 (communicated May 9th 1906).

1909. Mac Farland, F. M., The Opisthobranchiate Mollusca of the Branner-Agassiz Expedition to Brazil. Leland Stanford Junior University Publications, Univ. Series $\mathrm{N}^{0} 2$.

1910. Elıot, C., Part VIII (Supplementary) to: Alder and Hancock: A Moriograph of the British Nudibr. Moll., London, Ray Society, 1910.

1913. - - Japanese Nudibranchs. Journ. of the College of Science, Imperial University of Tokyo, Vol. XXXV, Art. 1, July 18th, 1913, S. 1 .

1915. JHERING, H. VON, Die Opisthobranchien der brasilianischen Küste. Nachr. B1. d. Deutschen Malakozool. Ges., 47 Jahrg., S. 133.

1917. VAYSSIÈRE, A., Recherches zoologiques et anatomiques sur les Mollusques Opisthobranches du Golfe de Marseille, 2me Suppl. Annales du Mus. d'Hist. Nat. de Marseille, Zoologie, Tome XVII, S. 53.

1922. L $\emptyset$ YNiNG, P., Nudibranchfaunaen i Dröbaksundet, I Fam. Aeolididae. Videnskapsselskapets Skrifter I, Mat.-Naturv. Klasse, 1922, $\mathrm{N}^{0} 6$.

\section{LITERATURÜBERSICHT ZUR GATTUNG PHIDIANA.}

1835-1843. D’ORbigny, A., Voyage dans l'Amérique méridionale, V, 3e partie. Mollusques. (S. 193 und 192, Taf. XIII, Fig. $1-7$ und Taf. XIV, Fig. 4-7).

1850. Gray, M. E., Figures of Moll. Anim. IV. S. 108 (war mir nicht zugänglich).

1852. Gould, Aug. A., U. S. Exploring Expedition, Vol. XII, Moll. and Shells. S. 305, Taf. 35, Fig. 401 (in dieser Arbeit wird Couthouy's Handschrift benutzt).

1854. Gay, Claudio, Hist. fis. y politica de Chile, Zool. V, 8. Moluscos (Hupée) p. 78. (war mir nicht zugänglich).

1855. Alder, J. and Hancock, A., A Monograph of British Nudibr. Moll., part VII, S. XXII, Gen. 36.

1857. Gray, J. E., Guide of Mollusca in the Brit. Mus., Part I, S. 224.

1861. BERGH, R., Om Forekomsten af Neldefiim hos Mollusker. Vidensk. Medd. fra Naturh. Foren. i Kjöbenhavn for 1860. S. 322 .

1864. - - Anatomiske Bidrag til Kundskab om Aeolidierne. Kgl. Danske Vidensk. Selsk. Skrifter, 5e Raekke, Nat. og Mat. Afd., VII Bd., 1868, p. 205.

1866. Alder, J. and HANCock, A., Notice of a Collection of Nudibranchiate Mollusca, made in India by Walter Elliot Esq., Transact. of the Zool. Soc. of London, V, S. 143, Taf. XXXIII, Fig. 14.

1867-'68. BeRgh, R., Phidiana lynceus og Ismaila monstrosa. Vidensk. Medd. fra Nat. hist. Foren. i Kjöbenh. for Aaret 1866. S. $97-116,2$ Taf. III-IV.

1873. - - Beiträge zur Kenntnis der Aeolidiaden I. Verh. d. K. K. Zool. bot. Ges. in Wien, XXIII Bd., S. 615-618, Taf. IX, Fig. 3-12, Taf. X, Fig. 1-3.

1875. MöRch, O. A. L., Synopsis Molluscorum marinorum Indiarum occidentalium. Malakozool. Blätter für 1874 und 1875, XXII Bd., p. 178.

1879. Bergh, R., Beiträge zur Kenntnis der Aeolidiaden, VI. Verh. d. K. K. zool. bot. Ges. in Wien, XXVIII Bd., S. 560-563. Taf. VI, Fig. $10-18$.

1885. Dall, W. H., List of Marine Mollusca... from American Localities between Cape Hatteras and Cape Rogue, including the Bermudas. Bull. U. S. Geol. Survey. $\mathrm{N}^{0} 24,1885$, p. 224.

1886. IHERING, H. voN, Zur Kenntnis der Nudibranchien der brasilianischen Küste. Jahrb. d. Deutschen Malakozool. Ges., 13er Jahrg., 1886, p. 239 und p. 240.

1892. BERGH, R., System der Nudibranchiaten Gasteropoden, in: Sempers Reisen im Archipel der Philippinen, Iler Teil, Wissensch. Res., 2 Bd., Malac. Unters. XVIII Heft, S. 1031.

1894. Plate, L., Mittheil. über zool. Studien, an der chilenischen Küste, V, Phidiana inca d'Orbigny, in den Sitz. ber. d. K. Preuss. Akad. d. Wiss. zu Berlin, S. 219-222.

1898. Bergh, R., Die Opisthobranchier der Sammlung Plate. Zool. Jahrb. hrsg. von Prof. Dr. J. W. Spengel, Suppl. IV. 3. Heft, 1898 , p. $549-560$. Taf. 31, Fig. $39-42$, Taf. 32, Fig. $1-18$ 
1904. Eliot, C., On some Nudibranchs from East-Africa and Zanzibar. Part VI. Proc. Zool. Soc. London, 1904, Vol. II, S. $287-288$.

1906a. - On the Nudibr. of Southern India and Ceylon, with special reference to the drawings by Kelaart and the collections belonging to Alder and Hancock..... Proc. Zool. Soc. 1906, II, S. 685. Taf. XLVII, Fig. 1.

1906b. Eliot, C. N. E., Report upon a Collection of Nudibranchiata from the Cape Verd Islands, with notes by C. Crossland. Proc. Malac. Soc. London VII. S. 156, Taf. XIV, Fig. 12. (Diese Zeitschrift war mir nicht zugänglich. Frl. Erna Mohr verdanke ich jedoch eine Abschrift der betreffenden Arbeit).

1910. Eliot, C., Alder, J. and Hancock, A., The Brit. Nudibr. Mollusca, Supplement, Part VIII, by Sir Ch. Eliot. Ray Soc. London. S. 10.

\section{LITERATURÜBERSICHT ZUR GATTUNG CALORIA.}

1888. Trinchese, S., Descrizione del Nuovo Genere Caloria Tr.. Mem. della R. Acc. delle Scienze dell' Istituto di Bologna..Ser. IV, Tomo IX, Bologna 1888, p. 291.

1890. Bergh, R., Die Cladohepatischen Nudibranchien. Zool. Jahrb. (Spengel), Abth. f. Systematik. Band V, 1890, p. 39.

1892. - System der Nudibranchiaten Gasteropoden. Reisen im Archipel der Philippinen von Dr. C. Semper, II, Wiss. Res. Bd. 2, Malacol. Unters., XVII Heft, 1892, p. 1033.

1920. HAAS, F., Opisthobranchier aus verschiedenen warmen Meeren. Archiv für Molluskenkunde 1920, Jahrg. LII, p. 142. 